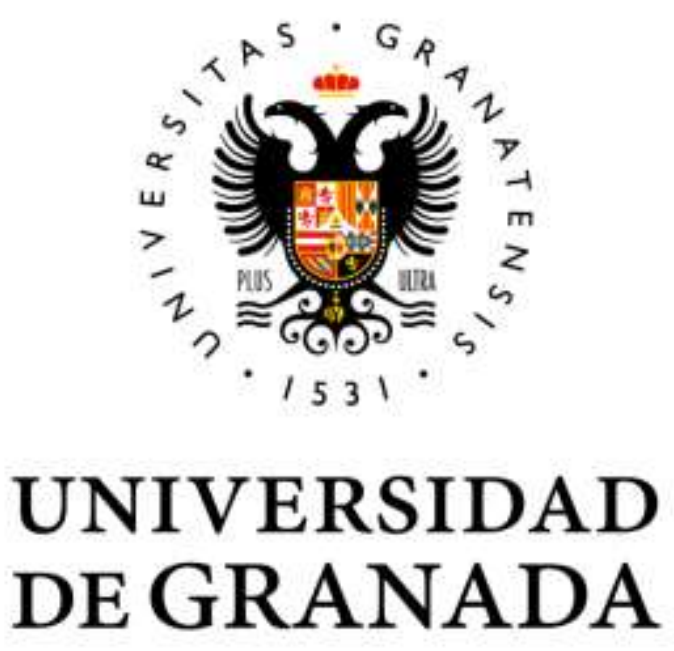

Máster en Didáctica de la Matemática

Departamento de Didáctica de la Matemática

Curso 2020 / 2021

Trabajo Fin de Máster

\title{
Análisis de las dimensiones del sentido espacial en futuros profesores
}

Carlos Alberto Monge Madriz

Granada, 2021 


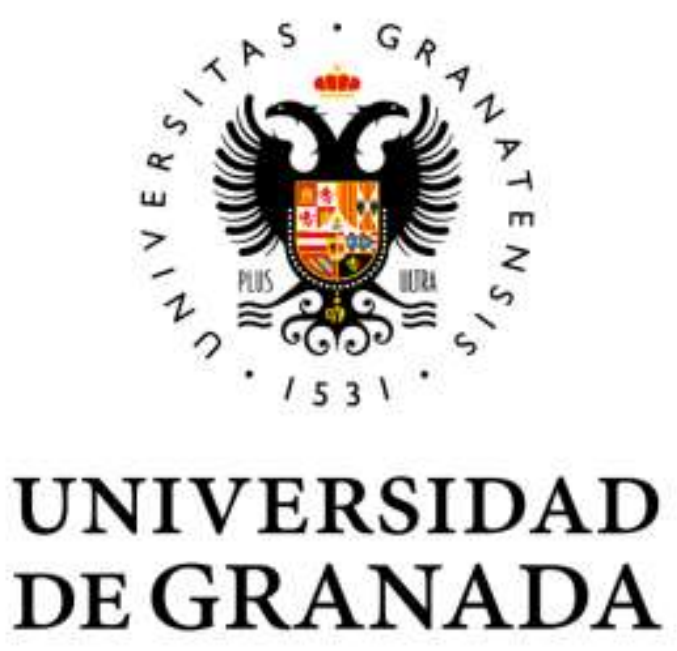

Máster en Didáctica de la Matemática

Departamento de Didáctica de la Matemática

Curso 2020 / 2021

Trabajo Fin de Máster

Análisis de las dimensiones del sentido espacial en futuros profesores

Presentado por

D. Carlos Alberto Monge Madriz

Fdo.: D. Carlos Alberto Monge Madriz

\author{
Dirigido por \\ Dr. D. Pablo Flores Martínez
}


A mi papá y a mi mamá que representan a las personas más importantes de mi vida, son mi bienestar, mi felicidad y el motor que llena de alegría mi día a día. ¡Este logro es para ustedes! 


\section{AGRADECIMIENTOS}

Un especial agradecimiento a mi profesor tutor Dr. Pablo Flores Martínez por su gran apoyo, la valiosa realimentación brindada en cada una de las etapas del estudio y por todo el tiempo invertido acompañándome como guía en este trabajo. Estoy muy satisfecho de todos los aprendizajes que he adquirido en este proceso gracias a él.

A mis compañeros del Instituto Tecnológico de Costa Rica que me apoyaron en la etapa del juicio de expertos de este trabajo, dedicando un espacio de su tiempo para brindarme valiosas recomendaciones y sugerencias a modo de realimentación.

Por último, un agradecimiento a los seis futuros profesores que formaron parte de esta investigación, que de manera muy anuente y sin ningún compromiso, accedieron a participar en todo lo requerido para este estudio. 


\title{
RESUMEN
}

En este trabajo se analiza qué sentido espacial tienen seis futuros profesores de matemáticas. Para ello se les proponen tres tareas geométricas sobre doblado de papel. A partir del análisis de las respuestas, se aprecia que resuelven la mayoría de las actividades, pero tienen dificultades para argumentar sus procedimientos. Si bien identifican elementos geométricos y movimientos, tienen conflictos para establecer las relaciones geométricas que las justifican y logran integrar solo parcialmente los componentes geométricos con habilidades de visualización.

Palabras clave: habilidades de visualización, profesores en formación, sentido espacial.

\begin{abstract}
In this work we analyze the spatial sense of six future mathematics teachers. For this, three geometric tasks of paper folding are proposed. From the analysis of the responses, it can be seen that they solve most of the activities, but have difficulties in arguing their procedures. They identify geometric elements and movements, but they have conflicts to establish the geometric relationships that justify them and partially integrate the geometric components with visualization skills.
\end{abstract}

Keywords: visualization abilities, pre-service teachers, spatial sense. 


\section{ÍNDICE}

INTRODUCCIÓN

CAPÍTULO 1. JUSTIFICACIÓN Y DETERMINACIÓN DEL PROBLEMA DE

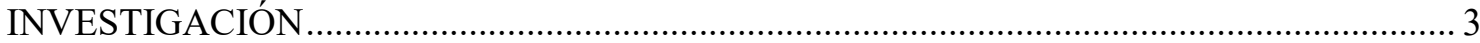

CAPÍTULO 2. MARCO TEÓRICO Y ANTECEDENTES _......................................................... 9

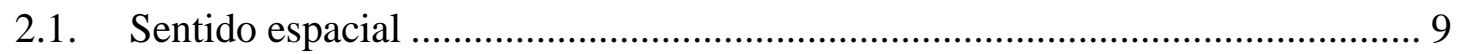

2.1.1. Sentido espacial y geometría _........................................................... 10

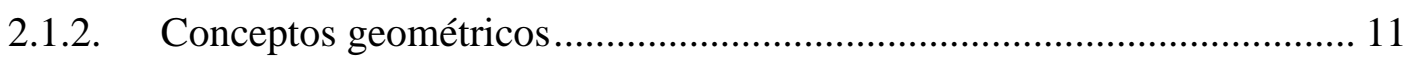

2.1.3. Destrezas para visualizar esos conceptos ............................................. 12

2.1.4. Relación de las componentes del sentido espacial ....................................... 15

2.1.5. Sentido espacial y profesores de matemáticas ............................................. 15

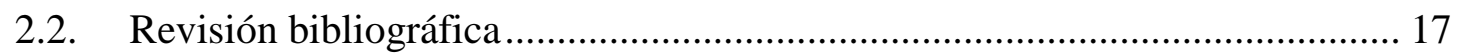

2.2.1. Investigaciones sobre razonamiento y conocimiento geométrico en futuros

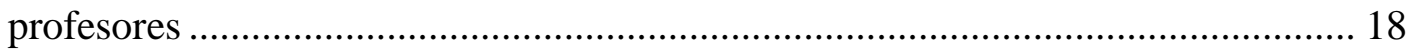

2.2.2. Investigaciones sobre sentido espacial, habilidades espaciales o destrezas de visualización en futuros profesores ............................................................... 20

2.2.3. Valoración de la revisión bibliográfica ................................................... 23

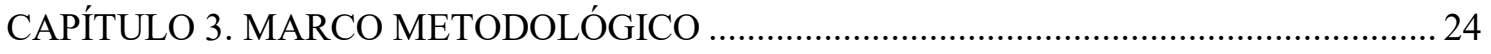

3.1. Descripción de la investigación ........................................................................ 24

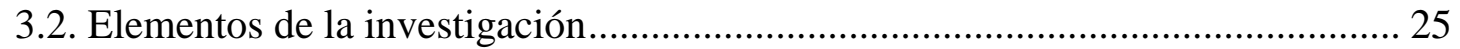

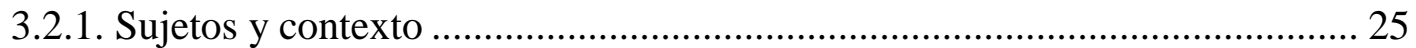

3.2.2. Instrumento para la recolección de datos y guía de actividades ................... 25

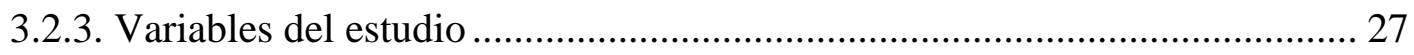

3.3. Método para el análisis de los datos ............................................................... 28

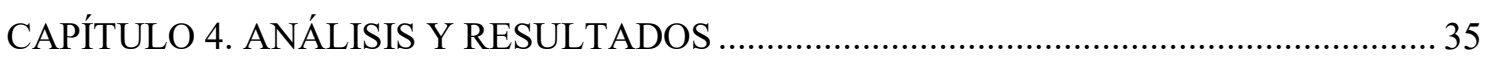

4.1. Análisis del componente de manejo de conceptos geométricos .......................... 35

4.1.1. Conceptos y elementos geométricos ......................................................... 35

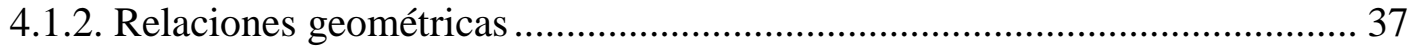

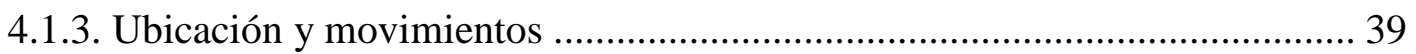

4.2. Análisis del componente de habilidades de visualización .................................. 41

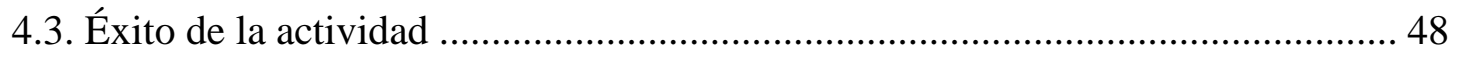


CAPÍTULO 5. CONCLUSIONES 50

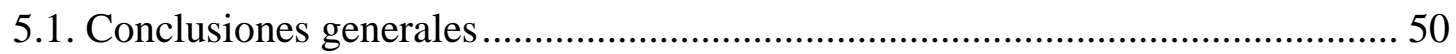

5.2. Limitaciones de la investigación........................................................................... 53

5.3. Expectativas para futuras investigaciones ...................................................... 54

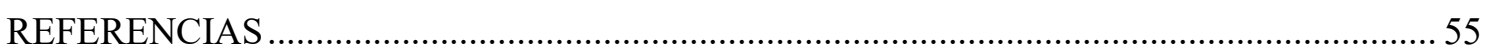

ANEXO A. RESOLUCIÓN DE LAS ACTIVIDADES SELECCIONADAS ............................... 62

ANEXO B. PROCESO DE EVALUACIÓN DE COMPONENTES GEOMÉTRICOS DEL JUICIO DE EXPERTOS

69

ANEXO C. COMPONENTES DEL SENTIDO ESPACIAL: CATEGORÍAS Y CONDUCTAS

MANIFESTADAS POR CADA UNO DE LOS FUTUROS PROFESORES 79 


\section{INTRODUCCIÓN}

Este documento corresponde al informe del Trabajo Fin de Máster como parte de los requerimientos de la Maestría en Didáctica de la Matemática de la Universidad de Granada, llevado a cabo en el curso 2020/2021 dentro del área de investigación de Didáctica de la Geometría. Se ha realizado un estudio que permita analizar el sentido espacial que han desarrollado futuros profesores de matemáticas al enfrentarse a tareas geométricas.

Los estudiantes que se encuentran en las aulas de los sistemas educativos alrededor del mundo, convergen en algo en común: son entes de una ciudadanía que toman decisiones y solucionan problemas que impactan su diario vivir y el de los demás. Por tanto, los sistemas educativos deben de encaminarse a generar ciudadanos que puedan comprender cómo funciona la sociedad actual y actuar dentro de los parámetros que esta impone. Considerando lo anterior, para este estudio tomamos en cuenta la importancia de una educación actualizada, que evoque una enseñanza funcional, capaz de promover el desarrollo de alumnos que se desempeñen de forma más competente. Lograr este aprendizaje evoca una enseñanza basada en situaciones que estimulen todas estas dimensiones, promoviendo la construcción de aprendizajes significativos en el estudiante. Parte de lo que propone el Ministerio de Educación Pública de Costa Rica (2015) en su llamada "Transformación Curricular: Educar para una nueva ciudadanía", va en línea con lo descrito anteriormente, más específicamente se busca “... formar personas con una serie de habilidades y competencias para resolver problemas, para aprender a lo largo de la vida, para tomar acciones y decisiones que contribuyan a su desarrollo personal sin demérito del bienestar de las demás personas”. (pp. 37-38)

Dentro de este enfoque de una enseñanza funcional, el docente tiene un papel muy importante para llevar a sus estudiantes por caminos que permitan el desarrollo de esas competencias, tomando en cuenta los distintos saberes matemáticos que se desean enseñar. $\mathrm{Y}$ esto deben de tenerlo muy en cuenta las diversas universidades que se encargan de la formación de docentes, basándose en pilares que permitan el desarrollo de profesores que forjen ciudadanos que puedan enfrentarse con éxito a las demandas de la sociedad actual. 
Los programas de estudio de matemáticas en Costa Rica abarcan distintas áreas de enseñanza, dentro de las que se destacan: Relaciones y Álgebra, Números, Medidas, Estadística y Probabilidad, Geometría. Una motivación personal para la realización de este estudio, radica en que, desde mi perspectiva como docente y estudiante, considero que una de las áreas anteriormente mencionadas, que mayor dificultad se tiene en su enseñanza y aprendizaje, es la geometría. He apreciado una enseñanza basada en fórmulas, conceptos, medidas o palabras, en ocasiones, buscando resaltar procesos algebraicos o algoritmos, restándole importancia a las representaciones visuales o imágenes. Usualmente me encuentro con estudiantes universitarios que manifiestan diversos errores o deficiencias geométricas que posiblemente arrastran desde la educación primaria o secundaria y que generan barreras para que adquieran aprendizajes mayores. Me he topado con estudiantes muy talentosos en procesos algebraicos o con buenos conocimientos del cálculo diferencial e integral, pero que cuando se enfrentan a alguna tarea que involucra geometría se vuelve en un obstáculo para obtener su solución o incluso, para llegar a interpretarla.

Queremos que el futuro profesor ayude a su estudiante a ubicarse en su medio utilizando la geometría, dotándole de herramientas que le permitan sentirse persona dentro de una realidad compleja. Sin embargo, tengo las sospechas de que la enseñanza de esta área está muy alejada de lo que realmente debería ser una geometría basada en una enseñanza funcional, además se encuentra distante de dotar de habilidades y destrezas espaciales. Con estas inquietudes manifestadas, me pregunto qué tipo de aprendizaje geométrico tienen estos estudiantes. Para ello es relevante exponer el concepto de sentido espacial, visto como una finalidad funcional del aprendizaje de la geometría, buscando que el estudiante maneje elementos y propiedades geométricas, relaciones entre sí, ubicación y movimientos, pero que tenga la visualización suficiente para otorgar a esos elementos de riqueza e identidad (Flores et al., 2015).

En el primer capítulo de este informe trataremos el planteamiento del problema, su justificación y expondremos los objetivos a alcanzar. En el segundo capítulo definiremos el marco teórico sobre el que basaremos el estudio, así como los antecedentes sobre el tema tratado. En el tercer capítulo describiremos la metodología de investigación empleada. En el cuarto capítulo realizaremos un análisis de los resultados y finalmente, externaremos las conclusiones y líneas a futuro de esta investigación en el quinto capítulo. 


\section{CAPÍTULO 1. JUSTIFICACIÓN Y DETERMINACIÓN DEL PROBLEMA DE INVESTIGACIÓN}

Costa Rica es uno de los países de la Organización para la Cooperación y el Desarrollo Económicos (OCDE) que participa en las pruebas del Programa Internacional para la Evaluación de Estudiantes (PISA). En las últimas pruebas aplicadas en el 2018, en el componente de matemáticas, cerca del $60 \%$ de estudiantes costarricenses que participaron, se encuentran en nivel 1 o inferior de competencias matemáticas (OECD, 2019a). Dentro de los ítems que se proponen en las pruebas PISA, se pueden encontrar algunos del área de geometría, específicamente en el bloque de preguntas de la categoría “Espacio y forma” (OECD, 2019b). Costa Rica, en el 2012, se encontraba en la posición 56 entre 65 países participantes, con poco más de un $60 \%$ de estudiantes que se situaban en un nivel 1 o inferior de competencias matemáticas en ítems de "Espacio y forma" (OECD, 2014). Los alumnos en el nivel 1 son capaces de reconocer y resolver problemas en contextos que sean familiares para ellos, usando representaciones gráficas de objetos geométricos y aplicando habilidades espaciales básicas que les permitan comparar longitudes, ángulos o reconocer propiedades básicas de la simetría (OECD, 2014).

Los resultados mostrados anteriormente son preocupantes, máxime que los niveles de competencias matemáticas que se proponen en PISA son seis y más de la mitad de los estudiantes costarricenses que participan en estas pruebas se encuentran ubicados en un nivel 1 o inferior. Estos rendimientos tan bajos, ponen en panorama una situación a la que se le debe prestar importante atención, puesto que, en palabras de Vega (2018), equivale a "tres años de formación menos para un joven costarricense en relación con un estudiante de un país OCDE” (Vega, 2018, párr. 3).

Lo anterior no es ajeno a otra realidad costarricense relacionada con pruebas matemáticas que describiremos a continuación. El Ministerio de Educación Pública de Costa Rica aplicó durante más de una década las Pruebas Nacionales de Bachillerato. Estos exámenes eran realizados por los estudiantes en el último nivel de secundaria (alumnos de 17 años) en todas las instituciones educativas del país. En el 2019 fue el último año de ejecución de estos exámenes, en donde aproximadamente el 50\% de los estudiantes que aplicaban las pruebas, obtenían puntuaciones entre 45 y 65 de un rango de 0 a 100 (Ministerio de 
Educación Pública, 2020). Para ese mismo año, seis de las siete habilidades de geometría evaluadas tenían puntuaciones menores a 60, en un rango de 0 a 100, para estudiantes de colegios diurnos y nocturnos (Ministerio de Educación Pública, 2020). En general, las puntuaciones para los ítems correspondientes al bloque de Geometría fueron de 51.34 puntos en promedio, en un intervalo de 0 a 100 para estudiantes que aplicaron la prueba a nivel nacional (Ministerio de Educación Pública, 2020). Esto no difiere con las puntuaciones de los ítems en geometría desde el 2015 hasta el 2019, donde el promedio para estos años fue de 53.43 puntos para una escala de 1 a 100 (Ministerio de Educación Pública, 2016, 2017, 2018, 2019).

Lo desarrollado en párrafos anteriores, ha mostrado que los resultados de pruebas de matemáticas en los estudiantes costarricenses no arrojan resultados favorecedores y los ítems del área de geometría no se alejan de esa realidad, cabe preguntarse ¿qué sucede con la enseñanza de la geometría que pareciera no generar aprendizajes significativos para un buen desempeño del estudiante en esta área?

Usualmente en la educación formal, la geometría tiende a ser difícil para los estudiantes, probablemente porque se presenta como un producto ya terminado, basándose en una enseñanza tradicional, de a lápiz y papel, que hace énfasis en fórmulas, cálculo de volúmenes y áreas, construcciones mecánicas o algorítmicas, memorización de propiedades y definiciones geométricas, dejando de lado el desarrollo de habilidades mayores; lo anterior provoca que los estudiantes tengan la idea de que la geometría es complicada y carece de aplicabilidad (Abrate, et al., 2006; Báez e Iglesias, 2007; Barrantes, 2002; Clements y Battista, 1992; Flores et al., 2015; Fernández-Blanco et al., 2019; Fortuny et al., 2010; Gamboa y Ballestero, 2009; New Jersey Mathematics Coalition, 1996).

En la educación primaria se hace énfasis en el estudio de las formas y sus propiedades, en la educación secundaria sobre las coordenadas y transformaciones, en la universidad se axiomatiza y se llena de algebra la geometría. Todas estas visiones alejan a esta área de las matemáticas de su estructura principal: el espacio. En las aulas se enseña esta geometría con poca conexión espacial, distanciando diversas habilidades que, de ser desarrolladas, son útiles para comprender ideas geométricas que puedan generar aprendizajes más significativos (Bishop, 1986). 
Todo lo reflexionado anteriormente permite dar un claro reflejo de que la enseñanza de la geometría se encuentra distanciada de su principal propósito, se aleja de una formación que le permita al estudiante entender su entorno y resolver situaciones problemáticas cotidianas (Gamboa y Ballestero, 2010). Esto nos hace cuestionarnos sobre cuáles deberán ser las estrategias pertinentes para llevar a cabo una enseñanza de la geometría que promueva aprendizajes significativos y el desarrollo de competencias en los estudiantes.

La intención del desarrollo de competencias matemáticas está estrechamente relacionada con la idea de una enseñanza funcional de las matemáticas, en donde los estudiantes puedan aplicar sus aprendizajes a la resolución de situaciones que se le presenten en su diario vivir (Gutiérrez et al., 2008; Rico y Lupiañez, 2008). Lo anterior, convierte la matemática en un medio de ayuda para que el ciudadano pueda sentirse persona en una realidad compleja. El enfoque funcional se aborda tratando de lograr que los estudiantes desarrollen su sentido matemático, definido por Ruíz-Hidalgo et al. (2019) como "el conjunto de capacidades relacionadas con el dominio en contexto de contenidos numéricos, geométricos, métricos y estadísticos, que permiten emplear estos contenidos de una manera funcional." (p. 122). Ese "sentido" busca que el estudio de las matemáticas sea visto desde una perspectiva en donde se comprendan y se contextualicen los conocimientos, abarcando cuatro diferentes tipos de sentidos en educación obligatoria: sentido numérico, sentido espacial, sentido de la medida y sentido estocástico (Rico, 2016). Por tanto, es de interés indagar en el concepto de sentido espacial, pues en palabras de Molina y Flores (2017): “Aprender geometría de manera funcional supone algo más que memorizar nombres, identificar formas, etc. Identificamos la intención funcional del aprendizaje geométrico con lograr que los alumnos desarrollen sentido espacial.” (p.79).

Ampliando estas ideas, autores como Hershkowitz et al. (1996), hacen alusión a un aprendizaje de la geometría coordinado con una buena visualización; es decir, que fomente una interacción de formas geométricas, sus relaciones con diversos elementos o figuras y sus transformaciones, todo ello siendo reforzado mediante elementos de la visualización; en conclusión, estos autores pretenden que las propiedades geométricas le sirvan al estudiante como herramientas que le favorezcan describir el espacio y las formas que le rodean, y en esta misma línea va la idea del concepto de sentido espacial. 
Tomando como referente a la National Council of Teachers of Mathematics, en el marco curricular de la New Jersey Mathematics Coalition (1996), se introduce la intención de desarrollar el sentido espacial, específicamente en el Estándar 7, en donde se explica la conexión entre conceptos geométricos tradicionales y visualización que componen este sentido espacial:

Todos los estudiantes desarrollarán el sentido espacial y una habilidad para usar las propiedades geométricas y las relaciones para resolver problemas en matemáticas y en la vida diaria (..). El sentido espacial es un sentido intuitivo para la forma y el espacio. Implica los conceptos de geometría tradicional, incluyendo una habilidad para reconocer, visualizar, representar y transformar formas geométricas. También supone otras formas, menos formales, de mirar el espacio de dos o tres dimensiones, tales como el doblado de papel, transformaciones, teselaciones y proyecciones(..). La geometría está presente en el mundo que nos rodea: arte, naturaleza y las cosas que hacemos (...). Los estudiantes de geometría pueden aplicar su sentido espacial y conocimiento de las propiedades de las formas y del espacio en el mundo real (p.209)

En lo anterior, se puede percibir una enseñanza de la geometría basada en características y propiedades de los elementos geométricos, sus relaciones, ubicación y movimientos, combinados con habilidades visualizadoras. La geometría es una herramienta para interpretar y reflexionar sobre el entorno físico, es esencial que la geometría y el razonamiento espacial reciban mayor atención en los procesos de enseñanza y en la investigación (Clements y Battista, 1992).

Intentando enlazar las ideas anteriores con el entorno educativo costarricense, el programa de estudios de matemáticas, en el área de geometría, hace referencia “al estudio de las características de las figuras geométricas y las relaciones entre ellas, la modelización geométrica y la visualización espacial, que permiten potenciar los procesos de visualización, clasificación, construcción y argumentación. Se desea subrayar el movimiento de las formas geométricas." (Ministerio de Educación Pública, 2012, p. 21). Considerando este enfoque de la Geometría que proponen los programas, se puede notar como "las características de las figuras geométricas y sus relaciones", "la modelización geométrica" y "el movimiento de las formas geométricas" y la "visualización" hacen referencia a dimensiones del concepto de sentido espacial propuesto por Flores et al. (2015). En otro apartado dedicado a la Geometría, se describe con mayor amplitud el enfoque que debe ser impregnado en su enseñanza:

...no se privilegia una aproximación a la Geometría basada en el estudio de objetos ideales y abstractos, sino más bien una que asuma la relación geométrica con los entornos espaciales. Esto busca fortalecer una mayor visualización en la Geometría: establecer 
contactos estrechos entre representaciones visuales y las formas geométricas. (Ministerio de Educación Pública, 2012, p. 52)

Se puede notar que cuando se indica "establecer contactos estrechos entre representaciones visuales y las formas geométricas", se hace referencia a la conexión entre los componentes del sentido espacial que abarca el concepto de sentido espacial y esto mismo es afirmado por los programas de estudio al indicar que "Lo anterior está asociado con un enfoque que busca darle mayor presencia al "sentido espacial", es decir la identificación, visualización y manipulación de las formas en el espacio.” (Ministerio de Educación Pública, 2012, p. 52). En palabras de Ruiz (2018), uno de los encargados de la dirección y elaboración de los nuevos programas, "Hay un sentido que invoca "entornos espaciales", y por lo tanto se pretende generar un "sentido espacial". (pp. 9596).

En resumen, en el apartado de geometría encontramos una pretensión funcional de la geometría que se manifiesta en el desarrollo de competencias matemáticas mediante la ejecución de distintos procesos matemáticos, "es decir formas de comprender, aprender y usar los conocimientos que promueven capacidades cognitivas transversales y la competencia matemática." (Ministerio de Educación Pública, 2012, p.56). Se promueve que el estudiante tenga una actitud positiva para aplicar a su diario vivir todas las áreas matemáticas del programa de estudios, incluida la de geometría. El currículo pretende que el docente involucre cinco ejes disciplinares en su acción de aula, en donde se destaca el de "Actitudes y creencias" con la pretensión de generar una confianza en la utilidad de las matemáticas (Ministerio de Educación Pública, 2012). También se encuentra que, en los conocimientos y habilidades a desarrollar dentro del plano y el espacio, hay un aporte métrico, pero hay una parte que no necesariamente se relaciona con medidas, en palabras del Ministerio de Educación Pública (2012): "No es conveniente enfatizar el uso de fórmulas sino más bien la visualización de las formas en el espacio.” (p. 52)

Por tanto, consideramos que los profesores deben disponer de destrezas propias que muestren la competencia que llamamos sentido espacial, aunque no tienen que identificar este constructo (sentido espacial), como concepto didáctico de su conocimiento profesional, puesto que no forma parte de su exigencia profesional como estudiantes universitarios. Sin embargo, como consecuencia de nuestras apreciaciones anteriores, consideramos que podría ser muy enriquecedor para su formación y futura práctica educativa que se incluyera como parte de su formación universitaria. 
Como se manifestó en apartados anteriores, el hecho de desarrollar el sentido espacial recae en la importancia que se concibe al enseñar matemáticas con sentido y en alusión a esto Ruíz-Hidalgo et al. (2019) indican: "la formación de profesores de matemáticas tiene que contribuir a que los futuros profesores aprecien qué significa enseñar matemáticas con sentido (matemático), y se preparen para lograr que su potencial alumnado aprenda matemáticas con sentido.” (p. 122). El desarrollo de habilidades espaciales en futuros profesores puede traer grandes beneficios para que sean capaces de tomarlas en cuenta en actividades de aula con sus futuros estudiantes, propiciándoles de herramientas y capacidades que incluso pueden influir en su vida profesional (Ozcan et al., 2016). Tomando en consideración lo anterior, es vital una orientación y atención adecuada de todos los entes que rodean a los aprendices, especialmente los docentes, como un esfuerzo por desarrollar las habilidades espaciales de los estudiantes tal y como sea requerido en los programas de estudios (Yani y Rosma, 2020).

De lo plantado en esta sección surge la siguiente pregunta de investigación y objetivos:

- ¿Qué componentes del sentido espacial están más desarrollados en los futuros profesores y cuáles requieren una atención especial en la formación inicial?

Objetivo general:

Analizar el desarrollo del sentido espacial que tienen futuros profesores de matemáticas de Costa Rica.

Objetivos específicos:

- O1. Analizar las diferentes componentes del sentido espacial que se encuentren presentes en una guía de tareas geométricas previamente seleccionadas.

- O2. Observar y describir las dimensiones o componentes del sentido espacial que manifiestan los futuros profesores al resolver las tareas geométricas.

- O3. Identificar las habilidades de visualización del sentido espacial que son utilizadas con mayor énfasis en las tareas geométricas que resuelven los futuros profesores. 


\section{CAPÍTULO 2. MARCO TEÓRICO Y ANTECEDENTES}

En este capítulo se realizará un recorrido por los principales referentes teóricos en los que se basa el presente estudio. Se desarrollarán conceptos relacionados con sentido espacial y sus dimensiones, y la relación de los profesores con esta finalidad del aprendizaje de la geometría. El capítulo finaliza realizando un recorrido por diversas investigaciones que consideramos como antecedentes para nuestro estudio.

\subsection{Sentido espacial}

Usualmente, en el sistema educativo tradicional, la enseñanza de la geometría principalmente se ha basado en el reconocimiento de figuras geométricas y sus propiedades, generando aprendizajes que se basan en la identificación de figuras prototípicas, situadas de una manera establecida, y que resultan más difíciles de identificar cuando ocupan otras posiciones o tienen características no estandarizadas. Una enseñanza de la geometría enfocada en desarrollar el sentido espacial, propone un aprendizaje que favorezca el dominio del entorno espacial, mediante un nivel de razonamiento en donde sean involucradas una serie de conocimientos geométricos, acompañados de habilidades y capacidades espaciales que el estudiante debería ir desarrollando.

Diversos autores han investigado la enseñanza y el aprendizaje de la geometría, algunos de los cuales han definido diversos elementos relacionados con el sentido espacial desde diversas perspectivas, sin que se haya consensuado una definición única de lo que es el sentido espacial y las habilidades que este involucra, presentándose múltiples definiciones relacionadas con este concepto (Guzel y Sener, 2010; Ihsan y Yildiz, 2019; Kosa y Karakus, 2018; Ünal et al., 2009).

Para este estudio se ha tomado la definición de sentido espacial que Flores et al. (2015) proponen: "modo intuitivo de entender el plano y el espacio, para identificar cuerpos, formas y sus representaciones, que implica manejar relaciones y conceptos de geometría de forma no convencional, incluyendo la habilidad para reconocer, visualizar, representar y transformar formas geométricas.” (pp.129-130). Estos autores, afirman que la idea de 
sentido espacial permite reforzar el aprendizaje geométrico, pero dando presencia al desarrollo de habilidades de visualización, ambos de manera conjunta y complementaria.

El sentido espacial abarca una amplia lista de habilidades que permiten que un individuo se desenvuelva en su entorno y todas esas acciones no solamente llegan a beneficiar el aprendizaje de la geometría, sino que colabora en otras áreas del conocimiento con las que está relacionado el espacio, como el manejo de proporciones, el uso de medidas, nociones del álgebra o los números (Lupiáñez y Flores, 2011). Otros autores amplían esta idea, resaltando la importancia que tiene el sentido espacial para el desarrollo de actividades del diario vivir (como la lectura de mapas o el entendimiento de letreros en la carretera), el pensamiento científico, comprensión de metáforas, para profesiones que tienen componentes artísticos, educación física, geografía, trabajos manuales, ingenieros, arquitectos, topógrafos, astrónomos, pilotos de avión entre otros (Del Grande, 1987; Diezmann y Watters, 2000; National Research Council, 2006; Newcombe, 2010; Stanic y Owens,1990; Yani y Rosma, 2020). Es importante recalcar que conceptos como "razonamiento espacial" o "pensamiento espacial", son precursores de la línea que considera el sentido espacial (Guzel y Sener, 2010; Ramírez, 2012).

Clements (1998) relaciona tener un buen sentido espacial con una mejor competencia en matemáticas; además, pueden desarrollar su inteligencia espacial en ambientes de aprendizaje formales e informales (Diezmann y Watters, 2000). Los investigadores concuerdan que el desarrollo de habilidades espaciales en la enseñanza de las matemáticas trae grandes beneficios para el aprendizaje, logrando mejorar la percepción, creatividad y generalización de conceptos (Guzel y Sener, 2010). Es por eso que los docentes en su práctica de aula deben de considerar la implementación de actividades que sean pertinentes para el desarrollo de este tipo competencias espaciales.

\subsubsection{Sentido espacial y geometría}

El manejo del sentido espacial congrega a los conceptos tradicionales de la geometría, pero también conlleva al manejo de ciertas habilidades que incluyen todas aquellas acciones que implican rotar, girar, trasladar, transformar, describir o caracterizar objetos o figuras, y las imágenes que nos creamos para representar los conceptos geométricos. Es por eso que una adecuada enseñanza de la geometría requiere del desarrollo de la intuición espacial en los estudiantes y el proponerles actividades que involucren el movimiento de objetos en el espacio, para que se logre analizar matemáticamente su entorno espacial 
evocando un adecuado desarrollo del mismo (Del Grande, 1987; Jones, 2001; New Jersey Mathematics Coalition, 1996). Abarca la forma en la que se observan espacios en dos y tres dimensiones con actividades como el doblado del papel, las transformaciones, teselaciones y proyecciones, en donde estas referentes al sentido espacial pueden ser aplicadas por los alumnos a las formas y el espacio que componen el mundo real (New Jersey Mathematics Coalition, 1996).

Se puede notar la relación que tiene la geometría y el sentido espacial con el enfoque funcional de su enseñanza, especialmente porque se centra en el espacio en el que nos encontramos y es necesaria para llevar a cabo actividades del día a día (Molina y Flores, 2017). Además, porque el objetivo de la enseñanza de esta área de las matemáticas “... es que los estudiantes y los ciudadanos en general se ubiquen y desplacen eficientemente en el medio en que se desenvuelven a través de herramientas útiles" (Cruz y Ramírez, 2018, p. 211). Es por ello que, el aprendizaje de la geometría debe estar impregnado de sentido espacial, logrando incorporar el conocimiento de las características de los objetos y del espacio en un mundo tangible (Molina y Flores, 2017).

Es importante resaltar lo que los autores Flores et al. (2015) subrayan sobre este sentido: "El sentido espacial destaca que el aprendizaje de objetos geométricos tiene que acompañarse con el descubrimiento y práctica de destrezas que permiten ubicarlos en el espacio, percibirlos y representarlos de diversas formas." (p.130). Es por eso que estos mismos investigadores resaltan dos componentes del sentido espacial: el manejo de conceptos geométricos y las destrezas para visualizar esos conceptos.

\subsubsection{Conceptos geométricos}

La resolución de situaciones prácticas relacionadas con el espacio requieren el conocimiento de las propiedades y características de objetos geométricos en ambientes de dos o tres dimensiones; por ejemplo, para identificar una determinada figura geométrica habrá que disponer de un repertorio de imágenes de esas figuras, conocer sus nombres, ser capaces de distinguirlas, pero también establecer relaciones entre los elementos de la misma, tratar sus movimientos, ubicación y regularidades. Esta componente, a su vez, se divide en tres apartados: propiedades de las formas y figuras, las relaciones geométricas, y la ubicación y movimientos. 
Propiedades de las formas y las figuras: se trata de la identificación de figuras por su nombre, su definición, manipular diversas representaciones, elaborar definiciones, dibujar o construirlas, caracterizarlas o dar propuestas de contraejemplos.

Relaciones geométricas: este apartado abarca todo lo relacionado con cualidades de los objetos geométricos como simetría, congruencia, equivalencias, características de clasificación o diferenciación de las mismas.

Ubicación y movimiento: supone situar en el plano y el espacio los elementos, apreciar posiciones relativas. Pero también tener conocimiento y lograr realizar movimientos, detectar aspectos que resultan invariantes al realizar esas transformaciones. Acá se ve la geometría desde una perspectiva más dinámica.

\subsubsection{Destrezas para visualizar esos conceptos}

Incluye a todas aquellas habilidades que ayudan a la visualización de elementos geométricos en el espacio, comprendiendo su disposición en el entorno (Aznarte y Ramírez, 2018), abarcando dos componentes, con los que también coinciden diversos autores (Clements, 1998; Gonzato et al., 2011; MacGee, 1979): orientación espacial y visualización espacial.

Orientación espacial: consiste en la habilidad para entender la disposición de los elementos en el espacio además de recordarlos desde diversas perspectivas (Flores et al., 2015), afecta a todas aquellas actividades que puedan estar relacionadas con la lectura o dibujo de mapas, planos o maquetas, descripción del recorrido entre dos lugares, leer o trabajar con sistemas de coordenadas (Gonzato et al., 2011), que estos últimos son de gran importancia para el aprendizaje del álgebra también. Por lo tanto, tener desarrollada esta habilidad, le permite a la persona lograr saber dónde está en un espacio determinado y cómo lograr moverse por el mundo (Clements, 1998).

Visualización espacial: es la capacidad de manipular o realizar movimientos de objetos mentalmente utilizando imágenes; esto puede involucrar la aplicación de transformaciones $\mathrm{u}$ operaciones geométricas a objetos en espacios de dos o tres dimensiones (Clements y Battista, 1992; Fernández et al., 2012; Kosa y Karakus, 2018). Visto desde un enfoque aplicado a la geometría, involucra un gran bagaje de imágenes, habilidades que puedan ser utilizadas para generar, razonar, modificar y externar 
información sobre las posiciones de objetos geométricos (Flores et al., 2015), esto también conlleva que se hagan traducciones de relaciones abstractas en representaciones más visuales (Clements y Battista, 1992).

Ampliando este concepto, Flores et al. (2015) indican que: "Para visualizar hay que crear y disponer de un buen repertorio de representaciones e imágenes gráficas de las formas, cuerpos y figuras geométricas, ser diestro para generar información sobre ellas y utilizarlas para resolver problemas prácticos.” (p.133). Con esto también concuerda la National Council of Teachers of Mathematics (2003) al indicar que se debe promover la utilización de la visualización "para resolver problemas dentro y fuera de las matemáticas" (p. 43).

Gutiérrez (1996) distingue cuatro componentes de gran relevancia dentro de la visualización: imágenes mentales, representaciones externas, procesos de visualización y habilidades de visualización. Se considera necesario abordar cada uno de estos conceptos a continuación.

Las imágenes mentales son definidas por Serrano et al. (2018) como "las representaciones que las personas podemos hacernos de los objetos físicos, de las relaciones matemáticas o de los conceptos matemáticos.” (p. 121). Las representaciones externas corresponden a manifestaciones que pueden darse de forma verbal o gráfica y que son referidas a un concepto o sus características, toman una imagen mental y las plasman físicamente por medio de bocetos, dibujos, diagramas o similares, buscando favorecer un razonamiento visual (Fernández, 2019; Ramírez, 2012).

Los procesos de visualización son definidos por Serrano et al. como "las acciones mentales o físicas en que están involucradas las imágenes.” (p.121). Gutiérrez (1996) amplia este concepto indicando que existen dos procesos que se logran con la visualización: en uno de ellos se toma la información y se transforma creando una imagen mental y el segundo proceso consiste en el inverso del anterior, se interpretan las imágenes mentales y se modifican en otros tipos de informaciones.

En el caso de las habilidades de visualización, son requeridas para procesar y crear imágenes visuales (Serrano et al., 2018). Del Grande (1990) reconoce siete distintas habilidades de visualización, las cuales se describen en seguida: 
a) Coordinación ojo-motor: es la capacidad de una persona de poder coordinar la visión con los movimientos que realice el cuerpo. Actividades de la vida cotidiana como ponerse ropa, sentarse, recortar o dibujar involucran esta habilidad. En el caso de la geometría puede evidenciarse en acciones como dibujar líneas en caminos estrechos, rectos o de forma curva, colorear regiones o unir puntos mediante diferentes tipos de líneas.

b) Percepción figura-contexto: acto visual de identificar una figura específica en un fondo dado por una imagen. Por ejemplo, si una persona rebota una bola contra el piso, y se queda viendo el movimiento del objeto, la atención visual la dirige a la bola, logrando discriminarla del fondo. En el caso de la geometría se aplica cuando se necesita distinguir una figura dentro de un conjunto de formas superpuestas, cuando es necesario completar una figura o cuando se forma una figura en función de otras (como el tangram).

c) Conservación de la percepción: consiste en la capacidad de reconocer figuras geométricas presentadas en diversos tamaños, matices, texturas y posiciones en el espacio y discriminarlas de figuras geométricas similares. Por ejemplo, se sabe que una cancha de futbol es rectangular, pero muy pocas veces se logra ver esta figura de forma completa. En el caso de tareas geométricas que involucran esta habilidad se pueden destacar aquellas en donde es necesario identificar formas de figuras semejantes, ordenar objetos por su tamaño o identificar figuras que tienen mismo tamaño y forma.

d) Percepción de posición en el espacio: capacidad de establecer relaciones entre un elemento en el espacio con otro cuando se ha modificado su posición. En geometría puede relacionarse con actividades para las que es necesario identificar figuras congruentes dentro de dibujos complejos.

e) Percepción de las relaciones espaciales: capacidad de ver dos o más objetos en relación con uno mismo o en relación a otros. En geometría puede ejemplificarse con tareas como la de construir una torre con cubos, en donde puede observarse la posición de los cubos con relación a uno solo de ellos o relacionados entre sí.

f) Discriminación visual: capacidad de identificar aspectos similares y diferentes entre objetos. 
g) Memoria visual: capacidad de recordar objetos que están ausentes y relacionar sus características con otros objetos que se están mirando o no. Se puede relacionar con el concepto de "memoria fotográfica". Esta habilidad puede estar presente cuando se les solicita a los estudiantes que copien figuras del papel a un geoplano.

En los apartados anteriores, se reafirma la complejidad y el inmenso abarque de habilidades que están involucradas dentro del concepto de sentido espacial, cuyo desarrollo permitirá la ejecución de actividades de la vida cotidiana, y no solo situaciones propias de la geometría desde el punto escolar.

\subsubsection{Relación de las componentes del sentido espacial}

Las componentes que fueron desarrolladas en los apartados anteriores no pueden entenderse de forma independiente. Esa dependencia entre las dimensiones, es la que admite resaltar la fortaleza del sentido espacial y el elemento clave que favorece establecer esa relación es la visualización (Cruz y Ramírez, 2018; Flores et al, 2015), tal y como puede observarse en la figura 1 de Flores et al. (2015), en la que se quiere expresar, de manera dinámica, que las componentes se verán acrecentadas si se asocian y conjugan con las habilidades de visualización.
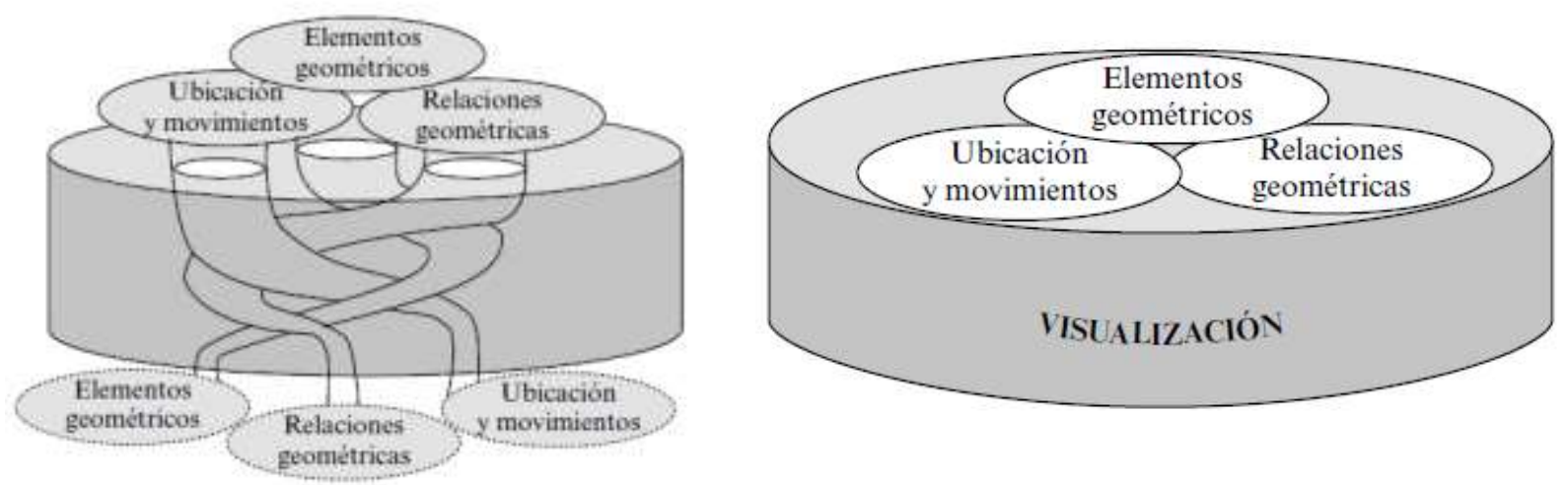

Figura 1. Relación de los componentes geométricos con la visualización

\subsubsection{Sentido espacial y profesores de matemáticas}

Serrano et al. (2018) afirman que "Los profesores tenemos que ser capaces de reconocer dónde y cómo vamos a poder infundir en la actividad escolar para lograr un desarrollo significativo del sentido espacial en nuestros alumnos." (p. 118). El docente en ejercicio y los futuros profesores deben percatarse de la relevancia para el aprendizaje que tiene una enseñanza de las matemáticas con sentido espacial, por eso es necesario que se tenga una adecuada comprensión de cómo los estudiantes aprenden sobre el espacio y la 
geometría, además de conocer actividades y enfoques de enseñanza dentro de esta temática (Clements, 1998), siendo conscientes de que el sentido espacial no es una asignatura concreta sino que debe de ir de la mano de los contenidos geométricos (Newcombe, 2010). Es por eso que diversos autores (Clements, 1998; Del Grande, 1990; Flores et al., 2015; Gonzato et al., 2011 Stanic y Owens; Serrano et al., 2018; Stanic y Owens, 1990), brindan algunas sugerencias que deben tomar en cuenta los profesores para un adecuado desarrollo del sentido espacial en sus estudiantes:

- Involucrar situaciones de aula que impregnen de sentido a los objetos geométricos, con la intención de que se vaya graduando la incorporación de habilidades que permitan identificar esos objetos en un espacio.

- Tener un amplio y diverso repertorio de tareas de visualización y orientación espacial.

- Fomentar el uso de dibujos que estén bien construidos y que sean precisos, apoyar tareas que permitan que el estudiante recorte o utilice materiales concretos antes de que lleguen a etapas en donde sea necesaria la visualización y la imaginación.

- Conocer que el uso de computadoras puede contribuir a la ejecución de actividades que de forma física pueden ser difícil de realizar.

- Generar una práctica continua, tener un uso adecuado el lenguaje y gestos, favorecer actividades que involucren mapas, los diagramas, bocetos y analogías.

Si el docente incorpora dentro de su planeación didáctica aspectos que permitan conectar los conceptos geométricos con las habilidades espaciales, favorecerá el diagnóstico de dificultades que surjan en el proceso de aprendizaje, además de tener una noción más clara del cómo los alumnos aprenden geometría (Del Grande, 1990). Otra labor importante que debe llevar a cabo el profesor dentro de esta línea, es la de motivar a sus estudiantes, buscando crear hábitos que le permitan aplicar las habilidades del sentido espacial a situaciones problema dentro de su entorno cotidiano (Flores et al., 2015).

Todas las sugerencias desarrolladas en este apartado, solo las puede llevar a cabo un docente que sea consciente del sentido espacial y que pueda planificar actividades que evoquen esas recomendaciones. 


\subsection{Revisión bibliográfica}

En capítulos anteriores fue definida el área problemática a investigar y el sustento teórico que lo fundamenta. A continuación, se realizará una revisión de las investigaciones relacionadas con la temática a investigar, mostrando la variedad de aspectos en los que los estudios se han basado. En una primera sección se presentarán investigaciones que indagan las formas de pensamiento, razonamiento y conocimiento, en una segunda sección mostramos algunos resultados de investigaciones sobre sentido espacial o habilidades espaciales y destrezas visualices. Para finalizar, realizamos una valoración de la bibliografía consultada.

Para la revisión bibliográfica de los antecedentes, se consideró la búsqueda en bases de datos como Scopus, Eric, Sumarios ISOC, SSCI, Dialnet y TESEO. Se consultaron repositorios digitales como DIGIBUG de la Universidad de Granada, GREDOS de la Universidad de Salamanca y FUNES que está especializado en Educación Matemática. Se utilizó el buscador virtual Google Scholar por ser sencillo de usar y gratuito. En relación a las revistas analizadas, resaltamos las búsquedas realizadas en Educational Studies in Mathematics, Educación Matemática, International Electronic Journal of Elementary Education, International Journal for Mathematics Teaching and Learning, Journal on Mathematics Education y Universal Journal of Educational Research. De los congresos y eventos científicos, se realizó una revisión de las actas del PME, ICME y SEIEM.

Las palabras clave definidas a priori para realizar las búsquedas fueron: "sentido espacial geometría", "habilidades espaciales geometría", "visualización”, "desarrollo cognitivo en geometría"; todas ellas combinadas con las palabras "maestro" o "profesor", esto para las búsquedas en español. Al realizar las búsquedas en inglés se consideraron las palabras clave: "spatial sense", "visual spatial ability", "spatial skills", "visualization skills", combinadas con la palabra "teachers". Luego de unas búsquedas iniciales se observaron las palabras clave que indicaban algunos autores en sus artículos, entonces se decidió involucrar dentro de los siguientes motores de búsqueda a palabras como: "pre-service teachers", "reasoning skills on geometric teachers", "geometry teachers skills", "conocimientos geométricos en futuros profesores o maestros", "pensamiento geométrico en futuros profesores o maestros". 
En bases de datos como Scopus, Eric y SSCI no se encontraron resultados con palabras en español. Además, dentro de los motores de búsqueda que presentaban miles de resultados, se decidió consultar aquellos que iban desde el año 2015, sin embargo, en general se presentan estudios de la última década. En los sitios que lo permitían, se filtraba la búsqueda en categorías como "educación", "educación primaria", "educación secundaria", "pedagogía" o "matemáticas".

Esta búsqueda condujo a muchos documentos, sin embargo, se decidió revisar a profundidad únicamente aquellos que estuvieran relacionados con futuros profesores de secundaria o primaria y en temáticas afines a lo que se desea realizar en este estudio, como lo son pensamiento o razonamiento geométrico, conocimiento geométrico, sentido espacial, habilidades espaciales y visualización. A continuación, se hace un recorrido por cada una de ellas.

\subsubsection{Investigaciones sobre razonamiento y conocimiento geométrico en futuros profesores}

En esta sección se agrupan todos aquellos estudios relacionados con formas de razonamiento, pensamiento o conocimiento geométrico.

Resaltamos la investigación de Carreño y Climent (2010), quienes estudiaron el conocimiento geométrico en función de las capacidades y destrezas de los Niveles de Van Hiele. Se aplicaron cuatro test sobre los temas de ángulos, triángulos y polígonos a 12 futuros profesores de matemáticas. Los resultados del estudio indican que los estudiantes de maestro tienen imágenes prototípicas muy arraigadas que les causan conflictos al realizar algunas de las tareas que se proponen. Además, el conocimiento geométrico es escaso conceptualmente y muy débil al establecer relaciones entre elementos de la geometría. Se muestra ausencia de un razonamiento formal y se utilizan ideas que parecen ser intuitivas basadas en la experimentación y en lo que pareciera funcionar para llevar a cabo las distintas tareas geométricas.

Cunningham y Roberts (2010), evaluaron las habilidades de 23 futuros docentes de una universidad en Estados Unidos al momento de resolver una serie de ejercicios geométricos. Se detectó que los profesores tienen habilidades para dibujar de manera adecuada elementos geométricos; sin embargo, presentan una escasa comprensión de conceptos y definiciones. Por ejemplo, tienen dificultades cuando se les solicita trazar la 
altura de un triángulo y esta cae fuera de uno de los lados de la figura, o con polígonos que al trazar su diagonal también caen fuera de la figura. Esto es interesante de retratar, puesto que en las tareas que se proponían, se adjuntaba la definición de la altura de un triángulo o la diagonal de una figura geométrica. Los investigadores concluyen que los futuros docentes, posiblemente han vivido una enseñanza geométrica basada en la memorización de conceptos y no necesariamente eso implica un dominio de los contenidos.

Estudios realizados en Eslovaquia no se alejan de lo expuesto en investigaciones anteriores. Žilková et al. (2015) pidieron a 95 futuros profesores, resolver tareas geométricas complejas relacionadas con la identificación de propiedades elementales de formas geométricas (triángulo, rectángulo, cuadrado, paralelogramo, rombo) que se ubicaban en un nivel 1 o 2 del Modelo de Van Hiele. Los investigadores concluyen que la tasa de éxito al resolver estas tareas fue preocupante, sobre todo pensando en que los participantes deberían tener suficientes conocimientos matemáticos, pues son profesores en formación. Se presentan dificultades al resolver problemas que involucran figuras geométricas como los paralelogramos, identifican figuras geométricas únicamente cuando son presentadas en formas estándar y carecen de un adecuado dominio de propiedades geométricas. Se demostró que los futuros profesores no tienen concepciones sólidas y estables ni siquiera en los niveles cognitivos más bajos sobre formas geométricas elementales y sus propiedades (Žilková et al., 2015).

Krajcevski y Sears, (2019) analizaron las respuestas de 16 futuros profesores de matemáticas, en un examen geométrico de seis ejercicios, con la finalidad de caracterizar sus razonamientos. Dentro de los resultados más importantes que se hallaron, se rescata que los participantes consideran que la comparación del área de dos figuras solamente se puede realizar si existen medidas de sus elementos, esto permite concluir que su visión del área, corresponde a un cálculo algorítmico mediante memorización de fórmulas. El examen presentaba representaciones geométricas atípicas de un triángulo, un cuadrado y un paralelogramo, esto generó dificultades en los futuros profesores cuando se les cuestionaba sobre elementos geométricos de estas figuras, como la mediana o la altura. Por tanto, se considera que las imágenes geométricas atípicas afectan los procesos cognitivos y las imágenes conceptuales de los estudiantes (Krajcevski y Sears, 2019). 
En esta línea, otra investigación realizada por Marchis (2012), evalúa los conocimientos básicos de futuros profesores de educación primaria sobre formas geométricas y sólidos. A los participantes se le expuso a un conjunto de problemas relacionados con formas geométricas planas y del espacio. Los resultados apoyan lo expuesto en investigaciones previas, se detectan deficientes conocimientos geométricos, carencias para definir las figuras geométricas básicas, utilizan propiedades de manera incorrecta, se presentan dificultades para dibujar el desarrollo plano de figuras en tres dimensiones.

\subsubsection{Investigaciones sobre sentido espacial, habilidades espaciales o destrezas de visualización en futuros profesores}

Hasta este momento se ha realizado un recorrido por investigaciones que muestran, de modo muy general, cómo se enfrentan los futuros profesores a distintas tareas geométricas permitiéndonos revisar su pensamiento y conocimiento en geometría. En este apartado hacemos énfasis en investigaciones que caracterizan el sentido espacial, habilidades espaciales o destrezas de visualización en futuros profesores.

Akayuure et al. (2016) realizan una investigación relacionada con las capacidades espaciales y el conocimiento geométrico en futuros profesores, investigando el efecto que pueden tener actividades relacionadas con plegado de papel y un test de rotación mental. Previo a la aplicación de actividades con papel, se detectaron dificultades en habilidades de orientación espacial, visualización espacial y conocimiento geométrico. Se concluye que la instrucción con doblado de papel provoca mejorías en las habilidades espaciales y el conocimiento geométrico de los futuros profesores.

Marchis (2017), trata de caracterizar cuantitativa y cualitativamente las habilidades espaciales de futuros profesores de matemática de educación primaria. A los participantes se le expuso a un conjunto de problemas tomados de libros de texto o de competencias matemáticas. Los resultados revelan la necesidad de desarrollar la capacidad espacial en futuros profesores además de competencias que les permitan resolver diversos problemas relacionados con la geometría espacial.

Roura (2020) trabajó con 54 futuros maestros de educación primaria, aplicándoles un test visual para analizar las componentes del sentido espacial requeridos para su resolución. Se encontró que la capacidad visual tiene un impacto en aquellas actividades que requieran uso de habilidades de sentido espacial. Se concluye que la mayoría de maestros 
se ubican en un nivel medio de visualización además de cometer errores con el manejo de rotaciones y simetría. Resultados similares son obtenidos por Ünal et al. (2009), los cuales realizaron una investigación con profesores en formación de educación media y secundaria en donde analizaron las diferencias de aprender geometría con bajas y altas habilidades espaciales, encontrando que las habilidades espaciales fueron importantes para la comprensión de los contenidos geométricos en los participantes del estudio: a mayor puntaje en la prueba de habilidad espacial se presenta una mejor comprensión geométrica.

Putri (2018) realizó una investigación con 35 futuros profesores a los que se les aplicó el test de Purdue. Los resultados registran que más del 50\% de los futuros profesores poseen una habilidad espacial en un nivel intermedio, mientras que el resto tenía un nivel alto y bajo. También se detecta que existe una correlación entre habilidad espacial y habilidad matemática al resolver problemas geométricos, es decir, los participantes que tienen una mejor habilidad espacial tienen más éxito en la resolución de problemas. Resultados similares, con respecto a la correlación entre habilidades espaciales y rendimiento de la geometría, han sido detectados por Ilhan (2021) en un estudio aplicado a 384 maestros en formación. Se evidencia que hay una correlación moderada entre percepción visual y habilidades de razonamiento sobre formas geométricas. Por esta misma línea se muestran los hallazgos de Ozsoy (2018), quien aplicó un estudio con futuros profesores de matemáticas al enfrentarlos a tareas que involucraban representaciones visuales en sus soluciones. Los resultados indican que los futuros profesores que tienen altas habilidades espaciales son más competentes para generar representaciones más estructuradas que aquellos que tienen bajas habilidades espaciales.

Fernández-Blanco et al. (2019), realizaron un estudio con 400 profesores en formación, a los cuales se les aplicaba una prueba acompañada de entrevistas semiestructuradas. Esta prueba analizaba diversos aspectos relacionados con las habilidades y capacidades espaciales tomando herramientas del enfoque ontosemiótico. En el análisis de los datos recolectados, se hace evidente que el uso de elementos visuales facilita mucho la resolución de las actividades propuestas. Se detecta que los futuros profesores no se encuentran acostumbrados a resolver tareas que involucran un razonamiento espacial y visual, cuando su formación se ha basado en el cálculo de áreas y volúmenes. En otro trabajo del grupo, Fernández-Blanco et al. (2012), realizan una investigación en donde 
estudian el desarrollo de capacidades de visualización y razonamiento espacial de estudiantes para maestro. Se detectaron deficiencias cognitivas, así como problemas al tratar tareas con algunos razonamientos mentales, además se resalta el uso de estructuras como imágenes metales, imágenes visuales o conceptos figurales cuando los maestros trabajan con una determinada actividad.

Estos resultados no se alejan de los obtenidos por Ortíz y Sandoval (2018). Estos investigadores realizan una experiencia con 17 futuros profesores de primaria, los cuales fueron sometidos a tareas geométricas en las que debían de-construir y re-construir figuras geométricas en dos y tres dimensiones, interpretar relaciones espaciales entre objetos y analizar el espacio en un determinado contexto. Se detectan deficiencias relacionadas con habilidades de razonamiento espacial y se evidencia escaso uso de lenguaje espacial relacionado con figuras en dos y tres dimensiones.

Por su parte Ozdemir y Goktepe (2015) realizan otro estudio con futuros profesores de matemáticas, al investigar las habilidades espaciales al resolver diversas tareas. Los docentes cuando son sometidos a actividades que involucran utilizar visualización en dos o tres dimensiones, comienzan a realizar cálculos sin dedicarse a profundizar con un nivel cognitivo mayor. Además, se evidencia que entre más alto sea el desarrollo de las habilidades visualizadoras, mejoran las respuestas de los participantes.

Metzger (2019) analizó las habilidades de razonamiento espacial de futuros profesores de matemáticas tras someterlos a la aplicación de distintas actividades geométricas y su capacidad para la confección de tareas geométricas. Detecta falta de flexibilidad en el razonamiento espacial de los profesores en formación, que evidencian dificultades en su tratamiento, esto podría deberse a la poca experiencia que tienen trabajando con actividades de este tipo.

Considerando que en la búsqueda bibliográfica se hallaron muchos estudios relacionados con visualización, además de que las destrezas de visualización son tomadas en cuenta como un componente del sentido espacial, creemos que es importante resaltar un par de estudios relevantes.

Godino et al. (2016), realizaron un estudio denominado "Evaluación de Conocimientos Didáctico-Matemáticos sobre Visualización de Objetos Tridimensionales en Futuros Profesores de Educación Primaria”. Se aplicó un test que evaluaba conocimiento 
geométrico y conocimiento didáctico de futuros maestros. Detectaron serias deficiencias en el manejo de conceptos geométricos, dificultades en la representación plana de objetos en tres dimensiones y errores que comenten por manejar concepciones no correctas sobre la visualización de un objeto en tres dimensiones cuando se ha variado su estructura.

Autores como Markopoulos et al. (2015), proponen un estudio sobre las estrategias en visualización de objetos en tres dimensiones de futuros maestros. Detectando que los docentes participantes tienen dificultades al momento de codificar y descodificar información visual. Para los resultados enmarcados en relaciones que se pudieran realizar entre representaciones en dos dimensiones y posibles construcciones en tres dimensiones, se obtiene una evidente falta de análisis al dar sentido espacial a la información.

\subsubsection{Valoración de la revisión bibliográfica}

La literatura de investigación nos permite percibir que son pocos los estudios que analizan el sentido espacial en futuros profesores con ese término como tal, sin embargo, son varias que lo hacen desde la perspectiva de habilidades espaciales y muchos de ellos tomando como sujeto de estudio a profesores de educación primaria en formación. La mayoría de investigaciones presentadas, recalcan que las habilidades espaciales muestran ser importantes para la comprensión de los distintos contenidos geométricos. Esto se evidencia en los estudios que logran mostrar una correlación de habilidades espaciales con éxito en resolución de tareas geométricas, haciendo énfasis en que los participantes que presentan niveles intermedios o bajos de habilidades espaciales se enfrentan con mayores dificultades a la resolución de ejercicios y problemas geométricos. No hay costumbre de aplicar razonamientos visuales y espaciales en los profesores que participan en los estudios, esto también se detecta en tareas elaboradas por los docentes, dándole prioridad al manejo de conceptos geométricos sin requerir destrezas visuales. El que no se detecten habilidades espaciales altas en los docentes evoca una necesidad en el desarrollo de capacidades relacionadas con el sentido espacial en los educadores. En cuanto a investigaciones que analizan la visualización en distintas tareas, especialmente se resaltan dificultades para la visualización de objetos geométricos en tres dimensiones, también en los procesos de codificación y decodificación de información visual. Además, los profesores ponen de manifiesto obstáculos al tratar con relaciones de figuras y elementos de la geometría en dos y tres dimensiones. 


\section{CAPÍTULO 3. MARCO METODOLÓGICO}

\subsection{Descripción de la investigación}

La investigación que se realizó se enmarca dentro del tipo observacional y descriptivo con una metodología cualitativa, esto debido a que los objetivos formulados pretenden identificar y describir las componentes del sentido espacial que futuros profesores de matemática manifiestan al resolver tareas geométricas. En concordancia con Hernández et al. (2014) "los estudios descriptivos buscan especificar las propiedades, las características y los perfiles de personas, grupos, comunidades, procesos, objetos o cualquier otro fenómeno que se someta a un análisis" (p. 92). Consideramos una metodología cualitativa basada en un estudio de caso por tener una muestra reducida, apoyándonos de las ideas de Hernández et al. (2010), las investigaciones cualitativas no tienen la intención de realizar una generalización probabilística de sus hallazgos a grupos más amplios ni la intención de trabajar con muestras representativas, "se enfoca a comprender y profundizar los fenómenos, explorándolos desde la perspectiva de los participantes en un ambiente natural y en relación con el contexto" (Hernández et al., 2010, p.364).

La investigación consistió en dos fases, en la primera se realizó un análisis de posibles tareas para desarrollar en la sesión de intervención con los futuros profesores, de donde se decidió utilizar aquellas que involucran doblado de papel. Además, determinamos las posibles habilidades de visualización que se ponen en juego al resolverlas y las propiedades geométricas, relaciones, ubicaciones y movimientos, estos últimos con ayuda de la técnica de juicio de expertos. La segunda fase consistió en una sesión de intervención a modo de entrevista semiestructurada en donde se analizaban las dimensiones del sentido espacial que ponían de manifiesto seis futuros profesores de matemáticas y cuyos datos fueron analizados mediante la técnica de análisis de contenido.

Debemos indicar que nuestra investigación se ubica dentro de la línea de investigación llamada Didáctica de la Geometría, pues se centra en la comprensión de las componentes del sentido espacial de un grupo de futuros profesores de matemáticas. 


\subsection{Elementos de la investigación}

\subsubsection{Sujetos y contexto}

En concordancia con Hernández et al. (2010), en una investigación cualitativa "Se involucra a unos cuantos sujetos porque no se pretende necesariamente generalizar los resultados del estudio" (p.13). Por tanto, los sujetos que han participado en este estudio son seis futuros profesores de matemáticas, de los cuales una es mujer y cinco son hombres, quienes estudian el grado de Enseñanza de la Matemática con Entornos Tecnológicos del Instituto Tecnológico de Costa Rica. Esta institución de estudios superiores, es una de las cinco universidades públicas de Costa Rica que tiene 25 años formando profesores de matemáticas. Se han elegido estudiantes de tercer año, en este nivel ya han cursado materias de su programa de estudios, relacionadas con la geometría: Geometría I, Geometría II, Didáctica de la Geometría y Tópicos de Geometría. La selección de los sujetos se ha realizado de forma intencional y por disponibilidad, debido a que son estudiantes de la universidad donde labora el investigador.

\subsubsection{Instrumento para la recolección de datos y guía de actividades}

En concordancia con Hernández et al. (2010) el principal instrumento para la recolección de datos en una investigación de carácter cualitativa es el mismo investigador. El método para la recolección de datos se desarrolla mediante una sesión de intervención a modo de entrevista semiestructurada, los sujetos participantes del estudio tuvieron que resolver actividades geométricas de doblado de papel presentes en una guía previamente definida. Para diseñar las actividades o retos geométricos que pongan de manifiesto el sentido espacial, se ha tomado en cuenta la bibliografía citada en apartados anteriores, especialmente Akayuure et al. (2016) y Flores et al. (2015) sugieren tareas relacionadas con plegado de papel para el desarrollo del sentido espacial. Otro aspecto que motivó la elección de actividades con plegado de papel fue que, las sesiones de intervención se realizaron a distancia mediante una videoconferencia debido a la situación de la COVID19, entonces se requería de tareas que necesitaran de materiales sencillos de adquirir por parte de los participantes del estudio.

Con actividades de plegado de papel se pueden obtener las mismas construcciones geométricas que son realizables con regla y compás, pero sin obtener circunferencias completas (Flores et al., 2011; Ricotti, 2020). El trabajo con papel en geometría permite “... modelizar situaciones, resolver problemas, representar propiedades, construir con 
precisión, mejorar la visión espacial y, por qué no, recuperar o ejercitar la tan venida a menos destreza manual" (Ricotti, 2020, p. 8).

Específicamente la guía con actividades que permitió llevar a cabo la entrevista semiestructurada lo conforman tres tareas o retos, las cuales se detallan a continuación (en el anexo A se presentan las tareas con las posibles resoluciones propuestas por el investigador.):

Tarea 1. Hallar, mediante el doblado de una hoja de papel con bordes irregulares, la mediatriz de un segmento dado. a) Justifique su construcción, ¿por qué al realizar esos dobleces le permitieron obtener la mediatriz del segmento? b) Finalizada la construcción, ¿cómo podría doblar de otra manera para justificar que lo obtenido corresponde a la mediatriz del segmento dado?

Tarea 2. Hallar, mediante el doblado de una hoja de papel con bordes irregulares, la perpendicular por un punto exterior a una recta dada. Justifique su construcción, ¿por qué al realizar esos dobleces le permitieron obtener la recta perpendicular solicitada?

Tarea 3. Hallar, mediante el doblado de una hoja de papel con bordes irregulares, la paralela a una recta por un punto exterior a ella. Justifique su construcción, ¿por qué al realizar esos dobleces le permitieron obtener la recta paralela solicitada?

Los datos relativos a las acciones realizadas por los futuros profesores al enfrentarse a las distintas tareas propuestas en la guía de actividades, se han obtenido mediante entrevistas semiestructuradas y su realización ha sido de carácter individual. Las entrevistas semiestructuradas toman partida de una guía de preguntas (en este caso las tres tareas de la guía de actividades anteriormente descrita que sirven como reactivos) y el entrevistador puede introducir preguntas adicionales que le permitan clarificar ciertas ideas o lograr extraer más información (Hernández et al., 2010). Siguiendo las recomendaciones de Hernández et al. (2010), se generó un ambiente de naturalidad y confianza, en donde el entrevistado era el centro de atención, debido a que nos interesaba el contenido y la narrativa, se les solicitaba a los futuros profesores que trataran siempre de externar sus pensamientos en voz alta y de forma espontánea. El papel del investigador se basaba en un simple observador que en ocasiones intervenía con alguna pregunta que permitiera dar claridad a las acciones y razonamientos utilizados en la resolución de las tareas. 
Las fuentes de datos que permitieron su interpretación son la grabación en audio y video de la sesión de intervención (entrevista) en la cual los futuros profesores se enfrentan a las tareas geométricas, aunado a las anotaciones resultantes de la observación realizada por el investigador durante la entrevista y las construcciones a papel presentadas por los participantes como resultado de la resolución de las actividades geométricas planteadas.

\subsubsection{Variables del estudio}

Para identificar y describir las componentes del sentido espacial que futuros profesores de matemática manifiestan al resolver actividades de doblado de papel, es necesario declarar las siguientes variables:

- Los conceptos y elementos geométricos que el alumno maneja al momento de resolver las actividades. Específicamente que sepa identificar a través del nombre y la representación elementos dentro de una estructura mayor o características elementales que se obtienen directamente de la definición de una figura.

- Las relaciones geométricas existentes entre los distintos elementos geométricos que obtengan (congruencia, simetría, perpendicularidad, paralelismo), durante la resolución de las actividades. También todas aquellas relaciones de medida que logren identificar con respecto a segmentos o ángulos.

- Las ubicaciones y movimientos que los futuros profesores están en capacidad de identificar, elementos que varían o no al realizar movimientos, descripciones sobre distintas posiciones de elementos en el plano o el espacio y caracterizaciones geométricas de los movimientos utilizados (rotaciones o simetrías).

- Las habilidades de visualización que emplean los alumnos al resolver las distintas tareas. Los valores de esta variable serán las siete habilidades propuestas por Del Grande (1990) y que fueron mencionadas en el marco teórico: 1. Coordinación ojo motor, 2. Percepción figura-contexto, 3. Conservación de la percepción, 4. Percepción de la posición en el espacio, 5. Percepción de las relaciones espaciales, 6. Discriminación visual y 7. Memoria visual.

- El éxito en la actividad nos brinda información acerca de si el futuro profesor ha logrado completar la actividad de manera total, parcial o nula. 


\subsection{Método para el análisis de los datos}

Para este estudio se ha seleccionado el análisis de contenido para analizar el contenido de las entrevistas en donde los futuros profesores se enfrentaron a las tareas geométricas, transformando sus respuestas y las observaciones realizadas en nuestros datos de carácter cualitativo.

El análisis de contenido es de gran utilidad para analizar datos de observaciones y entrevistas (Hernández et al., 2010) y además es definido como “... un método para establecer y estudiar la diversidad de significados escolares de los conceptos y procedimientos de las matemáticas que aparecen en un texto (discurso del profesor, textos escolares y producciones escolares para la detección de sesgos)." (Rico, 2013, p.18). Cuyo objetivo principal es la realización de una revisión sistemática y objetiva de un material que comunique algún tipo de información a raíz de la exploración de su esqueleto interno (Mayring, 2004; Rico y Fernández, 2013). A grandes rasgos, el análisis de contenido se basa en una dimensión reductora que consiste en realizar una descomposición del contenido a analizar en unidades más sencillas, sintetizando los temas e identificando un sistema de categorías para que finalmente se busquen criterios que permitan caracterizar las unidades de contenido dentro de una categoría (Mayring, 2004; Rico y Fernández, 2013).

Detallando aún más el análisis de contenido, este inicia considerando las unidades de análisis en el texto que se analizará, que en este caso corresponde a párrafos de los comentarios manifestados por los estudiantes en las entrevistas realizadas al afrontarse a las tareas, y las observaciones realizadas por el investigador durante estas sesiones de intervención.

Denotaremos las respuestas de los futuros profesores como ( $R$ _iniciales del futuro profesor_número de tarea), las transcripciones de su conversación ( $C_{-}$iniciales del futuro profesor_número de tarea) y las observaciones (O_iniciales del futuro profesor_número de tarea). Analizando las respuestas podemos corroborar una o varias unidades de análisis, por ejemplo, en la transcripción de la respuesta del alumno $\mathrm{CH}$ en la tarea 3:

C_CH_3: "Porque la recta que cree, la nueva recta doblada que yo estoy diciendo que es paralela, es también perpendicular a la recta que dibujé. Por propiedad, si dos rectas 
son paralelas... mmm... Si dos rectas son perpendiculares a una misma, entonces ambas son paralelas."

Obtenemos las siguientes unidades de análisis:

- La nueva recta obtenida después de doblar es perpendicular a la recta dibujada previamente.

- $\quad \mathrm{Si}$ dos rectas son perpendiculares a una misma recta entonces son paralelas.

Como segundo paso, se definen las categorías que sirvan de apoyo para la interpretación de las unidades de análisis. Para ello se realizó un sistema de categorías a priori que se sometió a una evaluación a juicio de expertos en Educación Matemática que tienen experiencia brindando cursos de geometría o son docentes de carreras de formación de profesores, con la finalidad de brindar mayor validez, fiabilidad y objetividad a las variables, las categorías a utilizar y sus respectivas conductas. Para ello se realizaron dos etapas:

Etapa 1. Las tres actividades de doblado de papel que conforman el instrumento, fueron dividas entre los expertos y mediante sesiones de videoconferencia individuales, se les presentaba una tarea y su posible solución. Luego se mostraban eventuales conductas (previamente agrupadas en concordancia con las variables: "elementos y conceptos geométricos", "relaciones geométricas" y "ubicación y movimientos") que estuvieran involucradas en la resolución de la tarea y que posteriormente podrían ser clasificadas mediante un sistema de categorías. Para esta fase se contó con el apoyo de tres expertos que laboran en el Instituto Tecnológico de Costa Rica y uno de ellos en la Universidad de Costa Rica (ver tabla 1 del anexo B).

Como resultado de esta primera fase, todos los expertos estuvieron de acuerdo con las conductas que se les mostraban. Los únicos cambios presentados fueron relacionados con nombres de definiciones o propuestas para incluir más conductas, específicamente para los grupos de "elementos y conceptos geométricos" y de "relaciones geométricas". (En las tablas 2, 3 y 4 del anexo B se presentan las conductas revisadas por los expertos en esta primera etapa y las modificaciones sugeridas).

Etapa 2. Para la segunda etapa, realizamos una revisión de los cambios propuestos en las conductas que los jueces analizaron en la fase anterior y se establecieron las categorías a 
priori que agrupaban esas conductas y que permitirían el análisis de los datos mediante el análisis de contenido. Posteriormente, se consideraron otros nuevos expertos y algunos que participaron en la etapa anterior, para que evaluaran esta posible categorización con sus respectivas conductas. Nuevamente, se dividieron las tareas entre los jueces, se realizaron entrevistas por medio de videoconferencia en donde se presentaban las actividades con su solución y las categorías establecidas con sus respectivas conductas. Para esta fase participaron seis expertos en educación matemática que brindan cursos relacionados con formación de profesores o geometría, tres de ellos participaron en la etapa anterior y tres eran nuevos. Todos son profesores o investigadores del Instituto Tecnológico de Costa Rica, uno de ellos también labora para la Universidad de Costa Rica y otro también para la Universidad Estatal a Distancia (ver tabla 5 del anexo B).

Por unanimidad, todos los expertos manifestaron estar de acuerdo con las categorías que se presentaban. Sus observaciones se centraban en aspectos de redacción, posibles conductas dentro de las categorías que podrían estar repetidas o algunas conductas relacionadas con la variable de "relaciones geométricas" que debían ser consideradas. (En las tablas 6, 7 y 8 del anexo B se presentan los instrumentos con las categorías y las observaciones realizadas por los expertos).

Para determinar las categorías de análisis definitivas se tomaron en cuenta las sometidas al juicio de expertos con las respectivas modificaciones sugeridas y realizamos un estudio detallado de las respuestas de los alumnos al resolver las tareas, de modo que pudieran enriquecer las categorías con elementos que no fueron considerados a priori, sin embargo, estas respuestas no brindaron un aporte significativo a lo que ya se había definido con anterioridad. Es importante recalcar, que en el proceso de juicio de expertos solo consideramos el componente de "manejo de conceptos geométricos" del sentido espacial. Para las categorías relacionadas con "destrezas de visualización” se utilizaron las propuestas por Ramírez (2012) utilizadas en su investigación sobre habilidades de visualización y algunas conductas utilizadas en otros estudios (Ramírez, 2010; Salto, 2013). Las categorías para el componente de manejo de conceptos geométricos y las habilidades de visualización para las tareas se muestran en las tablas 1, 2, 3, 4, y 5. Cabe destacar que, para las habilidades de visualización, son consideradas las mismas conductas para las cuatro tareas. 
Tabla 1. Listado de categorías y conductas de las variables de conceptos y elementos geométricos y relaciones geométricas para la tarea 1

\section{Componentes \\ del sentido}

espacial

Conceptos y

elementos

geométricos

(CE)

\section{Categorías}

Conductas

CE1: Identifica a través del nombre
elementos geométricos dentro de una
estructura mayor.

Menciona o evidencia uso de:

- El concepto de mediatriz de un segmento

- Ángulos (llano o recto)

- Segmentos

- Puntos

- Punto medio

- Eje de simetría

- Recta perpendicular

-Triángulo

Relaciones geométricas

(RG)
RG1: Identifica relaciones entre diversos elementos geométricos.

RG2: Identifica relaciones de medida al doblar el papel .
Menciona o evidencia que: -Si un punto pertenece a la mediatriz de un segmento, equidista de sus extremos. -Si un punto equidista de los extremos del segmento, entonces pertenece a la mediatriz.

-Relaciones sobre triángulos que son congruentes.

-Relaciones de perpendicularidad. -Relaciones entre segmentos, rectas, ángulos o puntos que no evoquen medidas.

-Establece relaciones sobre segmentos o ángulos congruentes. -Establece relaciones entre longitudes y ángulos con sus respectivos elementos simétricos.

Tabla 2. Listado de categorías y conductas de las variables conceptos y elementos geométricos y relaciones geométricas para la tarea 2

\begin{tabular}{lll}
\hline $\begin{array}{c}\text { Componentes del } \\
\text { sentido espacial }\end{array}$ & \multicolumn{1}{c}{ Categorías } & \multicolumn{1}{c}{ Conductas } \\
\hline Conceptos y & CE1: Identifica a través del nombre & Menciona o evidencia uso de: \\
elementos & elementos geométricos dentro de & -Ángulos (llano o recto) \\
geométricos (CE) & una estructura mayor. & -Puntos \\
& & -Rectas perpendiculares \\
& & -Eje de simetría \\
\hline
\end{tabular}




\section{Relaciones geométricas $(\mathrm{RG})$ \\ RG1: Identifica relaciones entre diversos elementos geométricos.}

RG2: Identifica relaciones de medida al doblar el papel.
Menciona o evidencia que:

-Verifica por un punto exterior a una recta puede construirse una única perpendicular a dicha recta. -Establece relaciones de perpendicularidad. -Establece relaciones entre segmentos, rectas, ángulos o puntos que no evoquen medida.

-Establece relaciones sobre segmentos o ángulos congruentes. -Establece relaciones entre longitudes y ángulos con sus respectivos elementos simétricos.

Tabla 3. Listado de categorías y conductas de las variables conceptos y elementos geométricos y relaciones geométricas para la tarea 3

\begin{tabular}{|c|c|c|}
\hline $\begin{array}{l}\text { Componentes del sentido } \\
\text { espacial }\end{array}$ & Categorías & Conductas \\
\hline $\begin{array}{l}\text { Conceptos y elementos } \\
\text { geométricos (CE) }\end{array}$ & $\begin{array}{l}\text { CE1: Identifica a través del nombre } \\
\text { y la representación elementos } \\
\text { geométricos dentro de una } \\
\text { estructura mayor. }\end{array}$ & $\begin{array}{l}\text { Menciona o evidencia } \\
\text { uso de: } \\
\text {-Rectas paralelas } \\
\text {-Rectas perpendiculares } \\
\text {-Puntos } \\
\text {-Ángulos (rectos o } \\
\text { llanos) } \\
\text {-Eje de simetría }\end{array}$ \\
\hline \multirow[t]{2}{*}{ Relaciones geométricas (RG) } & $\begin{array}{l}\text { RG1: Identifica relaciones entre } \\
\text { diversos elementos geométricos. }\end{array}$ & $\begin{array}{l}\text {-Utiliza el hecho de que } \\
\text { si } a \perp b \text { y } b \perp c \Rightarrow a \| \\
b, \text { siempre que } a, b \text { y } c \\
\text { sean rectas coplanares. } \\
\text {-Establece relaciones } \\
\text { entre longitudes y } \\
\text { ángulos con sus } \\
\text { respectivos elementos } \\
\text { simétricos. } \\
\text {-Relaciones de } \\
\text { perpendicularidad. } \\
\text {-Relaciones de } \\
\text { paralelismo. } \\
\text {-Establece relaciones } \\
\text { entre segmentos, rectas, } \\
\text { ángulos o puntos que no } \\
\text { evoquen medida. }\end{array}$ \\
\hline & $\begin{array}{l}\text { RG2: Identifica relaciones de } \\
\text { medida al doblar el papel. }\end{array}$ & $\begin{array}{l}\text {-Establece relaciones } \\
\text { sobre segmentos o } \\
\text { ángulos congruentes } \\
\text {-Establece relaciones. } \\
\text { entre longitudes y } \\
\text { ángulos con sus } \\
\text { elementos simétricos. }\end{array}$ \\
\hline
\end{tabular}


Tabla 4. Listado de categorías y conductas de la variable de ubicación y movimientos para las tres tareas

\begin{tabular}{ll}
\hline \multicolumn{1}{c}{ Categorías } & \multicolumn{1}{c}{ Conductas } \\
\hline $\begin{array}{l}\text { UM1: Identifica elementos invariantes o } \\
\text { variantes al doblar. }\end{array}$ & $\begin{array}{l}\text { - Identifica elementos geométricos que cambian } \\
\text { cuando se hace algún movimiento. }\end{array}$ \\
$\begin{array}{l}\text { UM2: Sitúa los distintos dobleces para } \\
\text { obtener los elementos geométricos } \\
\text { deseados justificando geométricamente su } \\
\text { movimiento. }\end{array}$ & $\begin{array}{l}\text { - Identifica en qué momento realizar una rotación en } \\
\text { el espacio para obtener los elementos geométricos } \\
\text { deseados argumentando su razón de ser. }\end{array}$ \\
& $\begin{array}{l}\text { - Identifica ejes de simetría mediante el doblado del } \\
\text { papel. }\end{array}$ \\
$\begin{array}{l}\text { UM3: Describe distintas posiciones de } \\
\text { elementos en el plano y en el espacio }\end{array}$ & $\begin{array}{l}\text {-Describe posiciones en el plano (vértices, puntos, } \\
\text { justificando su movimiento. }\end{array}$ \\
& $\begin{array}{l}\text {-Describe posiciones con respecto a } \\
\text { Elementos (esquinas, interior, exterior, arriba, mitad, } \\
\text { abajo, en el medio...). }\end{array}$ \\
\hline
\end{tabular}

Tabla 5. Listado de categorías de las manifestaciones del componente de habilidades de visualización

\begin{tabular}{|c|c|c|}
\hline Habilidad & Categoría & Conductas \\
\hline $\begin{array}{l}\text { Coordinación ojo } \\
\text { motor }(\mathrm{COM})\end{array}$ & $\begin{array}{l}\text { COM1: Realiza dobleces para } \\
\text { obtener el cuadrado o sus distintos } \\
\text { elementos. }\end{array}$ & $\begin{array}{l}\text { - Realiza dobleces para obtener los } \\
\text { distintos elementos geométricos de } \\
\text { forma correcta. } \\
\text {-Logra generar un doblez por un punto, } \\
\text { línea o sector deseado. }\end{array}$ \\
\hline \multirow{2}{*}{$\begin{array}{l}\text { Percepción } \\
\text { figura-contexto } \\
\text { (FC) }\end{array}$} & $\begin{array}{l}\text { FC1: Forma una estructura a partir } \\
\text { de una menor. }\end{array}$ & $\begin{array}{l}\text { - Construye la figura completa } \\
\text { apoyándose de los dobleces realizados. } \\
\text { - Construye elementos geométricos } \\
\text { mediante el doblado de papel. }\end{array}$ \\
\hline & $\begin{array}{l}\text { FC2: Identifica elementos dentro de } \\
\text { una estructura mayor. }\end{array}$ & $\begin{array}{l}\text {-Identifica segmentos, rectas, ángulos, } \\
\text { triángulos o vértices de las figuras. }\end{array}$ \\
\hline \multirow{2}{*}{$\begin{array}{l}\text { Conservación de } \\
\text { la percepción } \\
\text { (CP) }\end{array}$} & $\begin{array}{l}\text { CP1: Utiliza criterios de igualdad o } \\
\text { congruencia haciendo referencia a } \\
\text { forma o tamaño, a movimientos } \\
\text { (rotaciones o volteos), perspectivas, } \\
\text { segmentos o ángulos. }\end{array}$ & $\begin{array}{l}\text { - Utilizar criterios de igualdad al } \\
\text { realizar los distintos movimientos o } \\
\text { dobleces sobre el papel. } \\
\text { - Comenta que al girar o voltear, } \\
\text { coincide la misma forma o la } \\
\text { construcción o los puntos y segmentos. }\end{array}$ \\
\hline & CP2: Identifica elementos ocultos. & $\begin{array}{l}\text {-Menciona elementos geométricos que } \\
\text { no están visibles a la vista por el } \\
\text { solapamiento del papel. }\end{array}$ \\
\hline $\begin{array}{l}\text { Percepción de la } \\
\text { posición en el } \\
\text { espacio (PE) }\end{array}$ & $\begin{array}{l}\text { PE1: Utiliza elementos de posición } \\
\text { respecto al objeto o a uno mismo } \\
\text { (sistema de referencia, } \\
\text { coordenadas, atrás, adelante, arriba, } \\
\text { cerca...). }\end{array}$ & $\begin{array}{l}\text { - Orienta de manera adecuada los } \\
\text { dobleces para obtener el elemento } \\
\text { geométrico deseado con respecto a } \\
\text { otros elementos } \\
\text { - Reconoce referencias (atrás, adelante, } \\
\text { izquierda....). }\end{array}$ \\
\hline
\end{tabular}


PE2: Identifica movimientos (rotaciones o simetrías) para obtener los elementos geométricos mediante el plegado del papel.

RE: Utiliza elementos de posición relativa entre dos objetos.

Percepción de las relaciones espaciales (RE)

Discriminación visual (DV)

Memoria visual (MV)
DV: Identificación de semejanzas o diferencias entre figuras

MV: Recordar elementos visuales en el proceso de razonamiento
- Utiliza rotaciones en el espacio para obtener los elementos geométricos que se desean construir o para justificar las construcciones realizadas.

- Utiliza simetrías adecuadas para para justificar las construcciones realizadas.

- Distingue simetrías entre elementos geométricos del papel.

- Identifica relaciones de paralelismo de los diversos dobleces que realiza y elementos geométricos obtenidos.

- Identifica relaciones de perpendicularidad de los diversos dobleces que realiza y elementos geométricos obtenidos.

- Identifica semejanzas y diferencias entre la figura a obtener y la construida. - Identifica semejanzas o diferencias entre los distintos elementos geométricos.

- Forma algún elemento geométrico apoyándose de una construcción anterior que requiere recordar los dobleces realizados.

Para medir la variable de éxito en la actividad, se utilizan las categorías presentes en la tabla 6, para cada una de las tareas geométricas propuestas en la guía de la entrevista.

Tabla 6. Listado de categorías para la variable de éxito en la actividad

\begin{tabular}{ll}
\hline \multicolumn{1}{c}{ Categoría } & \multicolumn{1}{c}{ Descripción } \\
\hline Éxito total & $\begin{array}{l}\text { El participante logra obtener la construcción solicitada } \\
\text { mediante el doblado de papel y además argumenta de } \\
\text { manera coherente los pasos realizados utilizando conceptos, } \\
\text { elementos, relaciones y movimientos geométricos } \\
\text { fundamentados. }\end{array}$ \\
& $\begin{array}{l}\text { Logra obtener la construcción solicitada mediante el } \\
\text { doblado de papel, sin embargo, sus justificaciones de } \\
\text { construcción son inexactas, insuficientes o incompletas. } \\
\text { Eenota ausencia en el manejo de argumentaciones basadas } \\
\text { en elementos, relaciones o movimientos geométricos. }\end{array}$ \\
& El participante intenta realizar la construcción, pero no \\
logra obtener de forma correcta lo solicitado o se da por \\
rendido.
\end{tabular}




\section{CAPÍTULO 4. ANÁLISIS Y RESULTADOS}

En este capítulo analizaremos los datos como resultado de las tres tareas de doblado de papel aplicadas en las entrevistas a los seis futuros profesores, caracterizando cada una de las componentes del sentido espacial manifestadas en sus respuestas y comentarios.

\subsection{Análisis del componente de manejo de conceptos geométricos}

\subsubsection{Conceptos y elementos geométricos}

Para esta variable únicamente se estableció una categoría, CE1: Identifica a través del nombre elementos geométricos dentro de una estructura mayor, considerada en las tres tareas de la guía de actividades. Con ella se pretende obtener los elementos y conceptos geométricos que el estudiante evoca al resolver la tarea. Un ejemplo en donde un participante pone en juego diversos elementos geométricos es: C_YK_2: “... más bien me salió la mediatriz del segmento, o sea M. Sobre el punto M puede pasar una perpendicular que no necesariamente es la mediatriz, ehh sí... que no necesariamente es." De donde podemos destacar los conceptos de mediatriz, punto, segmento y recta perpendicular.

En la tabla 7 se recogen todos los conceptos y elementos geométricos que evidenciaron los participantes para esta primera variable en las tres tareas realizadas (en las tablas 1, 2 y 3 del anexo C se presentan los conceptos y elementos geométricos manifestados por cada estudiante y su frecuencia relativa).

Tabla 7. Número de participantes que muestran la categoría de la variable elementos y conceptos geométricos para cada una de las tres tareas

\begin{tabular}{|c|c|c|c|c|}
\hline \multirow{2}{*}{$\begin{array}{l}\text { Categoría de la variable } \\
\text { conceptos y elementos } \\
\text { geométricos }\end{array}$} & \multirow{2}{*}{$\begin{array}{l}\text { Elemento o } \\
\text { concepto que } \\
\text { identifica }\end{array}$} & \multicolumn{3}{|c|}{$\begin{array}{c}\text { Número de participantes que lo } \\
\text { identifican }\end{array}$} \\
\hline & & Tarea 1 & Tarea 2 & Tarea 3 \\
\hline \multirow{9}{*}{$\begin{array}{l}\text { CE1: Identifica a través del } \\
\text { nombre elementos geométricos } \\
\text { dentro de una estructura mayor }\end{array}$} & Altura & & 1 & \\
\hline & Ángulo llano & & 2 & \\
\hline & Ángulo recto & 3 & 5 & \\
\hline & Bisectriz & 1 & & \\
\hline & Congruencia & 4 & 2 & 1 \\
\hline & Cuadrado & & 1 & \\
\hline & Lado & 1 & 1 & \\
\hline & Mediatriz & 5 & 1 & 1 \\
\hline & Punto & 6 & 6 & 6 \\
\hline
\end{tabular}




$\begin{array}{llll}\text { Punto equidistante } & 1 & 2 & \\ \begin{array}{l}\text { Punto homólogo } \\ \text { Punto medio }\end{array} & 5 & 1 & 1 \\ \text { Recta } & & 6 & 6 \\ \text { Recta paralela } & & & 6 \\ \text { Recta perpendicular } & 5 & 6 & 6 \\ \text { Recta oblicua } & 1 & & 2 \\ \text { Segmento } & 6 & 4 & 1 \\ \text { Triángulo } & & 1 & \\ \text { Triángulo equilátero } & 1 & & \\ \text { Vértice } & 2 & & \end{array}$

Hemos notado que los conceptos más utilizados por los futuros profesores para la primera tarea son: punto, punto medio, recta perpendicular, mediatriz y congruencia, esto porque son elementos geométricos base dentro de la construcción que debían realizar. Además, hemos detectado que la futura profesora DA, define de manera incompleta mediatriz, aunque logró construir el objeto geométrico de la tarea 1, indica que la mediatriz es un segmento que pasa por el punto medio, omitiendo la perpendicularidad. Otros conceptos menos mencionados, como el de triángulo equilátero, bisectriz o punto equidistante surgen solamente en el participante $\mathrm{CH}$, quién logró desarrollar más ideas en la parte b) de esta tarea.

Para la segunda tarea evidenciamos que los elementos geométricos más utilizados por los futuros profesores son los de punto, ángulo recto, recta y recta perpendicular, que, al igual que en la tarea anterior, son la base de la construcción que realizan.

En la tarea 3, los conceptos más utilizados son los de punto, recta, recta perpendicular y recta paralela, siendo manifestados por todos los futuros profesores. Los participantes AD y YK, utilizan la simetría para justificar su construcción, para lo que manifiestan utilizar conceptos como segmento, mediatriz o punto medio. Otros futuros profesores como JP y DA, hacen una exploración inicial de rectas en relación con el punto y la recta dibujada inicialmente, identificando que la recta es oblicua, aunque no utilizan ese nombre, sino que evocan este concepto. Por ejemplo, la estudiante DA indica, C_DA_3: “Me puede quedar no paralela, depende de cómo lo ponga.".

Analizamos los conceptos geométricos que se habían establecido en el análisis previo de las tres tareas (ver tablas 1, 2 y 3 del capítulo 3). Un $87.5 \%, 75 \%$ y $80 \%$ para las tres tareas respectivamente, de los conceptos previstos fueron utilizados al menos una vez por 
los futuros profesores, con excepción del concepto de eje de simetría que no fue mencionado por ningún participante.

\subsubsection{Relaciones geométricas}

En esta variable establecimos dos categorías. RG1: Identifica relaciones entre diversos elementos geométricos de las figuras, en donde queríamos destacar relaciones que se establecieran sin intervención de la acción de doblar el papel. Lo vemos, por ejemplo, en el comentario del participante $\mathrm{C}_{-} \mathrm{CH}_{-} 1 \mathrm{~b}$ : “Es que, si yo sé que esta es la mediatriz, un punto cualquiera sobre este doblez (señalando la recta que es mediatriz) tiene que equidistar del punto A y del punto B del segmento. "

Para la segunda categoría RG2: Identifica relaciones de medida al doblar el papel, queremos evidenciar todas aquellas relaciones que se produzcan gracias al proceso de doblado de papel y que pueden estar asociadas a medidas. Lo apreciamos, por ejemplo, el comentario del participante PE: C_PE_2: “Entonces ahí si divido, bueno cuando hago el doblez, como son rectos, el ángulo de 180 va a quedar dividido a la mitad y me quedaría de 90 y ahi ya sería perpendicular.".

En la tabla 8 presentamos los porcentajes de estudiantes que presentan al menos una respuesta que alude a las categorías establecidas para la variable de relaciones geométricas en las tres actividades. (En las tablas 4, 5 y 6 del anexo $\mathrm{C}$ se recogen los conceptos y elementos geométricos manifestados por cada estudiante y su frecuencia relativa).

Tabla 8. Porcentaje de participantes que expresan relaciones geométricas

\begin{tabular}{lccc}
\hline \multicolumn{1}{c}{ Categorías de la variable relaciones } & \multicolumn{3}{c}{ Porcentaje de participantes que siguen la categoría } \\
\cline { 2 - 4 } geométricas & Tarea 1 & Tarea 2 & Tarea 3 \\
\hline $\begin{array}{l}\text { RG1: Identifica relaciones entre } \\
\text { diversos elementos geométricos de las } \\
\text { figuras }\end{array}$ & $100 \%$ & $100 \%$ & $100 \%$ \\
$\begin{array}{l}\text { RG2: Identifica relaciones de medida al } \\
\text { doblar el papel }\end{array}$ & $66.67 \%$ & $83.33 \%$ & $50 \%$ \\
\hline
\end{tabular}

En la tarea 1 se presenta una mayor variedad de relaciones establecidas para la categoría RG1, en la que todos los participantes establecieron relaciones entre puntos o segmentos de recta. Otra relación bastante evidenciada ( 5 de los 6 participantes la manifestaron) fue la de relacionar el doblez generado y la perpendicularidad con el segmento dado. Sin embargo, apreciamos un escaso manejo de relaciones geométricas con respecto al 
concepto de mediatriz, que generaron impedimento de todos los participantes en la resolución de la parte b) de esta primera tarea. Solamente el futuro profesor $\mathrm{CH}$, manifestó, dentro de la categoría RG1, que, si un punto pertenece a la mediatriz de un segmento, equidista de sus extremos, siendo esta relación de importancia para seguir explorando otros elementos y habilidades de visualización por medio del papel y resolver con éxito la tarea. Para la categoría RG2 se aprecia una única relación geométrica establecida por participantes del estudio (4 de los 6 futuros profesores), y es aquella que permite relacionar los dos segmentos que bisecan la mediatriz mediante el doblado realizado.

Para la segunda actividad, todos los participantes logran establecer la relación de perpendicularidad entre las dos rectas. Algunos futuros profesores manifiestan el dominio de otras relaciones que pueden asociarse con la simetría con respecto a una recta y los puntos simétricos que se generan, otros destacan la unicidad de la recta perpendicular a otra que pasa por un punto, lo que corresponden a relaciones dentro de la categoría RG1. En menor medida son manifestadas las relaciones dentro de RG2. Dos participantes relacionan la medida de los ángulos al doblar el papel y cuatro futuros profesores manifiestan la congruencia de segmentos debido al doblado de papel generado por la simetría con respecto a una recta. Se presenta el caso del participante JP que realiza la tarea de forma parcial, debido a que establece muy pocas relaciones de la categoría RG1 y ninguna para la categoría de RG2, y no consigue integrar estas relaciones con habilidades de visualización, y por lo tanto no logra justificar su construcción. En el caso del futuro profesor $\mathrm{YK}$, establece muchas relaciones de medida, algunas de ellas incorrectas, y aunque completa la actividad, no evidencia que las relaciones geométricas puestas de manifiesto justifiquen de forma acertada su construcción, se basa simplemente en puras intuiciones.

Para la tarea 3, observamos que todos los estudiantes logran identificar relaciones dentro de la categoría R1. Específicamente cuatro de los profesores utilizan la relación "Siendo $a, b$ y $c$ rectas. Si $a \perp b$ y $b \perp c$ entonces $a \| b$, siempre que $a, b$ y $c$ sean rectas coplanares", que es indispensable para la realización exitosa de la tarea. La participante DA no evidencia esta relación y concluye de manera parcial la tarea, construyendo la recta paralela, pero sin poder justificar su construcción. En el caso del futuro profesor $\mathrm{AD}$, tampoco manifiesta la relación y, aunque construye una recta paralela, no cumple 
con las condiciones establecidas y obtiene un nivel nulo de ejecución de la actividad. Todos los participantes logran establecer relaciones de paralelismo y perpendicularidad. En la categoría RG2 solamente los futuros profesores AD, DA y YK llegan a manifestar relaciones relacionadas con el doblado de papel y son aquellos que utilizaron simetría como fundamento para sus construcciones.

En cuanto a las relaciones establecidas por medio de conductas y que se consideraron a priori en la resolución de la tarea (ver tablas 1, 2 y 3 del capítulo 3), para la tarea 1 en la categoría RG1, un $80 \%$ de ellas fueron utilizadas por al menos un futuro profesor, omitiéndose dos de ellas: "Si un punto equidista de los extremos del segmento, entonces pertenece a la mediatriz", y "Relaciones sobre triángulos que son congruentes". Sin embargo, el 50\% de las conductas para las relaciones RG2 son utilizadas por al menos un futuro profesor. Para la tarea 2 y 3, el 100\% de las relaciones geométricas establecidas a priori son utilizadas por al menos un profesor dentro de las categorías RG1 y RG2.

\subsubsection{Ubicación y movimientos}

El doblez sobre una recta puede interpretarse como una rotación en el espacio empleando esta recta como eje, o como una simetría axial en el plano, considerando la recta como eje. Los participantes que expresen el primer movimiento están aludiendo a la rotación que se realiza sobre el papel, mientras que los que señalan el segundo están pensando en el resultado sobre el mismo plano como una simetría.

Por lo anterior, hemos considerado la manifestación de rotación y simetría, únicamente en aquellas ocasiones que los futuros profesores hacen alguna alusión verbal a ese movimiento dentro de la argumentación de su construcción y que, de este modo, nos permita evidenciar que maneja este movimiento dándole carácter geométrico. Únicamente la futura profesora DA en la tarea 2 hace referencia a una rotación cuando indica C_DA_2: “...si le doy vuelta y giro por el mismo doblez, pero es lo mismo.” E1 resto de participantes únicamente realizan el movimiento, pero no explicitan su nombre ni lo asocian con relaciones geométricas, solamente le dan un manejo meramente intuitivo.

Con respecto a la simetría, este movimiento fue el que se manifestó con mayor frecuencia y destacamos que los futuros profesores identifican la simetría, pero ninguno hace referencia a la rotación con la que puede estar asociada. Por ejemplo, el comentario 
C_AD_2: “... podría aplicar simetría axial, más bien hacer una reflexión del punto $P$ al... (se detiene a pensar). Tendría el punto P reflejado al otro lado y eso me aseguraría que la recta que pasa por esos dos puntos es perpendicular a la recta." Solamente el futuro profesor PE manifiesta este movimiento en la tarea 1, cuatro participantes lo hacen en la tarea 2 y dos profesores en la tarea 3. El participante JP es el único que no evidencia de forma verbal ningún movimiento dotándolo de características geométricas para las tres tareas. (En las tablas 7, 8 y 9 del anexo $\mathrm{C}$ se encuentran los movimientos realizados por participante y por tarea).

Para la variable de ubicación y movimientos se establecen tres categorías. La primera de ellas es la UM1: Identifica elementos invariantes o variantes al doblar, en la que se pretende identificar a los participantes que, cuando realizan un movimiento de doblado del papel, detectan elementos geométricos que varían o se mantienen constantes. Por ejemplo, el comentario del participante C_PE_2: “Entonces ahí si divido, bueno cuando hago el doblez, como son rectos, el ángulo de 180 va a quedar dividido a la mitad y me quedaría de 90 y ahí ya sería perpendicular.", manifiesta que el futuro profesor sabe que con un movimiento de papel (rotación en el espacio) logra bisecar un ángulo, es decir, la magnitud de este varía.

La segunda, UM2: Sitúa los distintos dobleces para obtener los elementos geométricos deseados, trata de identificar si los futuros profesores detectan la relevancia que tienen los movimientos de rotación y simetría dentro de argumentación geométrica de su construcción. Por ejemplo, el comentario C_PE_2: “Bueno, si aplico simetría del punto $\underline{A \text { con este punto (señala con el dedo el punto medio) me tendría que dar el punto B }}$ porque intenté que coincidieran con la misma distancia".

La intención de la categoría UM3: Identifica distintas posiciones de elementos en el plano y en el espacio, es la de detectar cómo los participantes describen distintas posiciones en el espacio y en el plano. Por ejemplo, esta última categoría se presenta en el comentario de C_CH_1a: "Porque al hacer yo un doblez y poner un punto encima del otro punto del segmento, aseguro que las dos mitades sean iguales y solo se van a doblar en el punto medio.", en donde el futuro profesor logra describir la ubicación que está presente entre elementos geométricos al realizar un movimiento. 
En la tabla 9 presentamos el porcentaje de estudiantes que manifestaron al menos una conducta dentro de las categorías para la variable de ubicación y movimientos en las tres tareas (en las tablas 10, 11 y 12 del anexo C se recogen las conductas de ubicación y movimientos manifestados por cada estudiante y su frecuencia relativa).

Tarea 9. Porcentaje de futuros profesores que expresan la variable de ubicación y movimiento en para cada una de las tres tareas

\begin{tabular}{|c|c|c|c|}
\hline \multirow{2}{*}{$\begin{array}{c}\text { Categorías de la variable ubicación y } \\
\text { movimiento }\end{array}$} & \multicolumn{3}{|c|}{$\begin{array}{c}\text { Porcentaje de participantes que siguen la } \\
\text { categoría }\end{array}$} \\
\hline & Tarea 1 & Tarea 2 & Tarea 3 \\
\hline $\begin{array}{l}\text { UM1: Identifica elementos invariantes o } \\
\text { variantes al doblar. }\end{array}$ & $100 \%$ & $66.67 \%$ & $66,67 \%$ \\
\hline $\begin{array}{l}\text { UM2: Sitúa los distintos dobleces para } \\
\text { obtener los elementos geométricos deseados } \\
\text { justificando geométricamente su movimiento. }\end{array}$ & $16,67 \%$ & $83.33 \%$ & $33.33 \%$ \\
\hline $\begin{array}{l}\text { UM3: Identifica distintas posiciones de } \\
\text { elementos en el plano y en el espacio. }\end{array}$ & $100 \%$ & $100 \%$ & $100 \%$ \\
\hline
\end{tabular}

El $100 \%$ de los futuros profesores manifiestan conductas clasificables dentro de la categoría UM1 para la primera tarea, pues todos logran evidenciar que, con un movimiento del papel, el segmento inicialmente dibujado se divide a la mitad. La categoría UM2 es la que porcentajes de ocurrencia más bajos apreciamos para las tareas 1 y 3 , por la relación tan directa que tienen sus conductas con el movimiento de rotación y simetría, y como se indicó previamente, pocos futuros profesores hacen alusión verbalexplícita y dotan de carácter geométrico a estos movimientos. Para la categoría UM3 las conductas manifestadas por todos los participantes fueron las de "describir posiciones en el plano" y "describir posiciones con respecto a otros elementos".

De las conductas establecidas a priori (ver tabla 4 del capítulo 3), para UM2 de la primera y tercera tarea, son utilizadas $66.67 \%$ de ellas por al menos un futuro profesor. Las conductas de UM2 para la tercera tarea son evidenciadas en un 100\%. Además, para UM1 y UM3, en las tres tareas, sus conductas son manifestadas al $100 \%$ por al menos uno de los futuros profesores.

\subsection{Análisis del componente de habilidades de visualización}

En esta sección analizaremos las habilidades de visualización manifestadas en la resolución de las tres tareas. Hemos considerado las conductas más comunes que se han 
evidenciado en cada una de las tareas y llevamos un registro de cuántas veces se manifestó esa conducta dentro de la categoría.

En la tabla 10 exponemos el porcentaje de estudiantes por conducta manifestada dentro de cada una de las categorías de las habilidades espaciales (en las tablas 13, 14 y 15 del anexo $\mathrm{C}$ puede observarse cuáles estudiantes manifestaron esas conductas), hemos anotado aquellas que han sido manifestadas por al menos un estudiante para cada una de las categorías.

Tabla 10. Conductas dentro de las categorías de las habilidades de visualización manifestadas en las tres tareas geométricas

\begin{tabular}{|c|c|c|c|c|c|}
\hline \multirow[t]{2}{*}{ Habilidad } & \multirow[t]{2}{*}{ Categoría } & \multirow[t]{2}{*}{ Conductas } & \multicolumn{3}{|c|}{$\begin{array}{l}\text { Porcentaje de participantes que } \\
\text { manifiestan la conducta por } \\
\text { tarea }\end{array}$} \\
\hline & & & $\mathrm{T} 1$ & $\mathrm{~T} 2$ & T3 \\
\hline $\begin{array}{l}\text { Coordinaci } \\
\text { ón ojo } \\
\text { motor } \\
(\mathrm{COM})\end{array}$ & $\begin{array}{l}\text { COM1: Realiza } \\
\text { dobleces para } \\
\text { obtener los } \\
\text { distintos } \\
\text { elementos } \\
\text { geométricos. }\end{array}$ & $\begin{array}{l}\text { Realiza dobleces para } \\
\text { obtener los distintos } \\
\text { elementos geométricos } \\
\text { de forma correcta. } \\
\text { Logra generar un doblez } \\
\text { por un punto, línea o } \\
\text { sector deseado. }\end{array}$ & $16.67 \%$ & $33.33 \%$ & $16.67 \%$ \\
\hline $\begin{array}{l}\text { Percepción } \\
\text { figura- }\end{array}$ & $\begin{array}{l}\text { FC1: Forma una } \\
\text { estructura a partir } \\
\text { de una menor. }\end{array}$ & $\begin{array}{l}\text { Construye la figura } \\
\text { completa apoyándose de } \\
\text { los dobleces realizados. } \\
\text { Construye elementos } \\
\text { geométricos mediante el } \\
\text { doblado de papel. }\end{array}$ & $16.67 \%$ & $33.33 \%$ & $16.67 \%$ \\
\hline (FC) & $\begin{array}{l}\text { FC2: Identifica } \\
\text { elementos dentro } \\
\text { de una estructura } \\
\text { mayor. }\end{array}$ & $\begin{array}{l}\text { Identifica segmentos, } \\
\text { rectas, ángulos, } \\
\text { triángulos o vértices de } \\
\text { las figuras. }\end{array}$ & $83.33 \%$ & $100 \%$ & $100 \%$ \\
\hline & $\begin{array}{l}\text { CP1: Utiliza } \\
\text { criterios de } \\
\text { igualdad o } \\
\text { congruencia }\end{array}$ & $\begin{array}{l}\text { Utilizar criterios de } \\
\text { igualdad al realizar los } \\
\text { distintos movimientos o } \\
\text { dobleces sobre el papel. }\end{array}$ & $33.33 \%$ & $16.67 \%$ & $33.33 \%$ \\
\hline $\begin{array}{l}\text { Conservaci } \\
\text { ón de la } \\
\text { percepción } \\
\text { (CP) }\end{array}$ & $\begin{array}{l}\text { haciendo } \\
\text { referencia a forma } \\
\text { o tamaño, a } \\
\text { movimientos } \\
\text { (giros o volteos), } \\
\text { perspectivas, } \\
\text { segmentos o } \\
\text { ángulos. }\end{array}$ & $\begin{array}{l}\text { Comenta que al girar o } \\
\text { voltear, coincide la } \\
\text { misma forma o la } \\
\text { construcción o los } \\
\text { puntos y segmentos. }\end{array}$ & $100 \%$ & $100 \%$ & $100 \%$ \\
\hline
\end{tabular}


CP2: Identifica elementos ocultos.

PE1: Utiliza

elementos de posición respecto al objeto o a uno mismo (sistema de referencia, coordenadas, atrás, adelante, arriba, cerca...).

Percepción de la posición en el espacio (PE)

Percepción de las relaciones espaciales (RE)

Discrimina ción visual (DV)

\section{PE2: Identifica} movimientos (reflexiones, giros o volteos) en la realización de los dobleces.

\section{RE: Utiliza}

elementos de posición relativa entre dos objetos (dirección, orientación, paralelismo, coincidentes, perpendiculares, simétricos)
DV:

Identificación de semejanzas o diferencias entre figuras o sus elementos.

Menciona elementos geométricos que no están visibles a la vista por el solapamiento del $66.67 \% \quad 33.33 \% \quad 50 \%$ papel.

Orienta de manera adecuada los dobleces para obtener el elemento geométrico deseado con $100 \% \quad 100 \% \quad 100 \%$ respecto a otros elementos

- Reconoce referencias (atrás, adelante,

izquierda, arriba, abajo).

Utiliza rotaciones en el espacio para obtener los elementos geométricos que se desean construir o para justificar las construcciones realizadas.

Utiliza simetrías adecuadas para obtener los elementos geométricos que se desean construir o para justificar las construcciones realizadas.

Distingue simetrías entre los elementos geométricos del papel.

Identifica relaciones de paralelismo de los diversos dobleces que realiza y elementos geométricos obtenidos.

Identifica relaciones de perpendicularidad de los diversos dobleces que realiza y elementos geométricos obtenidos.

Identifica semejanzas y diferencias entre la figura o elementos geométrico a obtener y la figura o elemento geométrico construido. $83.33 \% \quad 100 \% \quad 100 \%$

$16.67 \% \quad 66.67 \% \quad 0 \%$

$0 \% \quad 0 \% \quad 100 \%$

$16.67 \% \quad 33.33 \% \quad 66.67 \%$

$0 \% \quad 33.33 \% \quad 0 \%$ 


\begin{tabular}{|c|c|c|c|c|c|}
\hline & & $\begin{array}{l}\text { Identifica semejanzas o } \\
\text { diferencias entre los } \\
\text { distintos elementos } \\
\text { geométricos. }\end{array}$ & & & \\
\hline $\begin{array}{l}\text { Memoria } \\
\text { visual } \\
\text { (MV) }\end{array}$ & $\begin{array}{l}\text { MV: Recordar } \\
\text { elementos } \\
\text { visuales en el } \\
\text { proceso de } \\
\text { razonamiento. }\end{array}$ & $\begin{array}{l}\text { Forma algún elemento } \\
\text { geométrico apoyándose } \\
\text { de una construcción } \\
\text { anterior que requiere } \\
\text { recordar los dobleces } \\
\text { realizados o elementos } \\
\text { geométricos que se } \\
\text { encuentran ocultos. }\end{array}$ & $0 \%$ & $100 \%$ & $100 \%$ \\
\hline
\end{tabular}

Para clasificar los distintos comentarios y respuestas de los futuros profesores al resolver las tareas, hemos realizado un detallado análisis de las entrevistas considerando las unidades de análisis tal y como lo establece el análisis de contenido. Por ejemplo, el estudiante YK realiza el siguiente comentario: C_YK_2: "La recta perpendicular a $P Q$ que pase por $M$, vamos a ver. Voy a poner el punto $Q$ sobre el M." Generando la respuesta que se muestra en la figura 2.

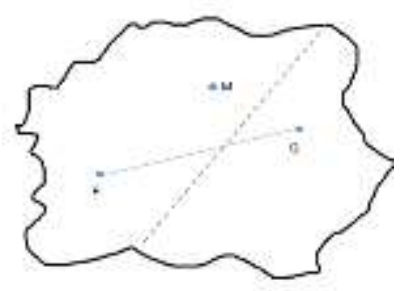

Figura 2. Respuesta del participante R_YK_2

Lo anterior permite evidenciar que el estudiante ubica un punto Q sobre otro $\mathrm{M}$ de forma correcta, lo que le permite obtener el doblez que desea, con lo que consideramos que tiene una adecuada "Coordinación ojo motor (COM)", logrando generar un doblez por un punto, línea o sector deseado.

$\mathrm{El}$ estudiante $\mathrm{CH}$ realiza el siguiente comentario: $\mathrm{C} \_\mathrm{CH}$ _3: "Bueno, convenientemente, aquí está mi punto, no se aprecia, pero ahí está mi punto y aquí va mi recta", que consideramos una conducta que se enmarca dentro de la categoría de "CP2: Identifica elementos ocultos" dentro de la habilidad de "Conservación de la percepción (CP)". Otro ejemplo se manifiesta en el comentario, C_JP_3: “...ahora que tengo la recta doblada la paso encima del punto. El problema es que la recta paralela no me va quedar encima del punto, como es lo que queremos entonces estoy pensando en otras formas de hacerlo...", 
en la que se evidencia la categoría DV1: "Identificación de semejanzas o diferencias entre figuras o sus elementos", dentro de la habilidad de "Discriminación visual (DV)" puesto que logra identificar que la recta construida con el doblado del papel, tiene diferencias con respecto a la recta que desea generar. El comentario del futuro profesor, C_CH_2: “...podría doblar el papel de forma que pase por ese punto y el punto que se ha reflejado.", alude a una manifestación de la habilidad de "Percepción de la Posición en el espacio (PE)" pues establece relaciones de objetos en el espacio.

En las tablas 11, 12 y 13 resumimos los resultados de las manifestaciones de las habilidades de visualización según las categorías y el porcentaje de participantes que han evidenciado al menos categoría para cada una de las tareas (en las tablas 16, 17 y 18 del anexo $\mathrm{C}$ se recogen las manifestaciones de las categorías por participantes del estudio).

Tarea 11. Manifestaciones de los futuros profesores que siguen las categorías de la variable de habilidades de visualización en para la tarea 1

\begin{tabular}{llccc}
\hline Habilidad & Categoría & $\begin{array}{c}\text { Número de veces } \\
\text { que se manifiesta }\end{array}$ & $\begin{array}{c}\text { Número de } \\
\text { participantes que } \\
\text { manifiestan la } \\
\text { categoría }\end{array}$ & $\begin{array}{c}\text { Porcentaje de } \\
\text { estudiantes que } \\
\text { manifiestan la } \\
\text { habilidad }\end{array}$ \\
\hline COM & COM1 & 11 & 6 & $100 \%$ \\
FC & FC1 & 7 & 6 & $100 \%$ \\
& FC2 & 9 & 5 & \\
& Total & 16 & 6 & $100 \%$ \\
CP & CP1 & 13 & 4 & $100 \%$ \\
& CP2 & 4 & 6 & $100 \%$ \\
PE & Total & 17 & 1 & $16.67 \%$ \\
& PE1 & 16 & 6 & \\
RE & PE2 & 1 & 6 & \\
DV & Total & 17 & 1 & \\
\hline
\end{tabular}

Tarea 12. Manifestaciones de los futuros profesores que siguen las categorías de la variable de habilidades de visualización en para la tarea 2

\begin{tabular}{llccc}
\hline Habilidad & Categoría & $\begin{array}{c}\text { Número de veces } \\
\text { que se manifiesta }\end{array}$ & $\begin{array}{c}\text { Número de } \\
\text { participantes que } \\
\text { manifiestan la } \\
\text { categoría }\end{array}$ & $\begin{array}{c}\text { Porcentaje de } \\
\text { estudiantes que } \\
\text { manifiestan la } \\
\text { habilidad }\end{array}$ \\
\hline COM & COM1 & 22 & 6 & $100 \%$ \\
FC & FC1 & 12 & 6 & $100 \%$ \\
& FC2 & 23 & 6 & \\
CP & Total & 35 & 6 & $100 \%$ \\
& CP1 & 13 & 2 &
\end{tabular}




\begin{tabular}{llccc} 
PE & PE1 & 21 & 6 & $100 \%$ \\
& PE2 & 5 & 5 & \\
& Total & 26 & & $100 \%$ \\
RE & RE1 & 10 & 6 & $66.67 \%$ \\
DV & DV1 & 5 & 4 & $100 \%$ \\
MV & MV1 & 6 & 6 & \\
\hline
\end{tabular}

Tarea 13. Manifestaciones de los futuros profesores que siguen las categorías de la variable de habilidades de visualización en para la tarea 3

\begin{tabular}{llccc}
\hline Habilidad & Categoría & $\begin{array}{c}\text { Número de veces } \\
\text { que se manifiesta }\end{array}$ & $\begin{array}{c}\text { Número de } \\
\text { participantes que } \\
\text { manifiestan la } \\
\text { categoría }\end{array}$ & $\begin{array}{c}\text { Porcentaje de } \\
\text { estudiantes que } \\
\text { manifiestan la } \\
\text { habilidad }\end{array}$ \\
\hline COM & COM1 & 20 & 6 & $100 \%$ \\
FC & FC1 & 15 & 6 & $100 \%$ \\
& FC2 & 13 & 6 & \\
CP & Total & 28 & & $100 \%$ \\
& CP1 & 14 & 6 & \\
& CP2 & 3 & 3 & $100 \%$ \\
PE & Total & 17 & 6 & $100 \%$ \\
& PE1 & 23 & 2 & $66.67 \%$ \\
RE & PE2 & 2 & & $100 \%$ \\
DV & Total & 25 & 6 & \\
MV & RE1 & 16 & 4 & \\
\hline
\end{tabular}

Las habilidades que mayoritariamente utilizan los participantes en la resolución de las tareas son las de "Percepción de la Posición en el Espacio (PE)" posiblemente porque el utilizar elementos de posición e identificar movimientos, son acciones de gran importancia en las tareas que evocan plegado de papel. También la "Percepción figura contexto (FC)" es utilizada en gran medida, probablemente porque el estar realizando dobleces de forma constante, los futuros profesores deben identificar elementos geométricos diferenciando los elementos principales y los accesorios. Por ejemplo, en la respuesta del participante $\mathrm{CH}$, que se presenta en la figura 3, después de doblar para construir un triángulo debe ubicar la figura aislándola del fondo o demás dobleces.

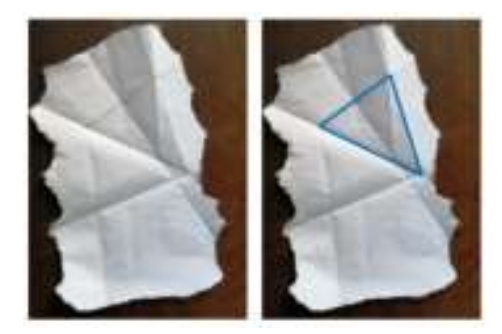

Figura 3. Respuesta del participante R_CH_1b 
Otra de las habilidades que destaca como una de las más manifestadas en las dos últimas tareas es la de "Coordinación ojo motor (COM)". Es evidente que debe existir una adecuada coordinación de la mano y la visión al momento de doblar el papel por el sitio que se desea. La "Conservación de la percepción (CP)" también tiende a destacarse como una de las habilidades más utilizadas (pero no con una frecuencia tan alta en comparación a COM, PE y FC, en las dos últimas tareas) posiblemente porque, por la temática de las actividades, es necesario reconocer las propiedades que mantiene un elemento geométrico cuando cambia de posición al doblar el papel, además de la continua coincidencia de puntos y segmentos al plegar.

En menor medida fueron desarrolladas la "Percepción de las Relaciones Espaciales (RE)" para las tareas 1 y 2, lo que podría deberse al tipo de actividad propuesta. Sin embargo, aumenta su frecuencia para la tarea 3 , donde utilizar elementos de posición relativa entre dos objetos, es fundamental para obtener la recta paralela solicitada. Lo apreciamos en el comentario del futuro profesor C_YK_3: "Y como esta es la mediatriz, es perpendicular a la recta $P P^{\prime}$ y $P P^{\prime}$ es perpendicular a $A B$ entonces esta recta que pasa por $P$, que sería la mediatriz tiene que ser paralela a $A B$.", se explicitan las relaciones de perpendicularidad y paralelismo entre distintas rectas.

La habilidad que menos se evidencia en las tres actividades, es la "Discriminación Visual (DV)". Para la primera tarea solo la apreciamos en un futuro profesor la puso en marcha, solo cuatro futuros profesores para la segunda y tercera actividad. Su manifestación dependía de la solución realizada por los participantes al resolver la tarea, algunos realizaban dobleces que les permitían percatarse de que obtenían elementos geométricos con diferencias a los que deseaban construir. También la "Memoria visual (MV)" es una de la que menos se destaca, posiblemente debido que es poco exigida para resolver las actividades. En la tarea 1 no hemos encontrado, ningún futuro profesor que la manifieste, y para la tarea 2 es apreciada en una única ocasión por cada uno de los profesores cuando justifican su construcción recordando los pasos realizados.

La MV aumenta la frecuencia de manifestación en la tercera tarea, posiblemente porque la mayoría de futuros profesores, debieron recordar los pasos realizados en la actividad anterior para obtener la perpendicularidad. En la observación de la entrevista del participante PE, se evidencia la aplicación de esta habilidad, O_PE_3: “El participante 
manifiesta que recuerda los pasos que realizó en la actividad anterior para construir una perpendicular y apoyar su construcción".

Podemos notar que en la tarea 1 , todos los participantes evidencian algún grado de todas las habilidades espaciales, con excepción de la DV que es manifestada solo por un $16.67 \%$ (un estudiante). En la tarea 2 todas las habilidades espaciales se evidencian en los futuros profesores con excepción, al igual que la tarea anterior, de la DV y la MV, manifestadas en un $66.67 \%$ y $83.33 \%$ respectivamente. Para la última tarea, todas las habilidades espaciales están presentes en todos los participantes, con excepción de la DV, que solo fue manifestada por un $66.67 \%$ de los futuros profesores.

Cabe destacar, que todas las conductas para las categorías de las habilidades de visualización que fueron definidas a priori, fueron manifestadas por al menos uno de los futuros profesores.

\section{3. Éxito de la actividad}

En este apartado presentamos el nivel de éxito que presentan los profesores al resolver las tres tareas de la guía de actividades. La información es recopilada en la tabla 14. (En las tablas 19, 20, 21 y 22 del anexo C se recopila el nivel de éxito por participante).

Tabla 14. Porcentaje de futuros profesores que alcanzan la categoría de la variable de éxito de la actividad visualización en las tres tareas

\begin{tabular}{lcccc}
\hline \multirow{2}{*}{ Categoría } & \multicolumn{5}{c}{ Porcentaje de participantes } \\
& Tarea 1a & Tarea 1b & Tarea 2 & Tarea 3 \\
\hline Éxito total & $0 \%$ & $0 \%$ & $50 \%$ & $16.67 \%$ \\
Éxito parcial & $100 \%$ & $16.67 \%$ & $50 \%$ & $66.67 \%$ \\
Éxito nulo & 0 & $83.33 \%$ & 0 & $16.67 \%$ \\
\hline
\end{tabular}

En la parte a) de la tarea 1 todos los futuros profesores obtienen un éxito parcial, esto es debido a que al trazar la mediatriz no lograron justificar porqué sus dobleces les permitían obtener una recta perpendicular. En la parte b) de la primera tarea cinco futuros profesores obtienen un éxito nulo, debido a que no lograron establecer mayores relaciones geométricas entre la mediatriz y segmento, solamente el participante $\mathrm{CH}$ logra evidenciar conocimiento de que si un punto pertenece a la mediatriz de un segmento este equidista de sus extremos, pero no puede justificarlo mediante el doblado de papel, por eso es clasificado dentro de "éxito parcial". 
Para la tarea 2, el éxito es parcial para los participantes JP, PE y YK esencialmente porque lograron trazar la recta perpendicular pero no llegan a darle sentido geométrico a su construcción, es decir, no saben por qué los pasos realizados les permitieron obtener la recta solicitada, echándose en falta conocimientos geométricos como relaciones y movimientos. Para la tarea 3, el único éxito total es para el participante YK. El éxito es parcial para los futuros profesores $\mathrm{CH}$, DA, JP y PE, debido a que logran obtener la recta paralela solicitada, sin embargo, no justifican de forma geométrica su construcción. En el caso de DA no logra establecer las relaciones geométricas adecuadas y en el resto de participantes no hay una argumentación geométrica relacionada con los movimientos utilizados (rotaciones o simetría). El participante AD logra obtener una recta paralela a la solicitada pero no pasa por el punto previamente dibujado, es por eso que se cataloga como éxito nulo.

Puede notarse que ninguna tarea tiene un $100 \%$ de éxito. Además, si consideramos de manera conjunta todas las tareas, el éxito parcial es lo más frecuente, puesto que los participantes realizan las construcciones, pero no logran justificarlas. Los dobleces les sugieren que han obtenido el elemento geométrico, pero para justificarlos emplean argumentos (en conceptos, relaciones y movimientos geométricos) solo basados en intuiciones, tal y como se aprecia en el comentario C_PE_1a: “Porque no sabría justificar que hice ahí un ángulo recto. Bueno es que sí parece recto, pero justificarlo como tal no sé.”. O el comentario C_JP_2: "Y luego lo parto a la mitad de modo que igual me calce y ahí están los 90 (del ángulo)”. JP establece los conceptos y relaciones geométricas adecuadas, sin embargo, no evidencia una correcta argumentación del movimiento geométrico que le permite establecer estas relaciones de bisección del ángulo (una simetría generada por el doblez realizado que evoca un giro en el espacio tomando como eje una recta). 


\section{CAPÍTULO 5. CONCLUSIONES}

En este capítulo presentamos las conclusiones de nuestro estudio, realizando una revisión de los objetivos propuestos y su cumplimiento, además de contrastar nuestros resultados con las investigaciones previas consideradas en el capítulo 2 referente al marco teórico. Finalmente externamos limitaciones, dificultades y futuras líneas de investigación.

\subsection{Conclusiones generales}

El objetivo principal de la investigación fue analizar el desarrollo del sentido espacial que tienen futuros profesores de matemáticas de Costa Rica. De este objetivo se desprendían otros específicos, que repasamos a continuación junto con su nivel de logro.

Analizar las diferentes componentes del sentido espacial que se encuentren presentes en una guía de actividades geométricas previamente seleccionadas, correspondía al primer objetivo. Para lograrlo, se eligieron actividades geométricas de doblado de papel, puesto que permiten el desarrollo del sentido espacial, en concordancia con lo comentado por Akayuure et al. (2016) y Flores et al. (2015). Posteriormente se realizó un análisis riguroso de las distintas conductas presentes en la solución de estas tareas y que están relacionadas con las componentes de los elementos o conceptos geométricos, relaciones geométricas y ubicaciones o movimientos. Estas conductas fueron sometidas, en dos etapas, a un juicio de expertos en Educación Matemática. Para las habilidades de visualización, se consideraron las categorías propuestas en el trabajo de Ramírez (2012) y algunas conductas asociadas a esas categorías se seleccionaron de trabajos previos (Ramírez, 2012; Salto, 2013).

El segundo objetivo, pretendía observar y describir las dimensiones o componentes del sentido espacial que manifiestan los futuros profesores al resolver las tareas geométricas. Esto se ha logrado mediante las sesiones de intervención (entrevistas) aplicadas a los futuros profesores en donde resolvían las tareas planteadas, y respondían a las preguntas realizadas por el investigador y el análisis de los comentarios y respuestas de los participantes. Nos apoyamos del método del análisis de contenido para analizar los comentarios y respuestas de los futuros profesores, transcribiendo las entrevistas, seleccionado las unidades de análisis y categorizando la información. 
En cuanto a los resultados referidos a las manifestaciones de los conceptos y elementos geométricos, hemos apreciado que los futuros profesores manejan los que son necesarios para la ejecución de las tareas. Observamos una mayor frecuencia en los conceptos de punto, recta, recta paralela y recta perpendicular.

Para la variable de relaciones geométricas, todos los participantes logran identificar relaciones entre diversos elementos geométricos. Varios futuros profesores, han manifestado escasas relaciones geométricas de las que se consideraron importantes para la conclusión exitosa de las actividades, coincidiendo con resultados de otras investigaciones sobre razonamiento y conocimiento geométrico (Carreño y Climent, 2010; Žilková et al., 2015). En la segunda parte de la primera tarea, solo la minoría de los participantes, tiene éxito en la actividad. La mayoría, manifestaron relaciones geométricas insuficientes alrededor de la mediatriz, conociendo este elemento geométrico únicamente de forma conceptual, pero sin poder relacionarlo con otras estructuras de la geometría. Otros participantes manifiestan relaciones inadecuadas de paralelismo y perpendicularidad, mientras que un participante establece relaciones de medida erróneas.

Sin duda, la variable más débil dentro de las dimensiones geométricas del sentido espacial, es la de ubicación y movimientos. Aunque la gran mayoría de futuros profesores identifica elementos variantes e invariantes cuando se aplica un movimiento o distintas posiciones de elementos, presentan problemas para justificar las razones que hacen que sean eficaces los movimientos o dobleces que realizan. Solamente un participante logra asociar un doblez con una rotación en el espacio tomando como eje a una recta. El movimiento que algunos futuros profesores identifican con un poco más de frecuencia, es el de simetría, sin embargo, no relacionan esta transformación geométrica con la rotación en el espacio sobre algún eje generado por el doblez del papel. Esto coincide con la investigación de Roura (2020) donde detecta fallos en los futuros profesores al tratar de identificar rotaciones y simetrías en actividades relacionadas con capacidad visual y sentido espacial.

En cuanto a las habilidades de visualización, los futuros profesores han manifestado las siete habilidades propuestas por Del Grande (1990). En la primera tarea hubo evidencia de utilización de seis habilidades de visualización propuestas por Del Grande (1990), excluyéndose la memoria visual. Paras las dos últimas tareas existió presencia de las siete habilidades de visualización. Algunas habilidades se manifiestan en mayor medida, al 
igual que las conductas asociadas a sus categorías, además todas son utilizadas por todos los futuros profesores, a excepción de la discriminación visual que en ocasiones algunos participantes no la pusieron de manifiesto.

Si consideramos de forma general y global el éxito de las tres tareas, lo más frecuente es que los participantes las desarrollen de forma parcial. Esto debido a que logran construir el objeto geométrico solicitado, sin llegar a entender el porqué de su construcción. No tienen argumentos para justificar por qué los dobleces realizados les dan garantía de que han obtenido los elementos geométricos deseados, basando sus argumentos únicamente en meras intuiciones. Por tanto, apreciamos que tienen dificultades para establecer una relación entre las habilidades visualizadores y los componentes geométricos, tal y como se pretende con el sentido espacial. Esto coincide con estudios realizados con futuros profesores, que, aunque no estudian el sentido espacial como tal, si obtienen conclusiones que permiten relacionar la visualización con componentes geométricos, como el de Fernández-Blanco et al. (2019) que detectaron grandes dificultades al momento de resolver actividades visualizadoras y de razonamiento espacial, evidenciando ausencia de una interrelación entre visualización y representaciones geométricas. Resaltamos que Akayuure et al. (2016), en una etapa de su estudio sobre habilidades espaciales y conocimiento geométrico, también encuentra dificultades en habilidades de orientación espacial, visualización espacial y conocimiento geométrico en futuros profesores. Con respecto al abordaje intuitivo de tareas geométricas, Carreño y Climent (2010) detectan que en las actividades geométricas propuestas a los sujetos de su investigación hay ausencia de razonamientos formales, se resuelven las tareas bajo la experimentación y se argumenta basándose en la intuición.

Además, por los comentarios, acciones y respuestas manifestadas durante las entrevistas, detectamos que los futuros profesores no se encuentran acostumbrados a realizar actividades que involucren una combinación de componentes geométricos con habilidades visualizadores o que evoquen un sentido espacial, coincidiendo con los resultados de otros estudios (Fernández-Blanco et al., 2019; Metzger, 2019).

El último objetivo específico, que consistía en identificar las habilidades de visualización del sentido espacial que son utilizadas con mayor énfasis en las tareas geométricas que resuelven los futuros profesores. Para ello hemos llevado un registro de las veces que manifiestan una conducta dentro de una categoría de una habilidad de visualización, 
apreciando que las que se presentan con un grado mayor de frecuencia son coordinación ojo motor (mayoritariamente en las dos últimas tareas), percepción de la posición en el espacio, percepción figura contexto y conservación de la percepción (Del Grande, 1990), posiblemente por la temática de las tareas geométricas que consistía en el plegado de papel. Además, hemos identificado el porcentaje de conductas y categorías más comunes que manifiestan los sujetos, dentro de cada una de las habilidades.

Los resultados de la investigación, al igual que las de otros autores (Marchis, 2017; Metzger, 2019; Ünal et al., 2009), muestran la necesidad incorporar, en la formación inicial de profesores, actividades manipulables que permitan el desarrollo de capacidades geométricas, integrando conceptos, elementos y relaciones geométricas, dando especial énfasis a la ubicación y movimientos, con habilidades de visualización

\subsection{Limitaciones de la investigación}

Se presentaron dificultades al momento de interpretar las acciones relacionadas con la variable de ubicación y movimientos, debido a que hay posibilidad de realizar una variedad de movimientos al momento de doblar el papel y es complicado determinar si los futuros profesores implícitamente están brindándole sentido geométrico a estas acciones. Es por ello que se decidió considerar aquellas manifestaciones que eran expresadas explícitamente y de forma verbal.

Otra de las limitaciones que encontramos, es que a pesar de tener grabadas las entrevistas, realizar anotaciones de las observaciones, obtener fotografías de las respuestas de los participantes y solicitarles a los futuros profesores que traten de exteriorizar sus pensamientos al llevar a cabo las sesiones de intervención, cabe la posibilidad de que los participantes estén utilizando habilidades de visualización complejas, que no se puedan expresar verbalmente ni son observables por las acciones que ejecutan.

Es complicado discernir si las habilidades de visualización que fueron manifestadas con menor frecuencia, no están tan presentes debido características propias de las tareas geométricas de doblado de papel o a que están menos desarrolladas por los futuros profesores.

Por último, consideramos como un obstáculo la situación de la pandemia de COVID-19, que limitó la diversidad de actividades geométricas que se pudieran haber desarrollado 
por los participantes, esto porque se debía procurar seleccionar materiales que los futuros profesores tuvieran de fácil acceso en sus hogares.

\subsection{Expectativas para futuras investigaciones}

Futuros estudios podrían llevarse a cabo replicando nuestra investigación con una muestra mayor de participantes o incluso con sujetos con otras características (profesores de secundaria y primaria que se encuentren en ejercicio de su profesión, por ejemplo). También podrían realizarse estudios similares, en donde se contrasten los resultados con dos grupos de futuros profesores: aquellos que se encuentran en una formación inicial con respecto a los que finalizan su formación.

Podrían replicarse investigaciones a futuro, que se centren en el análisis a profundidad de las habilidades visualizadoras que ponen en juego futuros profesores al enfrentarse a tareas de doblado de papel y cómo, el nivel de desarrollo de estas habilidades, influye en la facilidad para resolver las actividades geométricas y culminar con éxito la actividad.

Sería de interés desarrollar estudios que además de incorporar variables como las que hemos recogido en el nuestro, incluyan el nivel de dificultad, categorías de errores frecuentes, número de intentos antes de un éxito, y así caracterizar aún más las componentes del sentido espacial y su vinculación con la solución de las tareas. Además de poder intentar detectar relaciones entre las componentes geométricas y las habilidades de visualización que se encuentren presentes.

Otra línea abierta podría en consistir en utilizar tareas como las de nuestro estudio, pero solicitando que realicen una justificación de la construcción realizada con doblado de papel apoyándose de un software de geometría dinámica como GeoGebra. 


\section{REFERENCIAS}

Abrate, R., Delgado, G. y Pochulu, M. (2006). Caracterización de las actividades de Geometría que proponen los textos de Matemática. Revista Iberoamericana de Educación, 39(1), 1-9. https://rieoei.org/historico/deloslectores/1290Abrate.pdf

Akayuure, P., Asiedu-Addo, S. K. y Alebna, Victor. (2016). Investigating the Effect of Origami Instruction on Preservice Teachers' Spatial Ability and Geometric Knowledge for Teaching. International Journal of Education in Mathematics, Science and Technology, 4(3), 198-209. DOI:10.18404/ijemst.78424.

Aznarte, M. y Ramírez, R. (2018). Tareas con tangram para favorecer el sentido espacial. Épsilon, 98, 57-66. https://digibug.ugr.es/handle/10481/64633

Báez, R. e Iglesias, M. (2007). Principios didácticos a seguir en el proceso de enseñanza y aprendizaje de la geometría en la UPEL. "El Mácaro". Revista Enseñanza de la $\begin{array}{lllll}\text { Matemática, } & 12 & \text { al } & \text { 16(número extraordinario), }\end{array}$ http://funes.uniandes.edu.co/14702/

Barrantes, M. (2002). Recuerdos, expectativas y concepciones de los estudiantes para maestro sobre la geometría escolar y su enseñanza-aprendizaje [Tesis de Doctorado, Universidad de Extremadura].

Bishop, A. (1986). What are some obstacles to learning geometry? en R. Morris (Ed.), Studies in mathematics education: Teaching of geometry (Vol. 5, pp. 141-159). UNESCO.

Carreño, E. y Climent, N. (2010). Conocimiento del contenido sobre polígonos de estudiantes para profesor de matemáticas. PNA, 5(1), 11-23. https://digibug.ugr.es/bitstream/handle/10481/4981/Carrenno2010Conocimiento. pdf? sequence $=1 \&$ is Allowed $=\mathrm{y}$

Clements, D. H. y Battista, M. T. (1992). Geometry and spatial reasoning en D. A. Grouws (Ed.), Handbook of research on mathematics teaching and learning (pp. 420-464). Macmillan.

Clements, D. (1998). Geometric and Spatial Thinking in Young Children. National Science Foundation.

Cruz, A. y Ramírez, R. (2018). Componentes del sentido espacial en un test de capacidad espacial en L. J. Rodríguez-Muñiz, L. Muñiz-Rodríguez, A. Aguilar-González, P. 
Alonso, F. J. García García y A. Bruno (Eds.), Investigación en Educación Matemática XXII (pp. 211-220). SEIEM.

Cunningham, R. y Roberts, A. (2010). Reducing the Mismatch of Geometry Concept Definitions and Concept Images Held by Pre-Service Teachers. Issues in the Undergraduate Mathematics Preparation of School Teachers, 1, 1-17. https://files.eric.ed.gov/fulltext/EJ914254.pdf

Del Grande, J. J. (1987). Spatial Perception and Primary Geometry, en M. M. Lindquist (Ed.), Learning and Teaching Geometry (pp 127-135).National Council of Teachers of Mathematics.

Del Grande, J.J. (1990). Spatial Sense. The Arithmetic Teacher, 37(6), 14-20.

Diezmann, C. y Watters, J. (2000). Identifying and Supporting Spatial Intelligence in Young Children. Contemporary Issues in Early Childhood, 1(3), 299-313. doi.org/10.2304/ciec.2000.1.3.6

Fernández-Blanco, T.F., Díaz, J.D. y Cajaraville, J.A.C. (2012). Razonamiento Geométrico y Visualización Espacial desde el Punto de Vista Ontosemiótico. Bolema, 26(42), 39-63. https://www.redalyc.org/pdf/2912/291223573004.pdf

Fernández, A. (2019). Sentido espacial en secundaria [Tesis de maestría inédita, Universidad de Granada].

Férnandez-Blanco, T., Godino, J. D., Sequeiros P.G. y Diego-Mantecon, J.M. (2019). Skill Levels on Visualization and Spatial Reasoning in Pre-service Primary Teachers. Universal Journal of Educational Research, 7(12), 2647-2661. https://n9.cl/8ssef

Flores, P., Lupiáñez, J. L., Berenguer, L., Marín, A. y Molina, M. (2011). Materiales y recursos en el aula de matemáticas. Departamento de Didáctica de la Matemática de la Universidad de Granada.

Flores, P., Ramírez, R. y Del Río, A. (2015). Sentido Espacial en P. Flores y L. Rico. (Coords.), Enseñanza y aprendizaje de las Matemáticas en Educación Primaria (pp. 127-146). Pirámide.

Fortuny, J.M., Iranzo, N. y Morera, L. (2010). Geometría y tecnología en M.M. Moreno, A. Estrada, J. Carrillo y T.A. Sierra (Eds.), Investigación en Educación $\begin{array}{lll}\text { Matemática } \quad \text { XIV 69-85). } & \text { SEIEM. }\end{array}$ https://www.seiem.es/docs/actas/14/Actas14SEIEM.pdf 
Gamboa, R. y Ballestero, E. (2009). Algunas reflexiones sobre Didáctica de la Geometría. Cuadernos de Investigación y Formación en Educación Matemática, 4(5), 113136. https://www.revistas.ucr.ac.cr/index.php/cifem/article/download/6915/6601

Gamboa, R. y Ballestero, E. (2010). La enseñanza y aprendizaje de la geometría en secundaria, la perspectiva de los estudiantes. Revista Electrónica Educare, 14 (2), 125-142. https://www.redalyc.org/pdf/1941/194115606010.pdf

Gutiérrez, A. (1996). Visualization in 3-dimensional geometry: In search of a framework en L. Puig y A. Gutierrez (Eds.), Proceedings of the 20th P.M.E. Conference, 1 (pp. 3-19). Universidad de Valencia.

Gutiérrez, L., Martínez, E. y Nebreda, T. (2008). Las competencias básicas en las áreas de Matemáticas. Consejería de Educación de Cantabria. https://n9.cl/gapx9

Godino, J.D., Gonzato, M., Contreras, Á., Estepa, A. y Díaz-Batanero, C. (2016). Evaluación de Conocimientos Didáctico-Matemáticos sobre Visualización de Objetos Tridimensionales en Futuros Profesores de Educación Primaria. REDIMAT, 5(3), 235-262. http://dx.doi.org/10.4471/redimat.2016.1984

Gonzato, M., Fernández, T. y Díaz, J. (2011). Tareas para el desarrollo de habilidades de visualización y orientación espacial. Números, 77, 99-117. http://www.sinewton.org/numeros/numeros/77/Articulos_05.pdf

Guzel, N. y Sener, E. (2010). High school students' spatial ability and creativity in geometry. Procedia Social and Behavioral Sciences, 1, 1763-1766.

Hernández, R., Fernández, C. y Baptista, P. (2010). Metodología de la investigación (5 ed.). Mcgraw Hill.

Hernández Sampieri, R.; Fernández-Collado, C. y Baptista, P. (2014). Metodología de la investigación (6 ${ }^{\mathrm{a}}$ ed.). McGraw-Hill.

Hershkowitz, R., Parzysz, B. y Van Dormolen, I. (1996). Space and Shape en A. Bishop, K. Clements, C. Keitel, J. Kilpatrick y C. Laborde (Eds), International Handbook of Mathematics Education: I Part (pp. 161-237). Springer.

Ihsan, A. y Yildiz, B. (2019). The effect of computeraided 3D modeling activities on preservice teacher's spatial abilities and attitudes towards 3D modeling. Journal of Baltic Science Education, 18(3), 335-348. https://n9.cl/ajkxr

Ilhan, A. (2021). Analysis of the Correlations Between Visual Mathematics Literacy Perceptions, Reasoning Skills on Geometric Shapes and Geometry Performances of Pre-Service Mathematics Teachers. Participatory Educational Research, 8(1), 90-108. https://dergipark.org.tr/en/download/article-file/1058581 
Jones, K. (2001). Spatial thinking and visualization. Teaching and learning geometry, $11(19), 55-56$.

Kosa, T. y Karakus, F. (2018). The effects of computer-aided design software on engineering students' spatial visualisation skills. European Journal of Engineering Education, 43(2), 296-308.

Krajcevski, M. y Sears, R. (2019). Common Visual Representations as a Source for Misconceptions of Preservice Teachers in a Geometry Connection Course. International Journal for Mathematics Teaching and Learning, 20(1), 85-106. https://scholarcommons.usf.edu/cgi/viewcontent.cgi?article=1206\&context=tal_ facpub

Lupiáñez, J. y Flores, P. (2011). Sentido espacial en I. Segovia y L. Rico (Coords.), Matemáticas para maestros de Educación Primaria (pp.329-350). Pirámide.

Marchis, I. (2012). Preservice Primary School Teachers Elementary Geometry Knowledge. Acta Didactica Napocensia, 5(2), 33-40. https://files.eric.ed.gov/fulltext/EJ1054293.pdf

Marchis, I. (2017). Pre-service primary school teacher's spatial abilities. Acta Didactica Napocensia, 10(2), 123-130. https://files.eric.ed.gov/fulltext/EJ1156704.pdf

Markopoulos, C., Chaseling, M., Petta, K., Lake, W. y Boyd, W. (2015). Pre-Service Teachers' 3D Visualization Strategies. Creative Education, 6, 1053-1059. https://www.scirp.org/journal/paperinformation.aspx?paperid=57395

Mayring, P. (2004). Qualitative Content Analysis en U. Flick, E. Von Kardoff e I. Steinke (Eds.), A Companion to Qualitative Research (pp. 266-269). Sage Publications.

McGee, M. G. (1979). Human spatial abilities: Psychometric studies and environmental, genetic, hormonal, and neurological influences. Psychological Bulletin, 86(5), 889-918.

Metzger, M. (2019). Understanding preservice teacher's spatial reasoning and how it affects their work with elementary students [Tesis de Doctorado, Universidad de Nebraska]. https://n9.cl/c8q8rn

Ministerio de Educación Pública de Costa Rica. (2012). Programas de Estudio Matemáticas. Educación General Básica y Ciclo Diversificado. República de Costa Rica.

Ministerio de Educación Pública de Costa Rica. (2015). Fundamentación pedagógica de la transformación curricular. República de Costa Rica. 
https://www.mep.go.cr/sites/default/files/documentos/transf-curricular-vacademico-vf.pdf

Ministerio de Educación Pública. (2016). Informe Nacional Rendimiento y Desempeño Bachillerato 2015. Dirección de Gestión y Evaluación de la Calidad. https://dgec.mep.go.cr/sites/all/files/dgec_mep_go_cr/documentos/informe_naci onal_de_las_pruebas_de_bachillerato_2015.pdf

Ministerio de Educación Pública. (2017). Informe Bachillerato de la Educación Formal 2016. Dirección de Gestión y Evaluación de la Calidad. https://dgec.mep.go.cr/sites/all/files/dgec_mep_go_cr/documentos/informe_naci onal_2016_0.pdf

Ministerio de Educación Pública. (2018). Informe Nacional Rendimiento y Desempeño Bachillerato 2017. Dirección de Gestión y Evaluación de la Calidad. https://dgec.mep.go.cr/sites/all/files/dgec_mep_go_cr/documentos/informe_naci onal_2017.pdf

Ministerio de Educación Pública. (2019). Número de ítems por habilidades generales del Programa de estudio Pruebas Nacionales de Bachillerato 2019. Dirección de Gestión y Evaluación de la https://dgec.mep.go.cr/sites/all/files/dgec_mep_go_cr/documentos/distribucion_ de_items_matematicas_2019_-academico-oficial.pdf

Ministerio de Educación Pública. (2020). Informe Nacional Bachillerato 2019. Dirección de Gestión y Evaluación de la Calidad. https://dgec.mep.go.cr/sites/all/files/dgec_mep_go_cr/documentos/bachillerato_ 2019_-_informe_2019.pdf

Molina, F. y Flores, P. (2017). Sentido espacial en el inicio de la escritura en Educación Primaria. Épsilon, 34 (95), 77-98.

National Council of Teachers of Mathematics. (2003). Principios y Estándares para la educación matemática. National Research Council. (2006). SAEM THALES.

National Research Council. (2006). Learning to Think Spatially. The National Academies Press.

Newcombe, N. (2010). Increasing Math and Science Learning by Improving Spatial Thinking. American Educator.

New Jersey Mathematics Coalition. (1996). Geometry and spatial sense, Standard 7 en New Jersey Mathematics Curriculum Framework (pp. 209-249). 
http://archive.dimacs.rutgers.edu/nj_math_coalition/framework/ch07/ch07_k12o.html

OECD. (2014). PISA 2012 Results: What Students Know and Can Do - Student Performance in Mathematics, Reading and Science. OECD Publishing. http://dx.doi.org/10.1787/9789264208780-en

OECD. (2019a). PISA 2018 Results (Volume I): What Students Know and Can Do. https://doi.org/10.1787/5f07c754-en.

OECD. (2019b).PISA 2018 Assessment and analytical framework. OECD Publishing. https://n9.cl/8oafz

Ortiz, A. y Sandoval, I. (2018). Representaciones de cuerpos geométricos: una experiencia con profesores de primaria de Latinoamérica en L. J. RodríguezMuñiz, L. Muñiz-Rodríguez, A. Aguilar-González, P. Alonso, F. J. García y A. Bruno (Eds.). Investigación en Educación Matemática XXII (pp. 427-436). Actas XXII SEIEM. http://www.unioviedo.es/XXIISeiem/wpcontent/uploads/2018/09/ACTAS_Provisionales_20180830.pdf

Ozcan, K., Akbay, M. y Karakus, T. (2016). Effects Of Gaming Habits Of University Students On Their Spatial Skills. Kastamonu Education Journal, 24(1), 37-52. https://dergipark.org.tr/en/download/article-file/210019

Ozdemir, A. y Goktepe, S. (2015). The examination of elementary mathematics preservice teachers' spatial abilities. Procedia-Social and Behavioral Sciences, 174, 594-601. https://www.sciencedirect.com/science/article/pii/S1877042815006394

Ozsoy, G. (2018). Pre-service Teachers' Use of Visual Representations. International Electronic Journal of Elementary Education, 11(1), 49-54. https://iejee.com/index.php/IEJEE/article/view/632/367

Putri, R. (2018). Spatial Skill Profile of Mathematics Pre-Service Teachers. IOP Conf. Series: Journal of Physics. https://iopscience.iop.org/article/10.1088/17426596/947/1/012065/pdf

Ramírez, R. (2012). Habilidades de visualización de los alumnos con talento matemático [Tesis de Doctorado, Universidad de Granada]. https://digibug.ugr.es/handle/10481/23889

Rico, L. (2013). El método del Análisis Didáctico. Revista Iberoamericana de Educación Matemática, 33, 11-27.

Rico, L. y Fernández, A. (2013). Análisis didáctico y metodología de investigación en L. Rico, J. Lupiáñez, M. Molina (Coords), Análisis didáctico en educación 
matemática: metodología de investigación, formación de profesores e innovación curricular (pp. 1-22). Comares.

Rico, L. (2016). Matemáticas y análisis didáctico en L. Rico y A. Moreno (Coords.), Elementos de Didáctica para el profesor de Secundaria (1 ed., pp. 85-100). Ediciones Pirámide.

Rico, L. y Lupiáñez, J. (2008). Competencias matemáticas desde una perspectiva curricular. Alianza Editorial.

Ricotti, E. (2020). Geometría y origami: Una fiesta con papeles para la clase de Matemática. HomoSapiens.

Roura, R. (2020). Análisis de la capacidad visual y de la resolución de una tarea de sentido espacial en futuros maestros [Trabajo de Fin de Máster, Universidad de Granada]. https://n9.cl/69nit

Ruíz, A. (2018). Evaluación y Pruebas Nacionales para un Currículo de Matemáticas que Enfatiza Capacidades Superiores. Comité Internacional de Educación Matemática. https://revistas.ucr.ac.cr/index.php/cifem/article/view/31916

Ruíz-Hidalgo, J., Flores, P., Ramírez-Uclés, R. y Fernández-Plaza, J. (2019). Tareas que desarrollan el sentido matemático en la formación inicial de profesores. Educación Matemática, 31(1), 121-143.

Salto, C. (2013). Sentido especial en un juego de espejos. [Tesis de Maestría inédita, Universidad de Granada].

Serrano, Á.M., Ramírez, R. y Flores, P. (2018). El sentido espacial sobre traslaciones en un libro de texto. Números, 98, 117-131.

Stanic, G. y Owens, D. (1990). Spatial sense. The Aritmetic Teacher, 37(6), 48-51.

Ünal, H., Jakubowski, E. y Corey, D. (2009). Differences in learning geometry among high and low spatial ability pre-service mathematics teachers. International Journal of Mathematical Education in Science and Technology, 40(8), 997-1012.

Vega, R. (2018). ¿Por qué no logramos mejores aprendizajes y mayor logro educativo de nuestros estudiantes?. https://n9.cl/kuspe

Yani, M. y Rosma, F. (2020). Improving Students' Spatial Ability by Using Macromedia Flash on Geometry Materials. Malikussaleh Journal of Mathematics Learning, 3(1), 2620-6323.

Žilková, K., Gunčaga, J. y Kopáčová, J. (2015). Conceptios about geometric shapes in preservice primary teachers. Acta Didactica Napocensia, 8(1), 27-36. https://files.eric.ed.gov/fulltext/EJ1064381.pdf 


\section{ANEXO A. RESOLUCIÓN DE LAS ACTIVIDADES SELECCIONADAS}

Tarea 1. Hallar, mediante el doblado de una hoja de papel con bordes irregulares, la mediatriz de un segmento dado. a) Justifique su construcción, ¿por qué al realizar esos dobleces le permitieron obtener la mediatriz del segmento? b) Finalizada la construcción, ¿cómo podría doblar de otra manera para justificar que lo obtenido corresponde a la mediatriz del segmento dado?

\section{Solución parte a):}

Paso 1: Tome un papel de bordes irregulares y marque un segmento $\overline{A B}$ sobre él. Tal y como se muestra en la figura 1.

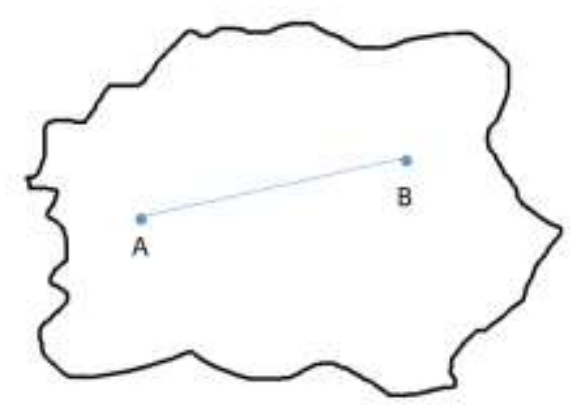

Figura 1. Segmento dibujado sobre el papel.

Paso 2: Doble el papel sobre el segmento $\overline{A B}$, como se muestra en la figura 2.

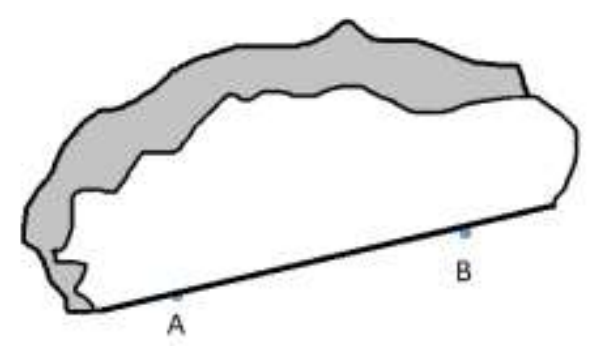

Figura 2. Doblez realizado sobre el segmento.

Paso 3: Doble el papel, de modo que el punto $A$ coincida sobre el punto $B$ (figura 3). 

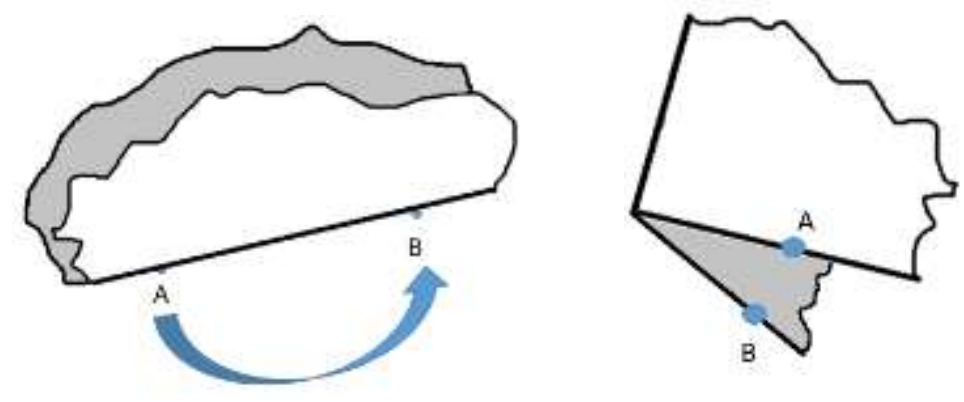

Figura 3. Doblez de modo que A coincida sobre B.

Paso 4: Se abre el papel y ha obtenido la mediatriz sobre $\overline{A B}$ (figura 4).

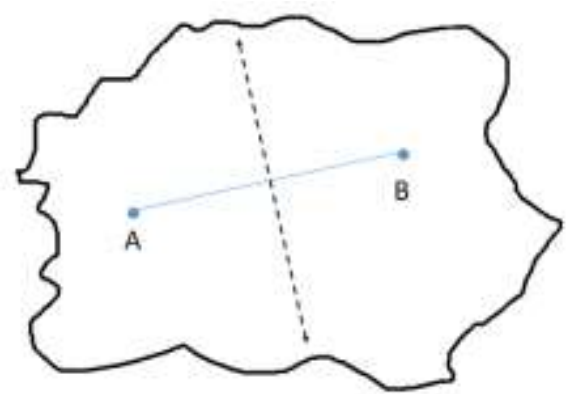

Figura 4. Mediatriz obtenida sobre $\overline{A B}$.

\section{Solución parte b):}

Paso 1: Se dobla $A$ sobre $B$, siguiendo el doblez de la mediatriz, y se ubica un punto $P$ sobre la misma (figura 5).

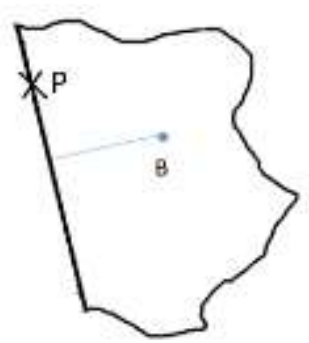

Figura 5. Doblez sobre la mediatriz.

Paso 2: Ahora se hace un nuevo pliegue desde $\mathrm{P}$ hasta los extremos superpuestos (figura $6)$. 

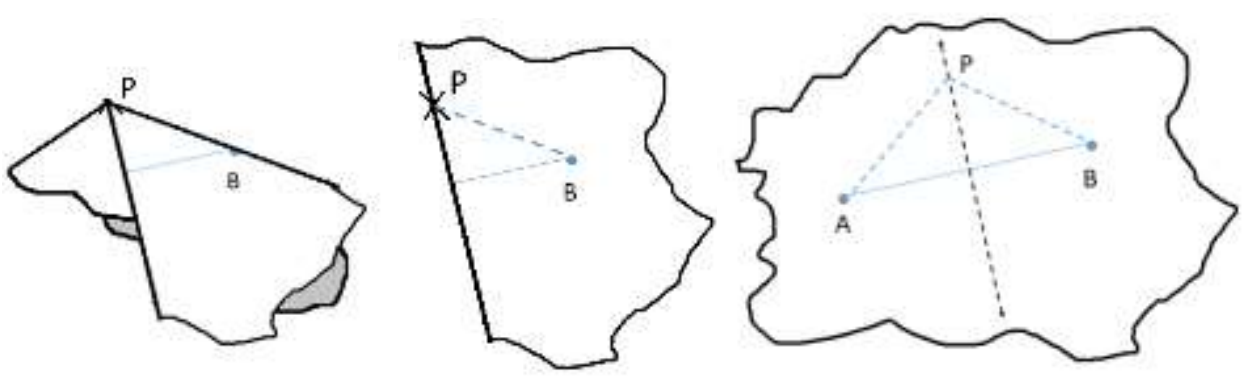

Figura 6. Pliegues sobre P.

Como los dobleces $\overline{P A}$ y $\overline{P B}$ se hicieron superpuestos entonces la medida de cada uno de estos segmentos es la misma y los dos triángulos rectángulos que componen el triángulo isósceles son congruentes. Además:

- Si un punto pertenece a la mediatriz de un segmento, equidista de sus extremos.

- Si un punto equidista de los extremos del segmento, entonces pertenece a la mediatriz.

- La mediatriz puede definirse como el lugar geométrico de los puntos en el plano que equidistan de los extremos del segmento.

Tarea 2. Hallar, mediante el doblado de una hoja de papel con bordes irregulares, la perpendicular por un punto exterior a una recta dada. Justifique su construcción, ¿por qué al realizar esos dobleces le permitieron obtener la recta perpendicular solicitada?

\section{Solución 1}

Paso 1: Se marca sobre el papel de bordes irregulares un punto y una recta (figura 7).

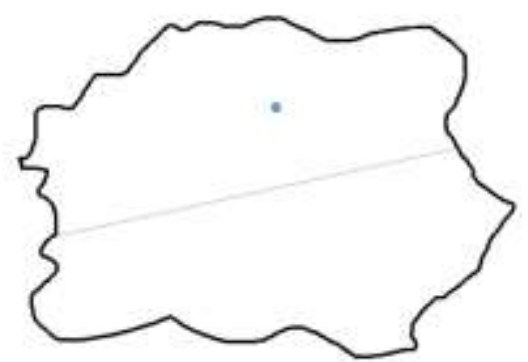

Figura 7. Punto y recta trazados sobre el papel.

Paso 2: Se dobla el papel sobre la recta (figura 8). 


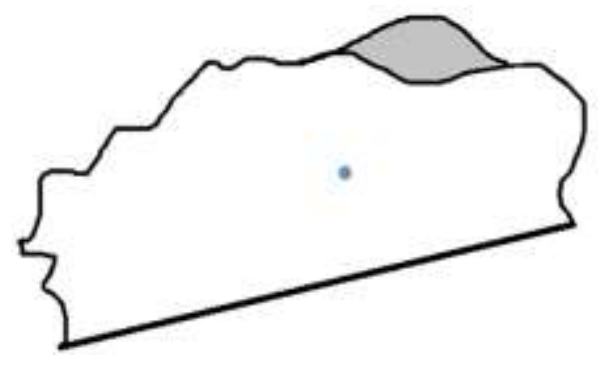

Figura 8. Doblez del papel sobre la recta.

Paso 3: Se vuelve a doblar, de modo que el doblez pase sobre el punto marcado y que coincidan los segmentos de recta (figura 9).

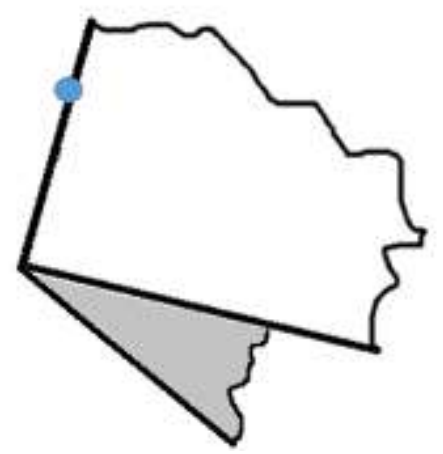

Figura 9. Doblez del papel sobre el punto dibujado.

Paso 4: Finalmente se abre el papel y se obtiene la recta perpendicular buscada (figura $10)$.

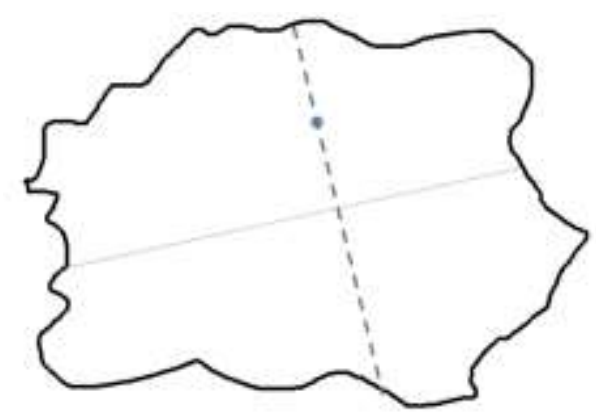

Figura 10. Recta finalmente construida.

\section{Solución 2}

Paso 1: Se marca sobre el papel de bordes irregulares un punto y una recta (figura 11). 


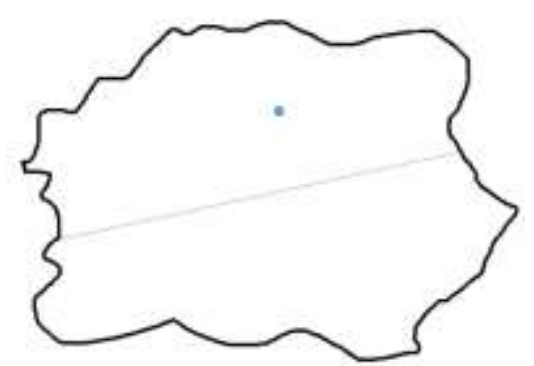

Figura 11. Punto y recta trazados sobre el papel.

Paso 2: Se dobla el papel sobre la recta (figura 12).

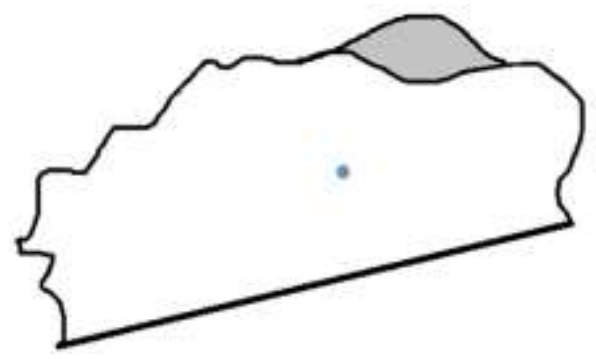

Figura 12. Doblez del papel sobre la recta.

Paso 3: Se realiza un par de pequeños dobleces sobre el punto, con la finalidad de generar su simétrico en el otro lado del papel y de abre (figura 13).

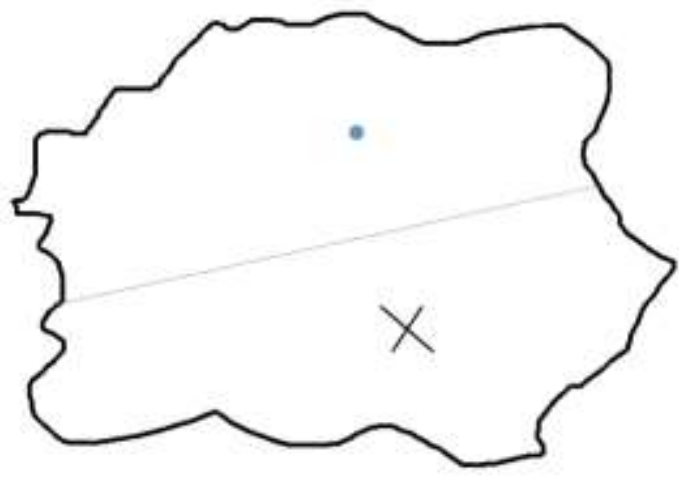

Figura 13. Punto simétrico generado por el doblez.

Paso 4: Luego se dobla el papel sobre el punto dibujado y su simétrico, se abre y se obtiene la recta buscada (figura 14). 

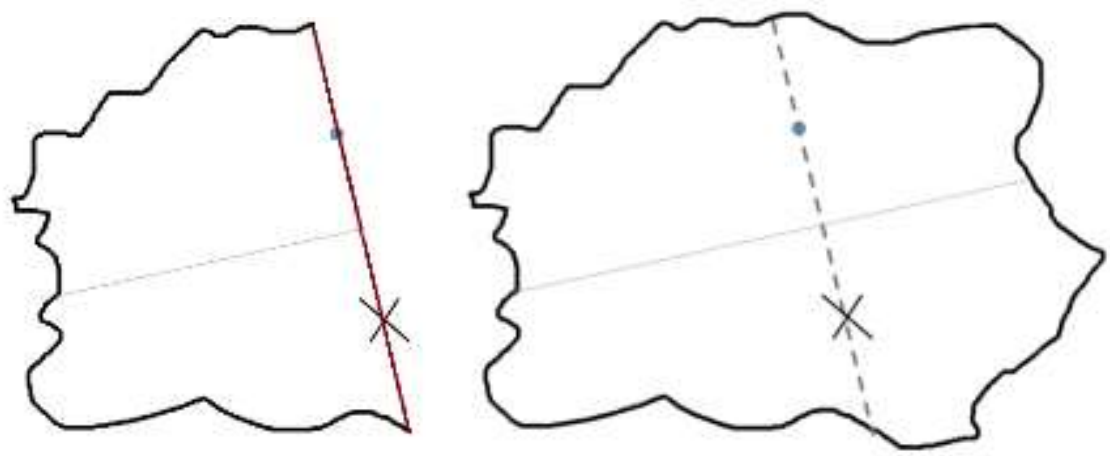

Figura 14. Recta perpendicular finalmente conseguida.

Tarea 3. Hallar, mediante el doblado de una hoja de papel con bordes irregulares, la paralela a una recta por un punto exterior a ella. Justifique su construcción, ¿por qué al realizar esos dobleces le permitieron obtener la recta paralela solicitada?

\section{Solución 1}

Paso 1: Repita los pasos del 1 al 3, de la solución 1 de la actividad 2, mantenido el papel de la misma forma que la figura 15.

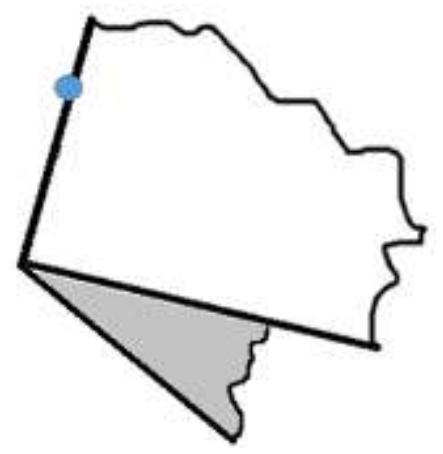

Figura 15. Doblez del papel sobre el punto dibujado.

Paso 2: Trace otra perpendicular que pase por el punto previamente dibujado, manteniendo siempre el papel de la forma de la figura 15, guíese considerando la figura 16. 


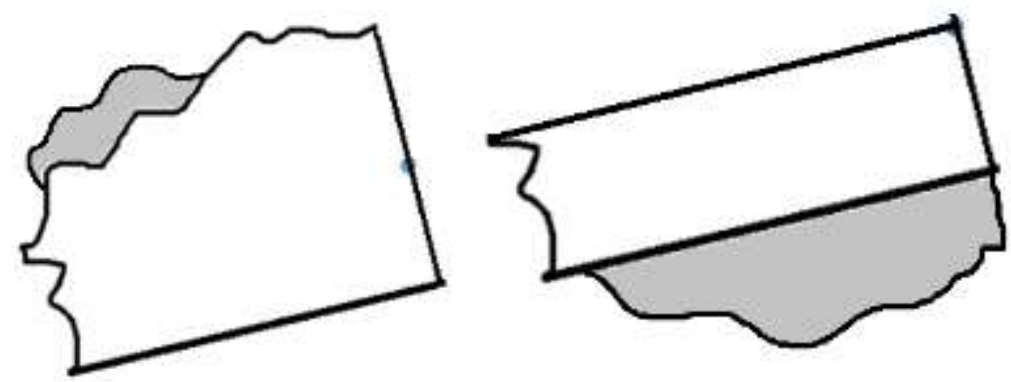

Figura 16. Doblez que permite trazar otra perpendicular.

Paso 3: Abra el papel y habrá obtenido la paralela buscada (figura 17).

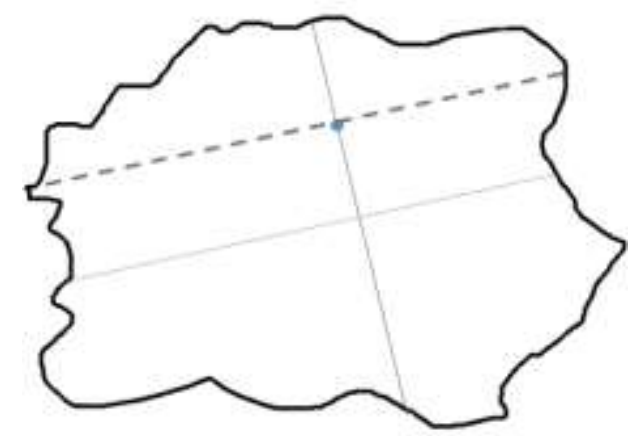

Figura 17. Paralela buscada trazada sobre el papel.

Recuerde que si $a$ y $b$ son rectas en donde $a \perp b$ y $b \perp c \Rightarrow a \| b$, siempre que $a, b$ y $c$ sean coplanares.

\section{Solución 2}

Consiste en obtener una recta perpendicular al punto dibujado, al igual que se hizo en los pasos 1, 2, 3 y 4 de la solución 2 de la tarea 2. Luego, utilizando la misma estrategia, obtenga una perpendicular a la recta perpendicular anterior y que pase por el punto dibujado inicialmente. Se abre el papel y obtendrá la paralela buscada, quedará igual que en la figura 17. 


\section{ANEXO B. PROCESO DE EVALUACIÓN DE COMPONENTES GEOMÉTRICOS DEL JUICIO DE}

\section{EXPERTOS}

Tabla 1. Expertos en Educación Matemática que participaron en la primera etapa de revisión del sistema de categorías a priori dentro del juicio de expertos

\begin{tabular}{llc}
\hline \multicolumn{1}{c}{ Experto } & \multicolumn{1}{c}{ Institución para la que labora } & Tarea que revisó \\
\hline $\begin{array}{l}\text { Doctor Luis Gerardo Meza } \\
\text { Cascante }\end{array}$ & $\begin{array}{l}\text { Profesor Catedrático del Instituto } \\
\text { Tecnológico de Costa Rica }\end{array}$ & Tarea 3 \\
Máster Marvin Abarca Fuentes & $\begin{array}{l}\text { Profesor del Instituto Tecnológico } 2 \\
\text { de Costa Rica }\end{array}$ & $\begin{array}{l}\text { Trofesor del Instituto Tecnológico } 1 \\
\text { de Costa Rica y de la Universidad } \\
\text { de Costa Rica }\end{array}$ \\
\hline
\end{tabular}

Tabla 2. Conductas para la tarea 1 que fueron presentadas a los expertos y sus observaciones en la primera etapa del juicio de expertos

\begin{tabular}{lll}
\hline $\begin{array}{c}\text { Componentes del } \\
\text { sentido espacial }\end{array}$ & \multicolumn{1}{c}{ Conductas al resolver la tarea } & \multicolumn{1}{c}{$\begin{array}{c}\text { Observaciones del juez } \\
\text { experto }\end{array}$} \\
\hline $\begin{array}{l}\text { Conceptos y elementos } \\
\text { geométricos }\end{array}$ & $\begin{array}{l}\text { Menciona: } \\
\text { El concepto de mediatriz de un } \\
\text { segmento } \\
\text { Ángulos (ángulo llano, recto) }\end{array}$ & $\begin{array}{l}\text { El experto concuerda con } \\
\text { los elementos indicados. }\end{array}$ \\
& $\begin{array}{l}\text { Segmento } \\
\text { Punto medio } \\
\text { Eje de simetría } \\
\text { Recta perpendicular }\end{array}$ & \\
Relaciones geométricas & $\begin{array}{l}\text { Si un punto pertenece a la mediatriz } \\
\text { de un segmento, equidista de sus } \\
\text { extremos }\end{array}$ & $\begin{array}{l}\text { El experto concuerda con } \\
\text { los elementos indicados sin } \\
\text { embargo concuerda con } \\
\text { que se agregue "Relaciones } \\
\text { sobre segmentos o ángulos } \\
\text { congruentes". }\end{array}$ \\
& $\begin{array}{l}\text { Si un punto equidista de los } \\
\text { extremos del segmento, entonces } \\
\text { pertenece a la mediatriz. }\end{array}$ & \\
& $\begin{array}{l}\text { Establecer relaciones entre } \\
\text { longitudes y ángulos con sus } \\
\text { respectivas simetrías }\end{array}$ \\
& $\begin{array}{l}\text { Relaciones sobre triángulos que son } \\
\text { congruentes (criterios de } \\
\text { congruencia) }\end{array}$ \\
&
\end{tabular}


Relaciones de medida al doblar las figuras (área, lados y ángulos)

Ubicación y movimiento Identifica elementos invariantes o
regularidades al doblar
Describe posiciones con respecto a elementos (Esquinas, interior, exterior, arriba, $\operatorname{mitad} . .$.

Situar los distintos dobleces para obtener los elementos geométricos deseados

Realiza rotaciones en el espacio para obtener los ejes de simetría

Describe posiciones en el plano

(vértices, lados, ángulos que coinciden)

Describe posiciones con respecto a elementos (Esquinas, interior, exterior, arriba, mitad...)
El experto sugiere que se agregue una conducta en donde el participante eventualmente considere simetrías que observa sin asociarlas al movimiento de rotación. El resto de conductas le parecen pertinentes.

Tabla 3. Conductas para la tarea 2 que fueron presentadas a los expertos y sus observaciones en la primera etapa del juicio de expertos

\begin{tabular}{|c|c|c|}
\hline $\begin{array}{c}\text { Componentes del } \\
\text { sentido espacial }\end{array}$ & Posibles conductas & Observaciones del juez experto \\
\hline $\begin{array}{l}\text { Conceptos y } \\
\text { elementos } \\
\text { geométricos }\end{array}$ & $\begin{array}{l}\text { Menciona: } \\
\text { Ángulos llanos } \\
\text { Puntos } \\
\text { Rectas perpendiculares } \\
\text { Ángulos rectos } \\
\text { Mediatriz } \\
\text { Simetría }\end{array}$ & $\begin{array}{l}\text { Le parecen bien los elementos } \\
\text { geométricos, sin embargo } \\
\text { sugiere eliminar el de } \\
\text { mediatriz. }\end{array}$ \\
\hline $\begin{array}{l}\text { Relaciones } \\
\text { geométricas }\end{array}$ & $\begin{array}{l}\text { Por un punto exterior a una recta } \\
\text { puede construirse una única } \\
\text { perpendicular a dicha recta } \\
\text { Relaciones de medida al doblar el } \\
\text { papel (lados y ángulos) }\end{array}$ & $\begin{array}{l}\text { Sugiere agregar "relaciones de } \\
\text { perpendicularidad entre rectas" }\end{array}$ \\
\hline $\begin{array}{l}\text { Ubicación y } \\
\text { movimiento }\end{array}$ & $\begin{array}{l}\text { Identifica elementos invariantes o } \\
\text { regularidades al doblar } \\
\text { Distingue cuando hacer una rotación } \\
\text { en el espacio con el papel } \\
\text { Ejes de simetría mediante el doblado } \\
\text { de papel } \\
\text { Describe posiciones en el plano } \\
\text { (vértices, lados, ángulos que } \\
\text { coinciden) }\end{array}$ & $\begin{array}{l}\text { Está de acuerdo con las } \\
\text { conductas expuestas (para estas } \\
\text { ya se consideraron algunas } \\
\text { sugerencias propuestas por el } \\
\text { juez en la tarea 1) }\end{array}$ \\
\hline
\end{tabular}


Describe posiciones con respecto a

elementos (Esquinas, interior,

exterior, arriba, mitad...)

Situar los distintos dobleces para

obtener los elementos geométricos

deseados

Tabla 4. Conductas para la tarea 3 que fueron presentadas a los expertos y sus observaciones en la primera etapa del juicio de expertos

\begin{tabular}{|c|c|c|}
\hline $\begin{array}{l}\text { Componentes del } \\
\text { sentido espacial }\end{array}$ & Categorías posibles & $\begin{array}{c}\text { Observaciones del juez } \\
\text { experto }\end{array}$ \\
\hline $\begin{array}{l}\text { Conceptos y elementos } \\
\text { geométricos }\end{array}$ & $\begin{array}{l}\text { Menciona: } \\
\text { Rectas paralelas } \\
\text { Rectas perpendiculares } \\
\text { Puntos } \\
\text { Puntos coplanares } \\
\text { Ángulos rectos } \\
\text { Ángulo llano }\end{array}$ & $\begin{array}{l}\text { El experto concuerda con los } \\
\text { elementos indicados. }\end{array}$ \\
\hline \multirow[t]{4}{*}{ Relaciones geométricas } & $\begin{array}{l}\text { Utiliza el hecho de que si } a \perp b \text { y } \\
b \perp c \Rightarrow a \| b, \text { siempre que } a, b \text { y } \\
c \text { sean coplanares }\end{array}$ & $\begin{array}{l}\text { El experto concuerda con los } \\
\text { elementos indicados. }\end{array}$ \\
\hline & $\begin{array}{l}\text { Relaciones de medida al doblar las } \\
\text { figuras (lados y ángulos) }\end{array}$ & \\
\hline & $\begin{array}{l}\text { Relaciones de paralelismo y } \\
\text { perpendicularidad }\end{array}$ & \\
\hline & $\begin{array}{l}\text { Establecer relaciones entre } \\
\text { longitudes y ángulos con sus } \\
\text { respectivas simetrías }\end{array}$ & \\
\hline \multirow[t]{4}{*}{$\begin{array}{l}\text { Ubicación y } \\
\text { movimiento }\end{array}$} & $\begin{array}{l}\text { Identifica en qué momento realizar } \\
\text { una rotación en el espacio para } \\
\text { obtener los elementos deseados }\end{array}$ & $\begin{array}{l}\text { El experto concuerda con los } \\
\text { elementos indicados. }\end{array}$ \\
\hline & $\begin{array}{l}\text { Identifica ejes de simetría } \\
\text { mediante el doblado de papel }\end{array}$ & \\
\hline & $\begin{array}{l}\text { Situar los distintos dobleces para } \\
\text { obtener los elementos geométricos } \\
\text { deseados }\end{array}$ & \\
\hline & $\begin{array}{l}\text { Describe posiciones en el plano } \\
\text { (vértices, lados, ángulos que } \\
\text { coinciden) }\end{array}$ & \\
\hline
\end{tabular}


Tabla 5. Expertos en Educación Matemática que participaron en la segunda etapa de revisión del sistema de categorías a priori dentro del juicio de expertos

\begin{tabular}{|c|c|c|}
\hline Experto & Institución para la que labora & Tarea que revisó \\
\hline $\begin{array}{l}\text { Doctora Zuleyka Suárez Valdés- } \\
\text { Ayala }\end{array}$ & $\begin{array}{l}\text { Profesora del Instituto } \\
\text { Tecnológico de Costa Rica }\end{array}$ & Tarea 1 \\
\hline Máster Rebeca Solís Ortega & $\begin{array}{l}\text { Profesora del Instituto } \\
\text { Tecnológico de Costa Rica }\end{array}$ & Tarea 3 \\
\hline Máster Marvin Abarca Fuentes & $\begin{array}{l}\text { Profesor del Instituto Tecnológico } \\
\text { de Costa Rica }\end{array}$ & Tarea 1 \\
\hline Máster Reiman Acuña Chacón & $\begin{array}{l}\text { Profesor del Instituto Tecnológico } \\
\text { de Costa Rica y de la Universidad } \\
\text { de Costa Rica }\end{array}$ & Tarea 2 \\
\hline $\begin{array}{l}\text { Licenciado Samuel Valverde } \\
\text { Sánchez }\end{array}$ & $\begin{array}{l}\text { Profesor del Instituto Tecnológico } \\
\text { de Costa Rica }\end{array}$ & Tarea 3 \\
\hline Licenciada Ivonne Sánchez & Profesora del Instituto & Tarea 2 \\
\hline Fernández & $\begin{array}{l}\text { Tecnológico de Costa Rica y de la } \\
\text { Universidad Estatal a Distancia }\end{array}$ & \\
\hline
\end{tabular}

Tabla 6. Categorías y conductas para la tarea 1 que fueron presentadas a los expertos, sus observaciones y criterios de decisión que se tomaron

\begin{tabular}{|c|c|c|c|c|}
\hline $\begin{array}{l}\text { Componentes del } \\
\text { sentido espacial }\end{array}$ & Categorías & Conductas & $\begin{array}{l}\text { Observaciones de los jueces } \\
\text { expertos }\end{array}$ & Criterio de decisión \\
\hline $\begin{array}{l}\text { Conceptos y elementos } \\
\text { geométricos }(\mathrm{CE})\end{array}$ & $\begin{array}{l}\text { CE1: Identifica a través } \\
\text { del nombre elementos } \\
\text { dentro de una estructura } \\
\text { mayor }\end{array}$ & $\begin{array}{l}\text { Menciona o evidencia: } \\
\text { - El concepto de mediatriz } \\
\text { de un segmento } \\
\text { - Ángulos (ángulo llano, } \\
\text { recto) } \\
\text { - Segmentos } \\
\text { - Punto medio } \\
\text { - Eje de simetría } \\
\text { - Recta perpendicular }\end{array}$ & $\begin{array}{l}\text { Por unanimidad ambos } \\
\text { acuerdan que están bien las } \\
\text { categorías y conductas. Un } \\
\text { juez sugiere agregar el } \\
\text { elemento de "triángulo } \\
\text { isósceles". }\end{array}$ & $\begin{array}{l}\text { Se decide considerar todos los } \\
\text { elementos geométricos, inclusive } \\
\text { triángulo, pero no especificando que } \\
\text { sea isósceles, puesto que no es } \\
\text { indispensable para la solución de la } \\
\text { tarea que se reafirme el tipo de } \\
\text { triángulo. }\end{array}$ \\
\hline
\end{tabular}


Relaciones

geométricas (RG)

Ubicación y

movimiento (UM)
RG1: Identifica

elementos geométricos

de las figuras

Menciona o evidencia que:

-Si un punto pertenece a la

mediatriz de un segmento,

equidista de sus extremos

-Si un punto equidista de

los extremos del segmento,

entonces pertenece a la

mediatriz.

- Relaciones sobre

triángulos que son

congruentes (criterios de

congruencia)

RG3: Relaciones de medida al doblar las figuras (área, lados y ángulos)

\section{-Relaciones sobre segmentos o ángulos \\ congruentes.}

-Establecer relaciones entre longitudes y ángulos con sus respectivas simetrías.

UM1: Identifica elementos invariantes o regularidades al doblar

UM2: Sitúa los distintos dobleces para obtener

- Identifica ejes de simetría mediante el doblado del papel
Por unanimidad ambos acuerdan que están bien las categorías y conductas. Un juez sugiere agregar "relación de

perpendicularidad entre la recta y el segmento".

\section{Por unanimidad ambos} acuerdan que están bien las categorías y conductas. Un juez sugiere agregar reemplazar las palabras "respectivas simetrías" por "respectivos elementos simétricos". Otro juez recomienda agregar la palabra "establece" para la primer conducta.

Por unanimidad ambos acuerdan que están bien las categorías y conductas

Por unanimidad ambos acuerdan que están bien las categorías y conductas.
Se decide considerar todas las conductas y agregar "Relaciones de perpendicularidad" y "Relaciones entre segmentos, ángulos o puntos".

Se asume el cambio de redacción y se conservan ambas conductas.

Se decide agregar al menos una conducta para esta categoría por sugerencia de un juez en la tarea 2.

Se decide eliminar la tercera conducta debido a que puede ser incluida en la primera conducta. Además, se decide 
los elementos

geométricos deseados

UM3: Describe

distintas posiciones de

elementos en el plano y

en el espacio
- Realiza rotaciones en el espacio para obtener los ejes de simetría

- Verifica con simetrías que la construcción realizada es una mediatriz

-Describe posiciones en el plano (vértices, lados,

ángulos que coinciden)

-Describe posiciones con respecto a elementos

(esquinas, interior, exterior, arriba, mitad...)

- Describe movimientos

como rotaciones en el

espacio, superposición de

elementos
Uno de los jueces sugiere reemplazar "realizada es una mediatriz" por

"corresponde a la mediatriz

del segmento"

Por unanimidad ambos acuerdan que están bien las categorías y conductas. mejorar la redacción de la segunda conducta de modo que se lea -

"Identifica en qué momento realizar una rotación en el espacio para obtener los elementos geométricos deseados argumentando su razón de ser."

Se decide quedarse con las dos primeras conductas y eliminar la tercera porque podría estar incluida en la primera conducta de UM2.

Tabla 7. Categorías y conductas para la tarea 2 que fueron presentadas a los expertos, sus observaciones y criterios de decisión que se tomaron

\begin{tabular}{|c|c|c|c|c|}
\hline $\begin{array}{l}\text { Componentes del } \\
\text { sentido espacial }\end{array}$ & Categorías & Conductas & $\begin{array}{c}\text { Observaciones de los jueces } \\
\text { expertos }\end{array}$ & Criterio de decisión \\
\hline $\begin{array}{l}\text { Conceptos y } \\
\text { elementos } \\
\text { geométricos (CE) }\end{array}$ & $\begin{array}{l}\text { CE1: Identifica a } \\
\text { través del nombre } \\
\text { elementos dentro de } \\
\text { una estructura mayor }\end{array}$ & $\begin{array}{l}\text { Menciona: } \\
\text { Ángulos llanos } \\
\text { Puntos } \\
\text { Rectas perpendiculares } \\
\text { Ángulos rectos } \\
\text { Simetría } \\
\text { Planos } \\
\text { Puntos colineales }\end{array}$ & $\begin{array}{l}\text { Uno de los jueces sugiere } \\
\text { agregar la palabra "geométricos" } \\
\text { luego de la palabra "elementos" } \\
\text { en esta categoría. Otro juez } \\
\text { sugiere agregar los elementos } \\
\text { puntos homólogos, líneas } \\
\text { homólogas, rotación y puntos } \\
\text { colineales. }\end{array}$ & $\begin{array}{l}\text { Se decide incorporar la palabra } \\
\text { "geométricos" dentro de la } \\
\text { indicación de la categoría. Además, } \\
\text { se decide no considerar los elementos } \\
\text { "planos" y "puntos colineales" } \\
\text { puesto que no son conceptos } \\
\text { indispensables para ser mencionados } \\
\text { en la solución de la tarea. Además, se }\end{array}$ \\
\hline
\end{tabular}




\section{Relaciones}

geométricas (RG)

Ubicación y

movimiento (UM)

\section{RG1: Identifica}

relaciones entre

diversos elementos

geométricos de las

figuras

- Por un punto exterior a una recta puede construirse una única perpendicular a dicha recta.

-Establecer relaciones entre longitudes y ángulos con sus respectivas simetrías
RG2: Relaciones de medida al doblar el papel (lados y ángulos)

UM2: Identificar elementos invariantes o regularidades al doblar

UM2: Sitúa los distintos dobleces y cortes para obtener los elementos geométricos deseados
Uno de los jueces sugiere agregar la palabra "Verifica" al inicio de la primera conducta, además sugiere agregar la conducta de "Describe la relación entre elementos ya construidos con otras figuras geométricas conocidas".

Además, se sugiere agregar que identifique relaciones de perpendicularidad entre segmentos o rectas Y mover la segunda conducta a RG2.

Uno de los jueces sugiere agregar la palabra "Identifica" al inicio de la categoría, además de agregar conductas.

Uno de los jueces sugiere agregar al menos una conducta para esta categoría.

Existe unanimidad sobre las conductas presentadas. decide no considerar la palabra

"simetría" o "rotación" pues serán consideradas en la variables de movimientos.

Se decide tomar la sugerencia de agregar la palabra "verifica".

Además, no se incluye la conducta de "Describe la relación entre elementos ya construidos con otras figuras geométricas conocidas", puesto que se agregan las de "Relaciones de perpendicularidad", "Relaciones entre rectas, puntos, ángulos o segmentos" y se considera que la conducta sugerida está incluida entre esas dos. Además, se toma la sugerencia de mover la segunda conducta a RG2.

Se toma la sugerencia de agregar el "identifica" y se agregan conductas a esta categoría tal y como lo sugiere el juez. Se toman las mismas conductas de RG2 en la tarea 1. 


\begin{tabular}{|c|c|c|c|}
\hline \multirow{3}{*}{$\begin{array}{l}\text { UM3: Describe } \\
\text { distintas posiciones } \\
\text { de elementos en el } \\
\text { plano y en el espacio }\end{array}$} & $\begin{array}{l}\text { - Construye ejes de simetría } \\
\text { mediante el doblado de } \\
\text { papel }\end{array}$ & & \multirow{3}{*}{$\begin{array}{l}\text { Se decide dejar el verbo "describe" } \\
\text { considerando que si "describe" es } \\
\text { porque "identifica". Además, se } \\
\text { toman los mismos criterios de UM3 } \\
\text { de la tarea } 1 \text { para esta categoría. }\end{array}$} \\
\hline & $\begin{array}{l}\text {-Identifica posiciones en el } \\
\text { plano Giros, rotaciones, } \\
\text { traslación }\end{array}$ & $\begin{array}{l}\text { Existe unanimidad sobre las } \\
\text { conductas presentadas, un juez } \\
\text { sugiere cambiar los verbos } \\
\text { "describe" por "identifica". }\end{array}$ & \\
\hline & $\begin{array}{l}\text { - Describe posiciones con } \\
\text { respecto a elementos } \\
\text { (Esquinas, interior, exterior, } \\
\text { arriba, mitad...) (Hacer } \\
\text { salvedad) (puntos, } \\
\text { segmentos, rectas, vértices, } \\
\text { lados, ángulos que } \\
\text { coinciden) }\end{array}$ & & \\
\hline
\end{tabular}

Tabla 8. Categorías y conductas para la tarea 3 que fueron presentadas a los expertos, sus observaciones y criterios de decisión que se tomaron

\begin{tabular}{|c|c|c|c|c|}
\hline Componentes del sentido espacial & Categorías & Conductas & $\begin{array}{c}\text { Observaciones de los jueces } \\
\text { expertos }\end{array}$ & Criterio de decisión \\
\hline $\begin{array}{l}\text { Conceptos y elementos geométricos } \\
\text { (CE) }\end{array}$ & $\begin{array}{l}\text { CE1: Identifica a través del } \\
\text { nombre y la representación } \\
\text { elementos dentro de una } \\
\text { estructura mayor }\end{array}$ & $\begin{array}{l}\text { Menciona: } \\
\text {-Rectas paralelas } \\
\text {-Rectas perpendiculares } \\
\text {-Puntos } \\
\text {-Puntos coplanares } \\
\text {-Ángulos rectos } \\
\text {-Ángulo llano }\end{array}$ & $\begin{array}{l}\text { Por unanimidad los jueces } \\
\text { están de acuerdo con los } \\
\text { conceptos. Uno de los } \\
\text { jueces sugiere agregar } \\
\text { "intersección entre rectas", } \\
\text { "eje de simetría", "puntos } \\
\text { homólogos". }\end{array}$ & $\begin{array}{l}\text { El resto de palabras no se } \\
\text { consideran fundamentales } \\
\text { dentro de la resolución de } \\
\text { la tarea. }\end{array}$ \\
\hline Relaciones geométricas (RG) & $\begin{array}{l}\text { RG1: Identifica relaciones entre } \\
\text { diversos elementos geométricos } \\
\text { de las figuras }\end{array}$ & $\begin{array}{l}\text {-Utiliza el hecho de que si } \\
a \perp b \text { y } b \perp c \Rightarrow a \| b, \\
\text { siempre que } a, b \text { y } c \text { sean } \\
\text { rectas coplanares }\end{array}$ & $\begin{array}{l}\text { Por unanimidad los jueces } \\
\text { están de acuerdo con las } \\
\text { relaciones. }\end{array}$ & $\begin{array}{l}\text { Tomando en cuenta, } \\
\text { recomendaciones de jueces } \\
\text { en las tareas } 1 \text { y } 2 \text {, se } \\
\text { decide agregar: }\end{array}$ \\
\hline
\end{tabular}


-Establecer relaciones

entre longitudes y

ángulos con sus

respectivas simetrías

RG2: Relaciones de medida al doblar las figuras (área, lados y ángulos)

Ubicación y movimiento (UM)
UM1: Identifica elementos invariantes o regularidades al doblar

UM2: Sitúa los distintos dobleces y cortes para obtener los elementos geométricos deseados
- Identifica en qué momento realizar una rotación en el espacio
"Relaciones de perpendicularidad" "Relaciones de paralelismo"

"Relaciones entre

segmentos, puntos, rectas o ángulos que no impliquen medida".

No se acepta combinar

de los jueces sug combinar RG1 con RG2. El otro juez le parece bien la categoría.

Uno de los jueces considera que es dudosa la palabra "regularidades" que es mejor cambiarla por "variantes":

Uno de los jueces solicita eliminar las palabras "y cortes de la categoría".
RG1 con RG2, pues quiere separarse aquellas

relaciones que evocan medida con aquellas que

no. Además, anteriormente en esta categoría ningún juez ha sugerido eso. Se toman sugerencias de los expertos anteriores y se decide agregar conductas para esta categoría,

tomando las mismas conductas de RG2 de las tareas 1 y 2 .

Se considera pertinente el cambio propuesto y se corrige en las dos tareas anteriores, además se agrega una conducta tal y como han sugerido jueces en las tareas anteriores.

Se asume debido a que es un error de copiar la categoría de otras que se 
UM3: Describe distintas

posiciones de elementos en el

plano y en el espacio para obtener los

elementos geométricos

deseados

- Identifica ejes de simetría mediante el

doblado del papel

-Describe posiciones en el plano (vértices, lados, ángulos que coinciden)

-Describe posiciones con respecto a elementos

(Esquinas, interior,

exterior, arriba, mitad...) conducta las palabras abajo,

en el medio.
Ambos jueces están de acuerdo con ambas conductas.

habían tomado para otro instrumento que se había seleccionado.

Ambos jueces están de acuerdo con ambas conductas, uno sugiere agregar en la segunda

Se toma la sugerencia propuesta y se incluye en el resto de tareas también. 


\section{ANEXO C. COMPONENTES DEL SENTIDO ESPACIAL:}

\section{CATEGORÍAS Y CONDUCTAS MANIFESTADAS POR}

\section{CADA UNO DE LOS FUTUROS PROFESORES}

Tabla 1. Conceptos y elementos geométricos manifestados por cada futuro profesor al resolver la tarea 1

\begin{tabular}{|c|c|c|c|c|c|c|c|c|}
\hline \multirow{2}{*}{$\begin{array}{l}\text { Elementos o } \\
\text { conceptos } \\
\text { geométricos }\end{array}$} & \multicolumn{6}{|c|}{ Futuros profesores } & \multirow{2}{*}{$\begin{array}{c}\text { Cantidad de } \\
\text { participantes que lo } \\
\text { manifiestan }\end{array}$} & \multirow{2}{*}{$\begin{array}{l}\text { Porcentaje } \\
\text { de } \\
\text { participantes } \\
\text { que lo } \\
\text { manifiestan }\end{array}$} \\
\hline & $\mathrm{AD}$ & $\mathrm{CH}$ & DA & JP & $\mathrm{PE}$ & YK & & \\
\hline Ángulo recto & & & & $\mathrm{X}$ & $\mathrm{X}$ & $\mathrm{X}$ & 3 & $50 \%$ \\
\hline Bisectriz & & $X$ & & & & & 1 & $16.67 \%$ \\
\hline Congruencia & & $\mathrm{X}$ & $\mathrm{X}$ & & $X$ & $\mathrm{X}$ & 4 & $66.67 \%$ \\
\hline Lado & & $X$ & & & & & 1 & $16.67 \%$ \\
\hline Mediatriz & $X$ & $\mathrm{X}$ & & $\mathrm{X}$ & $X$ & $\mathrm{X}$ & 5 & $83.33 \%$ \\
\hline Punto & $X$ & $X$ & $\mathrm{X}$ & $\mathrm{X}$ & $X$ & $\mathrm{X}$ & 6 & $100 \%$ \\
\hline $\begin{array}{l}\text { Punto } \\
\text { equidistante }\end{array}$ & & $\mathrm{X}$ & & & & & 1 & $16.67 \%$ \\
\hline Punto medio & $X$ & $\mathrm{X}$ & & $\mathrm{X}$ & $X$ & $\mathrm{X}$ & 5 & $83.33 \%$ \\
\hline $\begin{array}{l}\text { Recta } \\
\text { perpendicular }\end{array}$ & $X$ & $X$ & & $\mathrm{X}$ & $X$ & $\mathrm{X}$ & 5 & $83.33 \%$ \\
\hline Recta oblicua & & $\mathrm{X}$ & & & & & 1 & $16.67 \%$ \\
\hline Segmento & $X$ & X & $\mathrm{X}$ & $\mathrm{X}$ & $X$ & $\mathrm{X}$ & 6 & $100 \%$ \\
\hline $\begin{array}{l}\text { Triángulo } \\
\text { equilátero }\end{array}$ & & $\mathrm{X}$ & & & & & 1 & $16.67 \%$ \\
\hline Vértice & & $\mathrm{X}$ & & $\mathrm{X}$ & & & 2 & $33.33 \%$ \\
\hline $\begin{array}{l}\text { Número de } \\
\text { conceptos o } \\
\text { elementos } \\
\text { utilizados }\end{array}$ & 5 & 12 & 3 & 7 & 7 & 7 & & \\
\hline
\end{tabular}

Tabla 2. Conceptos y elementos geométricos manifestados por cada futuro profesor al resolver la tarea 2

\begin{tabular}{|c|c|c|c|c|c|c|c|c|}
\hline \multirow{2}{*}{$\begin{array}{l}\text { Elementos o } \\
\text { conceptos } \\
\text { geométricos }\end{array}$} & \multicolumn{6}{|c|}{ Futuros profesores } & \multirow{2}{*}{$\begin{array}{l}\text { Cantidad de } \\
\text { participantes que } \\
\text { lo manifiestan }\end{array}$} & \multirow{2}{*}{$\begin{array}{l}\text { Porcentaje de } \\
\text { estudiantes que } \\
\text { lo manifiestan }\end{array}$} \\
\hline & $\mathrm{AD}$ & $\mathrm{CH}$ & DA & JP & $\mathrm{PE}$ & YK & & \\
\hline Altura & & & & & $\mathrm{X}$ & & 1 & $16.67 \%$ \\
\hline Ángulo Llano & & & $X$ & & $X$ & & 2 & $33.33 \%$ \\
\hline Ángulo recto & $X$ & $\mathrm{X}$ & $X$ & $X$ & $X$ & & 5 & $83.33 \%$ \\
\hline Congruencia & & $\mathrm{X}$ & & & & $X$ & 2 & $33.33 \%$ \\
\hline Cuadrado & & & & & $X$ & & 1 & $16.67 \%$ \\
\hline Lado & & & & & $\mathrm{X}$ & & 1 & $16.67 \%$ \\
\hline Mediatriz & & & & & & $X$ & 1 & $16.67 \%$ \\
\hline
\end{tabular}




\begin{tabular}{|c|c|c|c|c|c|c|c|c|}
\hline Punto & X & $\mathrm{X}$ & $X$ & $\mathrm{X}$ & $X$ & $X$ & 6 & $100 \%$ \\
\hline $\begin{array}{l}\text { Punto } \\
\text { homólogo }\end{array}$ & X & & & & & X & 2 & $33.33 \%$ \\
\hline Punto medio & & & & & & $X$ & 1 & $16.67 \%$ \\
\hline Recta & $\mathrm{X}$ & $\mathrm{X}$ & $X$ & $X$ & $X$ & $X$ & 6 & $100 \%$ \\
\hline $\begin{array}{l}\text { Recta } \\
\text { perpendicular }\end{array}$ & $\mathrm{X}$ & $\mathrm{X}$ & $X$ & $\mathrm{X}$ & $X$ & $X$ & 6 & $100 \%$ \\
\hline Segmento & & $\mathrm{X}$ & $X$ & & $X$ & $X$ & 4 & $66.67 \%$ \\
\hline Triángulo & & & & & & X & 1 & $16.67 \%$ \\
\hline $\begin{array}{l}\text { Número de } \\
\text { conceptos o } \\
\text { elementos } \\
\text { utilizados }\end{array}$ & 5 & 6 & 6 & 4 & 9 & 9 & & \\
\hline
\end{tabular}

Tabla 3. Conceptos y elementos geométricos manifestados por cada futuro profesor al resolver la tarea 3

\begin{tabular}{|c|c|c|c|c|c|c|c|c|}
\hline \multirow{2}{*}{$\begin{array}{l}\text { Elementos o } \\
\text { conceptos } \\
\text { geométricos }\end{array}$} & \multicolumn{6}{|c|}{ Futuros profesores } & \multirow{2}{*}{$\begin{array}{c}\text { Cantidad de } \\
\text { participantes que } \\
\text { lo manifiestan }\end{array}$} & \multirow{2}{*}{$\begin{array}{c}\text { Porcentaje de } \\
\text { participantes } \\
\text { que lo } \\
\text { manifiestan }\end{array}$} \\
\hline & $\mathrm{AD}$ & $\mathrm{CH}$ & DA & JP & $\mathrm{PE}$ & YK & & \\
\hline Congruencia & & & $\mathrm{X}$ & & & & 1 & $16.67 \%$ \\
\hline Mediatriz & & & & & & $X$ & 1 & $16.67 \%$ \\
\hline Punto & $X$ & $X$ & $X$ & $X$ & $X$ & $X$ & 6 & $100 \%$ \\
\hline Punto medio & & & & & & $X$ & 1 & $16.67 \%$ \\
\hline Recta & $X$ & $X$ & $X$ & $X$ & X & $X$ & 6 & $100 \%$ \\
\hline Recta paralela & $\mathrm{X}$ & $\mathrm{X}$ & $X$ & $X$ & $X$ & $\mathrm{X}$ & 6 & $100 \%$ \\
\hline $\begin{array}{l}\text { Recta } \\
\text { perpendicular }\end{array}$ & $\mathrm{X}$ & $\mathrm{X}$ & $\mathrm{X}$ & $X$ & $X$ & $X$ & 6 & $100 \%$ \\
\hline Recta oblicua & & & $\mathrm{X}$ & $X$ & & & 2 & $33.33 \%$ \\
\hline Segmento & & & & & & $\mathrm{X}$ & 1 & $16.67 \%$ \\
\hline $\begin{array}{l}\text { Número de } \\
\text { conceptos o } \\
\text { elementos } \\
\text { utilizados }\end{array}$ & 4 & 4 & 6 & 5 & 4 & 7 & & \\
\hline
\end{tabular}


Tabla 4. Relaciones geométricas manifestadas por cada futuro profesores al resolver la tarea 1

\begin{tabular}{|c|c|c|c|c|c|c|c|c|c|}
\hline \multirow[b]{2}{*}{ Categoría } & \multirow[b]{2}{*}{ Relaciones } & \multicolumn{6}{|c|}{ Futuros profesores } & \multirow{2}{*}{$\begin{array}{l}\text { Cantidad de } \\
\text { participantes } \\
\text { que lo } \\
\text { manifiestan }\end{array}$} & \multirow{2}{*}{$\begin{array}{l}\text { Porcentaje } \\
\text { de } \\
\text { participantes } \\
\text { que lo } \\
\text { manifiestan } \\
\end{array}$} \\
\hline & & $\mathrm{AD}$ & $\mathrm{CH}$ & DA & JP & PE & YK & & \\
\hline \multirow{7}{*}{$\begin{array}{l}\text { RG1: } \\
\text { Identifica } \\
\text { relaciones } \\
\text { entre } \\
\text { diversos } \\
\text { elementos } \\
\text { geométricos. }\end{array}$} & $\begin{array}{l}\text { Relaciones entre } \\
\text { puntos. }\end{array}$ & $\mathrm{X}$ & $X$ & $\mathrm{X}$ & $X$ & $\mathrm{X}$ & $\mathrm{X}$ & 6 & $100 \%$ \\
\hline & $\begin{array}{l}\text { Relaciones entre } \\
\text { segmentos. }\end{array}$ & $\mathrm{X}$ & $X$ & $\mathrm{X}$ & $X$ & $X$ & $\mathrm{X}$ & 6 & $100 \%$ \\
\hline & $\begin{array}{l}\text { Relaciones entre } \\
\text { ángulos. }\end{array}$ & & & & & & $\mathrm{X}$ & 1 & $16.67 \%$ \\
\hline & $\begin{array}{l}\text { Relaciones de } \\
\text { perpendicularidad. }\end{array}$ & $\mathrm{X}$ & $\mathrm{X}$ & & $\mathrm{X}$ & $\mathrm{X}$ & $\mathrm{X}$ & 5 & $83.33 \%$ \\
\hline & $\begin{array}{l}\text { Si un punto } \\
\text { pertenece a la } \\
\text { mediatriz de un } \\
\text { segmento, equidista } \\
\text { de sus extremos. }\end{array}$ & & $\mathrm{X}$ & & & & & 1 & $16.67 \%$ \\
\hline & $\begin{array}{l}\text { La mediatriz es } \\
\text { bisectriz en un } \\
\text { triángulo equilátero. }\end{array}$ & & $\mathrm{X}$ & & & & & 1 & $16.67 \%$ \\
\hline & $\begin{array}{l}\text { Unicidad de la } \\
\text { mediatriz. }\end{array}$ & & $X$ & & & & & 1 & $16.67 \%$ \\
\hline $\begin{array}{l}\text { RG2: } \\
\text { Identifica } \\
\text { relaciones }\end{array}$ & $\begin{array}{l}\text { Relación de medida } \\
\text { de segmentos al } \\
\text { doblar. }\end{array}$ & & & & & & & & \\
\hline $\begin{array}{l}\text { de medida al } \\
\text { doblar el } \\
\text { papel. }\end{array}$ & & & $\mathrm{X}$ & & $\mathrm{X}$ & $\mathrm{X}$ & $\mathrm{X}$ & 4 & $66.67 \%$ \\
\hline \multicolumn{10}{|c|}{ Cantidad de relaciones manifestadas } \\
\hline & & 3 & 7 & 2 & 4 & 4 & 5 & & \\
\hline
\end{tabular}


Tabla 5. Relaciones geométricas manifestadas por cada futuro profesor al resolver la tarea 2

\begin{tabular}{|c|c|c|c|c|c|c|c|c|c|}
\hline \multirow[b]{2}{*}{ Categoría } & \multirow[b]{2}{*}{ Relaciones } & \multicolumn{6}{|c|}{ Futuros profesores } & \multirow{2}{*}{$\begin{array}{l}\text { Cantidad de } \\
\text { participantes } \\
\text { que lo } \\
\text { manifiestan }\end{array}$} & \multirow{2}{*}{$\begin{array}{l}\text { Porcentaje } \\
\text { de los } \\
\text { estudiantes } \\
\text { que lo } \\
\text { manifiesta }\end{array}$} \\
\hline & & $\mathrm{AD}$ & $\mathrm{CH}$ & DA & JP & PE & YK & & \\
\hline \multirow{6}{*}{$\begin{array}{l}\text { RG1: } \\
\text { Identifica } \\
\text { relaciones } \\
\text { entre } \\
\text { diversos } \\
\text { elementos } \\
\text { geométricos. }\end{array}$} & Relaciones entre puntos. & $X$ & & & & & $X$ & 2 & $33.33 \%$ \\
\hline & $\begin{array}{l}\text { Relaciones entre } \\
\text { segmentos de recta. }\end{array}$ & & $X$ & $X$ & & $X$ & & 3 & $50 \%$ \\
\hline & $\begin{array}{l}\text { Relaciones entre rectas } \\
\text { y puntos. }\end{array}$ & $X$ & $X$ & $\mathrm{X}$ & $X$ & $X$ & $X$ & 6 & $100 \%$ \\
\hline & $\begin{array}{l}\text { Relaciones de } \\
\text { perpendicularidad. }\end{array}$ & $X$ & $\mathrm{X}$ & $\mathrm{X}$ & $X$ & $X$ & $\mathrm{X}$ & 6 & $100 \%$ \\
\hline & $\begin{array}{l}\text { La recta que pasa por un } \\
\text { punto y es perpendicular } \\
\text { a otra recta es única. }\end{array}$ & & $\mathrm{X}$ & & & $\mathrm{X}$ & & 2 & $33.33 \%$ \\
\hline & $\begin{array}{l}\text { Los lados adyacentes de } \\
\text { un cuadrado son } \\
\text { perpendiculares. }\end{array}$ & & & & & $\mathrm{X}$ & & 1 & $16.67 \%$ \\
\hline \multirow{3}{*}{$\begin{array}{l}\text { RG2: } \\
\text { Identifica } \\
\text { relaciones } \\
\text { de medida al } \\
\text { doblar el } \\
\text { papel. }\end{array}$} & $\begin{array}{l}\text { Relación de medida de } \\
\text { segmentos al doblar. }\end{array}$ & & & & & & $\mathrm{X}$ & 1 & $16.67 \%$ \\
\hline & $\begin{array}{l}\text { Relación de medida de } \\
\text { ángulos al doblar. }\end{array}$ & & & $X$ & & $X$ & & 2 & $33.33 \%$ \\
\hline & $\begin{array}{l}\text { Establecer relaciones } \\
\text { entre longitudes con sus } \\
\text { respectivas simetrías. }\end{array}$ & $\mathrm{X}$ & $\mathrm{X}$ & & & $X$ & $\mathrm{X}$ & 4 & $66.67 \%$ \\
\hline \multicolumn{10}{|c|}{ Cantidad de relaciones manifestadas } \\
\hline & & 4 & 5 & 4 & 2 & 7 & 5 & & \\
\hline
\end{tabular}


Tabla 6. Relaciones geométricas manifestadas por cada futuro profesor al resolver la tarea 3

\begin{tabular}{|c|c|c|c|c|c|c|c|c|c|}
\hline \multirow{2}{*}{ Categoría } & \multirow{2}{*}{ Relaciones } & \multicolumn{6}{|c|}{ Futuros profesores } & \multirow{2}{*}{$\begin{array}{l}\text { Cantidad de } \\
\text { participantes } \\
\text { que lo } \\
\text { manifiestan }\end{array}$} & \multirow{2}{*}{$\begin{array}{l}\text { Porcentaje } \\
\text { de } \\
\text { participantes } \\
\text { que lo } \\
\text { manifiesta }\end{array}$} \\
\hline & & $\mathrm{AD}$ & $\mathrm{CH}$ & $\mathrm{DA}$ & JP & PE & YK & & \\
\hline \multirow{7}{*}{$\begin{array}{l}\text { RG1: } \\
\text { Identifica } \\
\text { relaciones } \\
\text { entre } \\
\text { diversos } \\
\text { elementos } \\
\text { geométricos. }\end{array}$} & $\begin{array}{l}\text { Relaciones entre } \\
\text { puntos. }\end{array}$ & $X$ & & & & & $\mathrm{X}$ & 2 & $33.33 \%$ \\
\hline & $\begin{array}{l}\text { Relaciones entre } \\
\text { segmentos de recta. }\end{array}$ & & $X$ & $X$ & $\mathrm{X}$ & $X$ & $\mathrm{X}$ & 5 & $83.33 \%$ \\
\hline & $\begin{array}{l}\text { Relaciones entre rectas } \\
\text { y puntos. }\end{array}$ & $\mathrm{X}$ & $\mathrm{X}$ & X & $X$ & $X$ & & 5 & $83.33 \%$ \\
\hline & $\begin{array}{l}\text { Relaciones de } \\
\text { perpendicularidad. }\end{array}$ & X & X & X & X & X & $X$ & 6 & $100 \%$ \\
\hline & $\begin{array}{l}\text { Establece relaciones de } \\
\text { paralelismo. }\end{array}$ & X & X & X & $X$ & X & X & 6 & $100 \%$ \\
\hline & $\begin{array}{l}\text { Establece relaciones } \\
\text { entre rectas oblicuas. }\end{array}$ & X & & X & & & X & 3 & $50 \%$ \\
\hline & $\begin{array}{l}\text { Utiliza el hecho de que } \\
\text { si } a \perp b \text { y } b \perp c \Rightarrow a \| b, \\
\text { siempre que } a, b \text { y c } \\
\text { sean rectas coplanares. }\end{array}$ & & $\mathrm{X}$ & $\mathrm{X}$ & $\mathrm{X}$ & $X$ & & 4 & $66.67 \%$ \\
\hline $\begin{array}{l}\text { RG2: } \\
\text { Identifica } \\
\text { relaciones }\end{array}$ & $\begin{array}{l}\text { Relación de medida de } \\
\text { segmentos al doblar. }\end{array}$ & $\mathrm{X}$ & & $\mathrm{X}$ & & & $X$ & 3 & $50 \%$ \\
\hline $\begin{array}{l}\text { de medida al } \\
\text { doblar el } \\
\text { papel. }\end{array}$ & $\begin{array}{l}\text { Establecer relaciones } \\
\text { entre longitudes con sus } \\
\text { respectivas simetrías. }\end{array}$ & & & & & & $\mathrm{X}$ & 1 & $16.67 \%$ \\
\hline \multicolumn{10}{|c|}{ Cantidad de relaciones manifestadas } \\
\hline & & 6 & 5 & 7 & 5 & 5 & 7 & & \\
\hline
\end{tabular}


Tabla 7. Movimientos manifestados por cada futuro profesor al resolver la tarea 1

\begin{tabular}{|c|c|c|c|c|c|c|c|c|}
\hline \multirow[t]{2}{*}{ Movimiento } & \multicolumn{6}{|c|}{ Futuros profesores } & \multirow{2}{*}{$\begin{array}{c}\text { Cantidad de } \\
\text { participantes } \\
\text { que lo } \\
\text { manifiestan }\end{array}$} & \multirow{2}{*}{$\begin{array}{c}\text { Porcentaje de } \\
\text { participantes } \\
\text { que lo } \\
\text { manifiestan }\end{array}$} \\
\hline & $\mathrm{AD}$ & $\mathrm{CH}$ & DA & JP & PE & YK & & \\
\hline Rotaciones & & & & & & & 0 & $0 \%$ \\
\hline Simetría & & & & & $X$ & & & $16.67 \%$ \\
\hline $\begin{array}{l}\text { Cantidad de movimientos } \\
\text { manifestados }\end{array}$ & & & & & 1 & & & \\
\hline
\end{tabular}

Tabla 8. Movimientos manifestados por cada futuro profesor al resolver la tarea 2

\begin{tabular}{|c|c|c|c|c|c|c|c|c|}
\hline \multirow[t]{2}{*}{ Movimiento } & \multicolumn{6}{|c|}{ Futuros profesores } & \multirow{2}{*}{$\begin{array}{c}\text { Cantidad de } \\
\text { participantes que } \\
\text { lo manifiestan }\end{array}$} & \multirow{2}{*}{$\begin{array}{c}\text { Porcentaje de } \\
\text { participantes } \\
\text { que lo } \\
\text { manifiestan }\end{array}$} \\
\hline & $\mathrm{AD}$ & $\mathrm{CH}$ & DA & JP & $\mathrm{PE}$ & YK & & \\
\hline Rotaciones & & & $\mathrm{X}$ & & & & 1 & $16.67 \%$ \\
\hline Simetría & $\mathrm{X}$ & $\mathrm{X}$ & & & $\mathrm{X}$ & $\mathrm{X}$ & 4 & $66.67 \%$ \\
\hline $\begin{array}{l}\text { Cantidad de movimientos } \\
\text { manifestados }\end{array}$ & 1 & 1 & 1 & & 1 & 1 & & \\
\hline
\end{tabular}

Tabla 9. Movimientos manifestados por cada futuro profesor al resolver la tarea 3

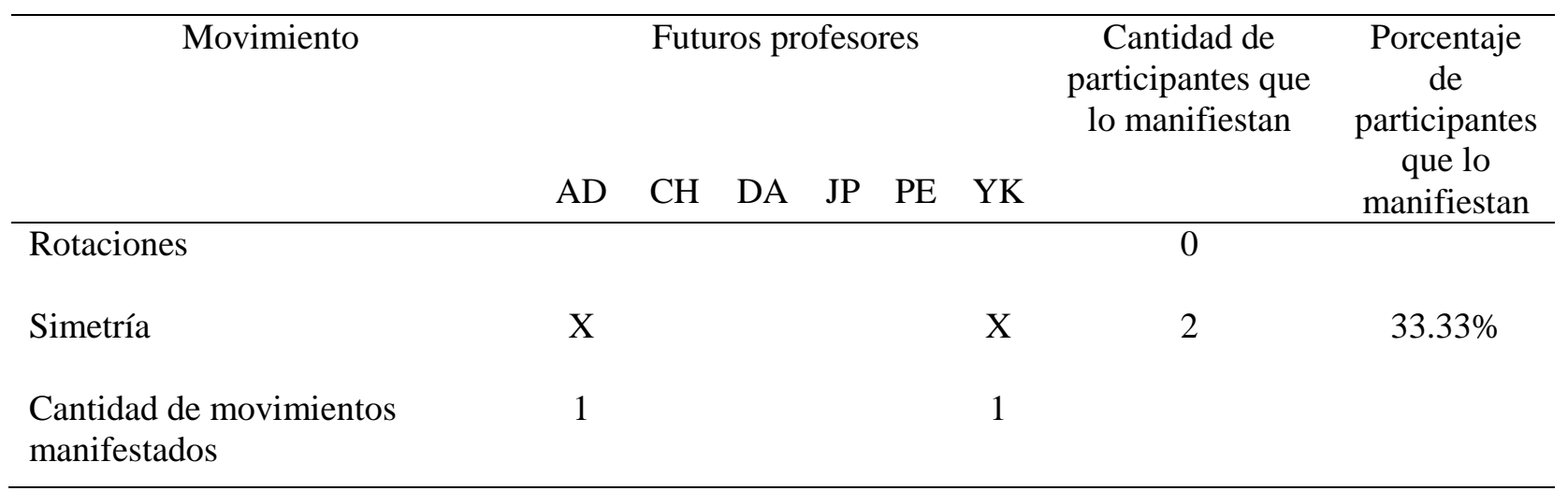


Tabla 10. Ubicación y movimientos manifestados por cada futuro profesor al resolver la tarea 1

\begin{tabular}{|c|c|c|c|c|c|c|c|c|c|}
\hline \multirow[t]{2}{*}{ Categoría } & \multirow[t]{2}{*}{ Conductas } & \multicolumn{6}{|c|}{ Futuros profesores } & \multirow{2}{*}{$\begin{array}{l}\text { Cantidad de } \\
\text { participantes } \\
\text { que lo } \\
\text { manifiestan }\end{array}$} & \multirow{2}{*}{$\begin{array}{l}\text { Porcentaje } \\
\text { de } \\
\text { estudiantes } \\
\text { que lo } \\
\text { manifiestan }\end{array}$} \\
\hline & & $\mathrm{AD}$ & $\mathrm{CH}$ & DA & $\mathrm{JP}$ & PE & YK & & \\
\hline $\begin{array}{l}\text { UM1: } \\
\text { Identifica } \\
\text { elementos } \\
\text { invariantes } \\
\text { o variantes } \\
\text { al doblar. }\end{array}$ & $\begin{array}{l}\text { Distingue diferencias } \\
\text { o similitudes entre } \\
\text { elementos } \\
\text { geométricos después } \\
\text { de realizar } \\
\text { movimientos o } \\
\text { cambiar la ubicación. }\end{array}$ & $\mathrm{X}$ & $\mathrm{X}$ & $\mathrm{X}$ & $\mathrm{X}$ & $\mathrm{X}$ & $\mathrm{X}$ & 6 & $100 \%$ \\
\hline \multirow[t]{2}{*}{$\begin{array}{l}\text { UM2: Sitúa } \\
\text { los distintos } \\
\text { dobleces } \\
\text { para } \\
\text { obtener los } \\
\text { elementos } \\
\text { geométricos } \\
\text { deseados. }\end{array}$} & $\begin{array}{l}\text { Identifica en qué } \\
\text { momento realizar una } \\
\text { rotación en el espacio } \\
\text { para obtener los } \\
\text { elementos } \\
\text { geométricos deseados } \\
\text { argumentando } \\
\text { geométricamente su } \\
\text { movimiento. }\end{array}$ & & & & & & & & $0 \%$ \\
\hline & $\begin{array}{l}\text { Identifica ejes de } \\
\text { simetría mediante el } \\
\text { doblado del papel. }\end{array}$ & & & & & $\mathrm{X}$ & & 1 & $16,67 \%$ \\
\hline \multirow{2}{*}{$\begin{array}{l}\text { UM3: } \\
\text { Describe } \\
\text { distintas } \\
\text { posiciones } \\
\text { de } \\
\text { elementos } \\
\text { en el plano } \\
\text { y en el } \\
\text { espacio }\end{array}$} & $\begin{array}{l}\text { Describe posiciones } \\
\text { en el plano (puntos, } \\
\text { vértices, segmentos o } \\
\text { ángulos que } \\
\text { coinciden). }\end{array}$ & $X$ & $X$ & $X$ & $X$ & $\mathrm{X}$ & $X$ & 6 & $100 \%$ \\
\hline & $\begin{array}{l}\text { Describe posiciones } \\
\text { con respecto a } \\
\text { elementos (esquinas, } \\
\text { interior, exterior, } \\
\text { arriba, mitad, abajo, } \\
\text { en el medio). }\end{array}$ & $X$ & $X$ & $X$ & $\mathrm{X}$ & $\mathrm{X}$ & $X$ & 6 & $100 \%$ \\
\hline \multicolumn{2}{|c|}{$\begin{array}{l}\text { Cantidad de ubicaciones y } \\
\text { movimientos manifestados }\end{array}$} & 3 & 3 & 3 & 3 & 4 & 3 & & \\
\hline
\end{tabular}


Tabla 11. Ubicación y movimientos manifestados por cada futuro profesor al resolver la tarea 2

\begin{tabular}{|c|c|c|c|c|c|c|c|c|c|}
\hline \multirow[t]{2}{*}{ Categoría } & \multirow[t]{2}{*}{ Conductas } & \multicolumn{6}{|c|}{ Futuros profesores } & \multirow{2}{*}{$\begin{array}{c}\text { Cantidad de } \\
\text { participantes } \\
\text { que lo } \\
\text { manifiestan }\end{array}$} & \multirow[b]{2}{*}{$\begin{array}{l}\text { Porcentaje } \\
\text { de } \\
\text { participantes } \\
\text { que lo } \\
\text { manifiestan } \\
\end{array}$} \\
\hline & & $\mathrm{AD}$ & $\mathrm{CH}$ & $\mathrm{DA}$ & JP & PE & YK & & \\
\hline $\begin{array}{l}\text { UM1: } \\
\text { Identifica } \\
\text { elementos } \\
\text { invariantes } \\
\text { o variantes } \\
\text { al doblar. }\end{array}$ & $\begin{array}{l}\text { Distingue diferencias o } \\
\text { similitudes entre } \\
\text { elementos geométricos } \\
\text { después de realizar } \\
\text { movimientos o cambiar } \\
\text { la ubicación. }\end{array}$ & & $\mathrm{X}$ & $\mathrm{X}$ & $\mathrm{X}$ & $X$ & & 4 & $66.67 \%$ \\
\hline \multirow[t]{2}{*}{$\begin{array}{l}\text { UM2: Sitúa } \\
\text { los distintos } \\
\text { dobleces } \\
\text { para } \\
\text { obtener los } \\
\text { elementos } \\
\text { geométricos } \\
\text { deseados. }\end{array}$} & $\begin{array}{l}\text { Identifica en qué } \\
\text { momento realizar una } \\
\text { rotación en el espacio } \\
\text { para obtener los } \\
\text { elementos geométricos } \\
\text { argumentando } \\
\text { geométricamente su } \\
\text { movimiento. }\end{array}$ & & & $\mathrm{X}$ & & & & 1 & $16.67 \%$ \\
\hline & $\begin{array}{l}\text { Identifica ejes de } \\
\text { simetría mediante el } \\
\text { doblado del papel. }\end{array}$ & $\mathrm{X}$ & $\mathrm{X}$ & & & $\mathrm{X}$ & $\mathrm{X}$ & 4 & $66.67 \%$ \\
\hline \multirow{2}{*}{$\begin{array}{l}\text { UM3: } \\
\text { Describe } \\
\text { distintas } \\
\text { posiciones } \\
\text { de } \\
\text { elementos } \\
\text { en el plano } \\
\text { y en el } \\
\text { espacio }\end{array}$} & $\begin{array}{l}\text { Describe posiciones en } \\
\text { el plano (puntos, } \\
\text { segmentos, vértices o } \\
\text { ángulos que coinciden } \\
\text { o se superponen). }\end{array}$ & $\mathrm{X}$ & $\mathrm{X}$ & $\mathrm{X}$ & $\mathrm{X}$ & $X$ & $\mathrm{X}$ & 6 & $100 \%$ \\
\hline & $\begin{array}{l}\text { Describe posiciones } \\
\text { con respecto a } \\
\text { elementos (esquinas, } \\
\text { interior, exterior, arriba, } \\
\text { mitad, abajo, en el } \\
\text { medio). }\end{array}$ & $\mathrm{X}$ & $\mathrm{X}$ & $\mathrm{X}$ & $\mathrm{X}$ & $X$ & $\mathrm{X}$ & 6 & $100 \%$ \\
\hline \multicolumn{2}{|c|}{ Cantidad de categorías manifestadas } & 3 & 4 & 4 & 3 & 4 & 3 & & \\
\hline
\end{tabular}


Tabla 12. Ubicación y movimientos manifestados por cada futuro profesor al resolver la tarea 3

\begin{tabular}{|c|c|c|c|c|c|c|c|c|c|}
\hline \multirow[b]{2}{*}{ Categoría } & \multirow[b]{2}{*}{ Conductas } & \multicolumn{6}{|c|}{ Futuros profesores } & \multirow{2}{*}{$\begin{array}{l}\text { Cantidad de } \\
\text { participantes } \\
\text { que lo } \\
\text { manifiestan }\end{array}$} & \multirow{2}{*}{$\begin{array}{l}\text { Porcentaje } \\
\text { de } \\
\text { estudiantes } \\
\text { que lo } \\
\text { manifiesta }\end{array}$} \\
\hline & & $\mathrm{AD}$ & $\mathrm{CH}$ & DA & JP & PE & YK & & \\
\hline $\begin{array}{l}\text { UM1: } \\
\text { Identifica } \\
\text { elementos } \\
\text { invariantes } \\
\text { o variantes } \\
\text { al doblar. }\end{array}$ & $\begin{array}{l}\text { Distingue diferencias o } \\
\text { similitudes entre } \\
\text { elementos geométricos } \\
\text { después de realizar } \\
\text { movimientos o cambiar la } \\
\text { ubicación. }\end{array}$ & $\mathrm{X}$ & & $\mathrm{X}$ & $\mathrm{X}$ & & $\mathrm{X}$ & 4 & $66.67 \%$ \\
\hline \multirow[t]{2}{*}{$\begin{array}{l}\text { UM2: Sitúa } \\
\text { los distintos } \\
\text { dobleces } \\
\text { para } \\
\text { obtener los } \\
\text { elementos } \\
\text { geométricos } \\
\text { deseados. }\end{array}$} & $\begin{array}{l}\text { Identifica en qué } \\
\text { momento realizar una } \\
\text { rotación en el espacio } \\
\text { para obtener los } \\
\text { elementos geométricos } \\
\text { deseados argumentando } \\
\text { geométricamente su } \\
\text { movimiento. }\end{array}$ & & & & & & & & $0 \%$ \\
\hline & $\begin{array}{l}\text { Identifica ejes de simetría } \\
\text { mediante el doblado del } \\
\text { papel. }\end{array}$ & $X$ & & & & & $X$ & & $33.33 \%$ \\
\hline \multirow{2}{*}{$\begin{array}{l}\text { UM3: } \\
\text { Describe } \\
\text { distintas } \\
\text { posiciones } \\
\text { de } \\
\text { elementos } \\
\text { en el plano } \\
\text { y en el } \\
\text { espacio }\end{array}$} & $\begin{array}{l}\text { Describe posiciones en el } \\
\text { plano (puntos, } \\
\text { segmentos, vértices o } \\
\text { ángulos que coinciden o } \\
\text { se superponen) }\end{array}$ & $\mathrm{X}$ & $\mathrm{X}$ & $X$ & $\mathrm{X}$ & $X$ & $X$ & 6 & $100 \%$ \\
\hline & $\begin{array}{l}\text { Describe posiciones con } \\
\text { respecto a } \\
\text { elementos (esquinas, } \\
\text { interior, exterior, arriba, } \\
\text { mitad, abajo, en el } \\
\text { medio...). }\end{array}$ & $X$ & $X$ & $X$ & $X$ & $X$ & $X$ & 6 & $100 \%$ \\
\hline \multicolumn{2}{|c|}{ Cantidad de categorías que manifiesta } & 4 & 4 & 3 & 3 & 2 & 4 & & \\
\hline
\end{tabular}


Tabla 13. Conjunto de conductas manifestadas por cada futuro profesor en cada una de las categorías para las habilidades de visualización de la tarea 1

\begin{tabular}{|c|c|c|c|c|c|c|c|c|c|}
\hline \multirow[b]{2}{*}{ Habilidad } & \multirow[b]{2}{*}{ Categoría } & \multirow[b]{2}{*}{ Conductas } & \multicolumn{6}{|c|}{ Estudiantes que la manifiestan } & \multirow{2}{*}{$\begin{array}{c}\text { Porcentaje de } \\
\text { estudiantes que la } \\
\text { manifiestan }\end{array}$} \\
\hline & & & $\mathrm{AD}$ & $\mathrm{CH}$ & DA & JP & PE & YK & \\
\hline \multirow{2}{*}{$\begin{array}{l}\text { Coordinación } \\
\text { ojo motor } \\
(\mathrm{COM})\end{array}$} & $\begin{array}{l}\text { COM1: Realiza dobleces } \\
\text { para obtener los distintos } \\
\text { elementos geométricos }\end{array}$ & $\begin{array}{l}\text { - Realiza dobleces para obtener los } \\
\text { distintos elementos geométricos de forma } \\
\text { correcta. }\end{array}$ & $X$ & $\mathrm{X}$ & $X$ & $\mathrm{X}$ & $X$ & $X$ & $100 \%$ \\
\hline & & $\begin{array}{l}\text {-Logra generar un doblez por un punto, } \\
\text { línea o sector deseado }\end{array}$ & & $X$ & & & & & $16.67 \%$ \\
\hline \multirow{3}{*}{$\begin{array}{l}\text { Percepción } \\
\text { figura-contexto } \\
\text { (FC) }\end{array}$} & $\begin{array}{l}\text { FC1: Forma una estructura } \\
\text { a partir de una menor. }\end{array}$ & $\begin{array}{l}\text { - Construye la figura completa apoyándose } \\
\text { de los dobleces realizados. }\end{array}$ & $X$ & $X$ & $X$ & $\mathrm{X}$ & $X$ & $X$ & $100 \%$ \\
\hline & & $\begin{array}{l}\text { - Construye elementos geométricos } \\
\text { mediante el doblado de papel. }\end{array}$ & & $\mathrm{X}$ & & & & & $16.67 \%$ \\
\hline & $\begin{array}{l}\text { FC2: Identifica elementos } \\
\text { dentro de una estructura } \\
\text { mayor. }\end{array}$ & $\begin{array}{l}\text { - Identifica segmentos, rectas o ángulos, } \\
\text { triángulos o vértices de las figuras. }\end{array}$ & & $X$ & $X$ & $\mathrm{X}$ & $X$ & $X$ & $83.33 \%$ \\
\hline \multirow{2}{*}{$\begin{array}{l}\text { Conservación } \\
\text { de la } \\
\text { percepción } \\
\text { (CP) }\end{array}$} & $\begin{array}{l}\text { CP1: Utiliza criterios de } \\
\text { igualdad o congruencia } \\
\text { haciendo referencia a forma }\end{array}$ & $\begin{array}{l}\text { - Utilizar criterios de igualdad al realizar } \\
\text { los distintos movimientos o dobleces sobre } \\
\text { el papel. }\end{array}$ & & $X$ & & & & $X$ & $33.33 \%$ \\
\hline & $\begin{array}{l}\text { o tamaño, a movimientos } \\
\text { (giros, traslaciones, } \\
\text { volteos), perspectivas, } \\
\text { segmentos o ángulos. }\end{array}$ & $\begin{array}{l}\text { - Comenta que al girar o voltear, coincide } \\
\text { la misma forma o la construcción o los } \\
\text { puntos y segmentos. }\end{array}$ & $X$ & $X$ & $\mathrm{X}$ & $\mathrm{X}$ & $\mathrm{X}$ & $\mathrm{X}$ & $100 \%$ \\
\hline
\end{tabular}


CP2: Identifica elementos ocultos

PE1: Utiliza elementos de posición respecto al objeto o a uno mismo (sistema de referencia, coordenadas, atrás, adelante, arriba, cerca...)

Percepción de la posición en el espacio (PE)

PE2: Identifica

movimientos (reflexiones, giros o volteos) en la

realización de los dobleces.
-Menciona elementos geométricos que no están visibles a la vista por el

solapamiento del papel.

- Orienta de manera adecuada los dobleces para obtener el elemento geométrico deseado con respecto a otros elementos

- Reconoce referencias (atrás, adelante, izquierda, arriba, abajo, ...)

- Utiliza rotaciones en el espacio para obtener los elementos geométricos que se desean construir o para justificar las construcciones realizadas

- Utiliza simetrías adecuadas para para obtener los elementos geométricos

RE: Utiliza elementos de posición relativa entre dos objetos (dirección,

- Distingue simetrías entre elementos geométricos del papel.

- Identifica relaciones de las relaciones espaciales orientación, paralelismo, coincidentes, perpendiculares, simétricos) perpendicularidad de los diversos dobleces que realiza y elementos geométricos $\begin{array}{lllll}X & X & X & X & X\end{array}$ obtenidos.

- Identifica semejanzas y diferencias entre la figura o elementos geométrico a obtener
$\mathrm{X}$ 
Tabla 14. Conjunto de conductas manifestadas por cada futuro profesor en cada una de las categorías para las habilidades de visualización de la tarea 2

\begin{tabular}{|c|c|c|c|c|c|c|c|c|c|}
\hline \multirow[b]{2}{*}{ Habilidad } & \multirow[b]{2}{*}{ Categoría } & \multirow[b]{2}{*}{ Conductas } & \multicolumn{6}{|c|}{ Tareas en las que se manifiesta } & \multirow{2}{*}{$\begin{array}{c}\text { Porcentaje de } \\
\text { estudiantes que la } \\
\text { manifiestan }\end{array}$} \\
\hline & & & $\mathrm{AD}$ & $\mathrm{CH}$ & DA & JP & $\mathrm{PE}$ & YK & \\
\hline \multirow{2}{*}{$\begin{array}{l}\text { Coordinación } \\
\text { ojo motor } \\
(\mathrm{COM})\end{array}$} & $\begin{array}{l}\text { COM1: Realiza dobleces } \\
\text { para obtener los distintos } \\
\text { elementos geométricos }\end{array}$ & $\begin{array}{l}\text { - Realiza dobleces para obtener los } \\
\text { distintos elementos geométricos de forma } \\
\text { correcta. }\end{array}$ & $X$ & $X$ & $X$ & $X$ & $\mathrm{X}$ & $X$ & $100 \%$ \\
\hline & & $\begin{array}{l}\text {-Logra generar un doblez por un punto, } \\
\text { línea o sector deseado }\end{array}$ & & $X$ & & & & $X$ & $33.33 \%$ \\
\hline \multirow{3}{*}{$\begin{array}{l}\text { Percepción } \\
\text { figura-contexto } \\
\text { (FC) }\end{array}$} & $\begin{array}{l}\text { FC1: Forma una estructura } \\
\text { a partir de una menor. }\end{array}$ & $\begin{array}{l}\text { - Construye la figura completa } \\
\text { apoyándose de los dobleces realizados. }\end{array}$ & $X$ & $X$ & $X$ & $X$ & $\mathrm{X}$ & $X$ & $100 \%$ \\
\hline & & $\begin{array}{l}\text { - Construye elementos geométricos } \\
\text { mediante el doblado de papel. }\end{array}$ & & $X$ & & & & $X$ & $33.33 \%$ \\
\hline & $\begin{array}{l}\text { FC2: Identifica elementos } \\
\text { dentro de una estructura } \\
\text { mayor. }\end{array}$ & $\begin{array}{l}\text { - Identifica segmentos, rectas o ángulos, } \\
\text { triángulos o vértices de las figuras. }\end{array}$ & $X$ & $X$ & $X$ & $X$ & $\mathrm{X}$ & $X$ & $100 \%$ \\
\hline $\begin{array}{l}\text { Conservación } \\
\text { de la }\end{array}$ & $\begin{array}{l}\text { CP1: Utiliza criterios de } \\
\text { igualdad o congruencia } \\
\text { haciendo referencia a }\end{array}$ & $\begin{array}{l}\text { - Utilizar criterios de igualdad al realizar } \\
\text { los distintos movimientos o dobleces } \\
\text { sobre el papel. }\end{array}$ & & & & & & $X$ & $16.67 \%$ \\
\hline
\end{tabular}


percepción

(CP)

ángulos.
CP2: Identifica elementos
ocultos

PE1: Utiliza elementos de posición respecto al objeto o a uno mismo (sistema de referencia, coordenadas, atrás, adelante, arriba cerca...)

Percepción de la posición en el espacio (PE)

PE2: Identifica movimientos (reflexiones, giros o volteos) en la realización de los dobleces.

Percepción de las relaciones espaciales

RE: Utiliza elementos de posición relativa entre dos objetos (dirección,
- Comenta que al girar o voltear, coincide la misma forma o la construcción o los puntos y segmentos.

-Menciona elementos geométricos que no están visibles a la vista por el solapamiento del papel.

X X

$33.33 \%$

- Orienta de manera adecuada los dobleces para obtener el elemento geométrico deseado con respecto a otros elementos

- Reconoce referencias (atrás, adelante, izquierda, arriba, abajo, ...)

- Utiliza rotaciones en el espacio para obtener los elementos geométricos que se desean construir o para justificar las construcciones realizadas

- Utiliza simetrías adecuadas para obtener los elementos geométricos que se desean construir o para justificar las

- Distingue simetrías para obtener elementos geométricos mediante los dobleces del papel

$\begin{array}{lllll}X & X & X & X & 66.67 \%\end{array}$


- Identifica relaciones de perpendicularidad de los diversos dobleces que realiza y elementos geométricos obtenidos.

$\begin{array}{lllllll}X & X & X & X & X & X & 100 \%\end{array}$

DV: Identificación de semejanzas o diferencias entre figuras o sus

\section{Discriminación elementos.}

\begin{abstract}
visual (DV)
\end{abstract}
MV: Recordar elementos

Memoria

visual (MV) visuales en el proceso de razonamiento
- Identifica semejanzas y diferencias entre la figura o elementos geométrico a obtener y la figura o elemento geométrico construido.

- Identifica semejanzas o diferencias entre los distintos elementos geométricos.

- Forma algún elemento geométrico apoyándose de una construcción anterior que requiere recordar los dobleces realizados o elementos geométricos que se encuentran ocultos. 
Tabla 15. Conjunto de conductas manifestadas por cada futuro profesor en cada una de las categorías para las habilidades de visualización de la tarea 3

\begin{tabular}{|c|c|c|c|c|c|c|c|c|c|}
\hline \multirow[t]{2}{*}{ Habilidad } & \multirow[t]{2}{*}{ Categoría } & \multirow[t]{2}{*}{ Conductas } & \multicolumn{6}{|c|}{ Tareas en las que se manifiesta } & \multirow{2}{*}{$\begin{array}{l}\text { Porcentaje de } \\
\text { estudiantes que } \\
\text { la manifiestan }\end{array}$} \\
\hline & & & $\mathrm{AD}$ & $\mathrm{CH}$ & DA & $\mathrm{JP}$ & $\mathrm{PE}$ & YK & \\
\hline \multirow{2}{*}{$\begin{array}{l}\text { Coordinación } \\
\text { ojo motor } \\
\text { (COM) }\end{array}$} & $\begin{array}{l}\text { COM1: Realiza } \\
\text { dobleces para obtener } \\
\text { los distintos elementos } \\
\text { geométricos }\end{array}$ & $\begin{array}{l}\text { - Realiza dobleces para obtener los distintos } \\
\text { elementos geométricos de forma correcta. }\end{array}$ & $\mathrm{X}$ & $\mathrm{X}$ & $X$ & $\mathrm{X}$ & $\mathrm{X}$ & $\mathrm{X}$ & $100 \%$ \\
\hline & & $\begin{array}{l}\text {-Logra generar un doblez por un punto, línea o } \\
\text { sector deseado }\end{array}$ & & & & & & $X$ & $16.67 \%$ \\
\hline \multirow{3}{*}{$\begin{array}{l}\text { Percepción } \\
\text { figura-contexto } \\
\text { (FC) }\end{array}$} & $\begin{array}{l}\text { FC1: Forma una } \\
\text { estructura a partir de una } \\
\text { menor. }\end{array}$ & $\begin{array}{l}\text { - Construye la figura completa apoyándose de } \\
\text { los dobleces realizados. }\end{array}$ & $\mathrm{X}$ & $\mathrm{X}$ & $\mathrm{X}$ & $\mathrm{X}$ & $\mathrm{X}$ & $\mathrm{X}$ & $100 \%$ \\
\hline & & $\begin{array}{l}\text { - Construye elementos geométricos mediante el } \\
\text { doblado de papel. }\end{array}$ & & & & & & $\mathrm{X}$ & $16.67 \%$ \\
\hline & $\begin{array}{l}\text { FC2: Identifica } \\
\text { elementos dentro de una } \\
\text { estructura mayor. }\end{array}$ & $\begin{array}{l}\text { - Identifica segmentos, rectas o ángulos, } \\
\text { triángulos o vértices de las figuras. }\end{array}$ & $\mathrm{X}$ & $\mathrm{X}$ & $X$ & $\mathrm{X}$ & $\mathrm{X}$ & $\mathrm{X}$ & $100 \%$ \\
\hline $\begin{array}{l}\text { Conservación } \\
\text { de la } \\
\text { percepción } \\
\text { (CP) }\end{array}$ & $\begin{array}{l}\text { CP1: Utiliza criterios de } \\
\text { igualdad o congruencia } \\
\text { haciendo referencia a } \\
\text { forma o tamaño, a } \\
\text { movimientos (giros, } \\
\text { traslaciones, volteos), } \\
\text { perspectivas, segmentos } \\
\text { o ángulos. }\end{array}$ & $\begin{array}{l}\text { - Comenta que al girar o voltear, coincide la } \\
\text { misma forma o la construcción o los puntos y } \\
\text { segmentos. }\end{array}$ & $\mathrm{X}$ & $\mathrm{X}$ & $X$ & $\mathrm{X}$ & $X$ & $X$ & $33.33 \%$ \\
\hline
\end{tabular}




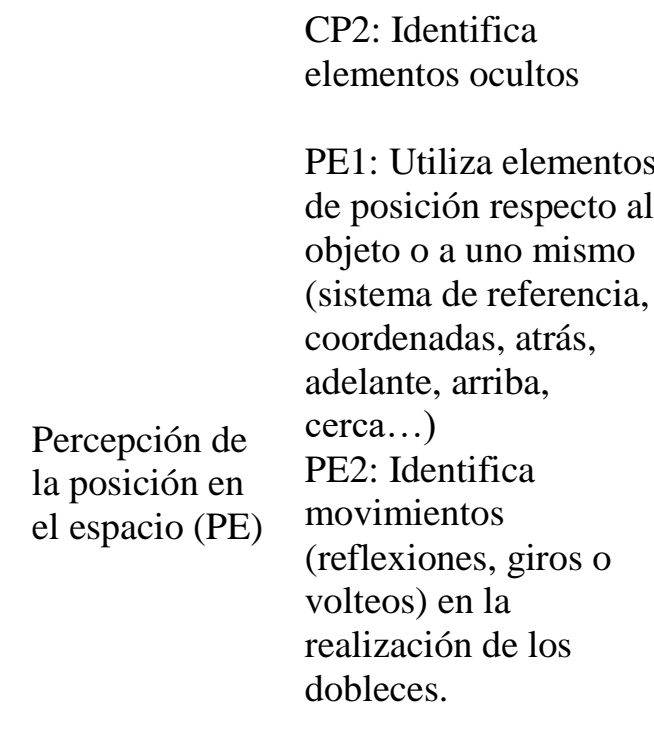

RE: Utiliza elementos de posición relativa entre dos objetos (dirección, orientación,

Percepción de las relaciones espaciales paralelismo, coincidentes, simétricos)

\section{Discriminación} visual (DV)

DV: Identificación de

-Menciona elementos geométricos que no están perpendiculares, visibles a la vista por el solapamiento del papel.

- Orienta de manera adecuada los dobleces para obtener el elemento geométrico deseado con respecto a otros elementos

- Reconoce referencias (atrás, adelante,

izquierda, arriba, abajo, ...)

- Utiliza rotaciones en el espacio para obtener los elementos geométricos que se desean construir o para justificar las construcciones realizadas

- Utiliza simetrías adecuadas para obtener los elementos geométricos que se desean construir o para justificar las construcciones realizadas.

X $\quad X \quad X$

$50 \%$

$\begin{array}{lllllll}X & X & X & X & X & X & 100 \%\end{array}$

- Distingue simetrías para obtener elementos geométricos mediante los dobleces del papel

- Identifica relaciones de paralelismo de los diversos dobleces que realiza y elementos geométricos obtenidos.

- Identifica relaciones de perpendicularidad de los diversos dobleces que realiza y elementos geométricos obtenidos. semejanzas o diferencias
X

$\begin{array}{lllllll}\text { X } & \text { X } & \text { X } & \text { X } & \text { X } & \text { X } & 100 \%\end{array}$

$\begin{array}{lllllll}\text { X } & X & X & X & X & X & 100 \%\end{array}$

$\begin{array}{lllllll}X & X & X & X & X & X & 100 \%\end{array}$

$\mathrm{X}$

X $\quad X \quad$ X $\quad 66.67 \%$

- Identifica semejanzas y diferencias entre la figura o elementos geométrico a obtener y la figura o elemento geométrico construido. 
entre figuras o sus

elementos.

MV: Recordar

- Forma algún elemento geométrico apoyándose

Memoria

elementos visuales en el

de una construcción anterior que requiere

recordar los dobleces realizados o elementos

$\begin{array}{llllll}X & X & X & X & X & X\end{array}$

$100 \%$

geométricos que se encuentran ocultos. 
Tabla 16. Cantidad de manifestaciones de habilidades de visualización por cada futuro profesor en la tarea 1

\begin{tabular}{llccccccc}
\hline \multirow{2}{*}{ Habilidad } & \multirow{2}{*}{ Categorías } & \multicolumn{9}{c}{ Futuros profesores } & \multirow{2}{*}{ Total } \\
& & AD & CH & DA & JP & PE & YK & \\
\hline COM & COM1 & 1 & 6 & 1 & 1 & 1 & 1 & 11 \\
FC & FC1 & 1 & 2 & 1 & 1 & 1 & 1 & 7 \\
& FC2 & 1 & 4 & 0 & 1 & 1 & 2 & 9 \\
CP & CP1 & 1 & 4 & 1 & 2 & 2 & 3 & 13 \\
& CP2 & 0 & 1 & 1 & 1 & 0 & 1 & 4 \\
PE & PE1 & 1 & 8 & 1 & 2 & 2 & 2 & 16 \\
& PE2 & 0 & 0 & 0 & 0 & 1 & 0 & 1 \\
RE & RE1 & 1 & 1 & 1 & 1 & 2 & 1 & 7 \\
DV & DV1 & 0 & 3 & 0 & 0 & 0 & 0 & 3 \\
MV & MV1 & 0 & 0 & 0 & 0 & 0 & 0 & 0 \\
\hline
\end{tabular}

Tabla 17. Cantidad de manifestaciones de habilidades de visualización por cada futuro profesor en la tarea 2

\begin{tabular}{llccccccc}
\hline \multirow{2}{*}{ Habilidad } & \multirow{2}{*}{ Categorías } & \multicolumn{9}{c}{ Futuros profesores } & \multirow{2}{*}{ Total } \\
& & AD & CH & DA & JP & PE & YK & \\
\hline COM & COM1 & 3 & 6 & 2 & 2 & 2 & 7 & 22 \\
FC & FC1 & 1 & 2 & 1 & 1 & 1 & 6 & 12 \\
& FC2 & 1 & 6 & 1 & 1 & 2 & 12 & 23 \\
CP & CP1 & 1 & 2 & 1 & 1 & 1 & 7 & 13 \\
& CP2 & 1 & 1 & 0 & 0 & 0 & 0 & 2 \\
PE & PE1 & 4 & 1 & 3 & 3 & 3 & 7 & 21 \\
& PE2 & 1 & 1 & 1 & 0 & 1 & 1 & 5 \\
RE & RE1 & 2 & 2 & 1 & 1 & 2 & 2 & 10 \\
DV & DV1 & 0 & 1 & 1 & 0 & 1 & 2 & 5 \\
MV & MV1 & 1 & 1 & 1 & 1 & 1 & 1 & 6 \\
\hline
\end{tabular}

Tabla 18. Cantidad de manifestaciones de habilidades de visualización por cada futuro profesor en la tarea 3

\begin{tabular}{llccccccc}
\hline \multirow{2}{*}{ Habilidad } & \multirow{2}{*}{ Categorías } & \multicolumn{7}{c}{ Futuros profesores } \\
& & AD & CH & DA & JP & PE & YK & Total \\
\hline COM & COM1 & 5 & 3 & 3 & 3 & 3 & 3 & 20 \\
FC & FC1 & 3 & 2 & 2 & 3 & 2 & 3 & 15 \\
& FC2 & 3 & 2 & 2 & 2 & 2 & 2 & 13 \\
CP & CP1 & 3 & 2 & 2 & 2 & 2 & 3 & 14 \\
& CP2 & 1 & 1 & 1 & 0 & 0 & 0 & 3 \\
PE & PE1 & 3 & 4 & 4 & 4 & 4 & 4 & 23 \\
& PE2 & 1 & 0 & 0 & 0 & 0 & 1 & 2 \\
RE & RE1 & 3 & 2 & 2 & 3 & 2 & 4 & 16 \\
DV & DV1 & 1 & 0 & 2 & 1 & 0 & 1 & 5 \\
MV & MV1 & 1 & 2 & 2 & 2 & 2 & 1 & 10 \\
\hline
\end{tabular}


Tabla 19. Nivel de éxito de cada futuro profesor en la tarea 1 a

\begin{tabular}{|c|c|c|c|c|c|c|c|c|}
\hline \multirow{2}{*}{$\begin{array}{l}\text { Nivel } \\
\text { de } \\
\text { éxito }\end{array}$} & \multicolumn{6}{|c|}{ Futuros profesores } & \multirow{2}{*}{$\begin{array}{c}\text { Cantidad de } \\
\text { participantes } \\
\text { que lo } \\
\text { manifiestan }\end{array}$} & \multirow{2}{*}{$\begin{array}{l}\text { Porcentaje de } \\
\text { participantes } \\
\text { que lo } \\
\text { manifiestan }\end{array}$} \\
\hline & $\mathrm{AD}$ & $\mathrm{CH}$ & DA & JP & PE & YK & & \\
\hline Total & & & & & & & 0 & $0 \%$ \\
\hline Parcial & $\mathrm{X}$ & $\mathrm{X}$ & $\mathrm{X}$ & $\mathrm{X}$ & $X$ & $\mathrm{X}$ & 6 & $100 \%$ \\
\hline Nulo & & & & & & & 0 & $0 \%$ \\
\hline
\end{tabular}

Tabla 20. Nivel de éxito de cada futuro profesor en la tarea $1 b$

\begin{tabular}{|c|c|c|c|c|c|c|c|c|}
\hline \multirow{2}{*}{$\begin{array}{l}\text { Nivel } \\
\text { de } \\
\text { éxito }\end{array}$} & \multicolumn{6}{|c|}{ Futuros profesores } & \multirow{2}{*}{$\begin{array}{l}\text { Cantidad de } \\
\text { participantes } \\
\text { que lo } \\
\text { manifiestan }\end{array}$} & \multirow{2}{*}{$\begin{array}{l}\text { Porcentaje } \\
\text { de } \\
\text { participantes } \\
\text { que lo } \\
\text { manifiestan }\end{array}$} \\
\hline & $\mathrm{AD}$ & $\mathrm{CH}$ & DA & JP & PE & YK & & \\
\hline Total & & & & & & & 0 & $0 \%$ \\
\hline Parcial & & X & & & & & 1 & $16.67 \%$ \\
\hline Nulo & $X$ & & X & X & $X$ & X & 5 & $83.33 \%$ \\
\hline
\end{tabular}

Tabla 21. Nivel de éxito de cada futuro profesor en la tarea 2

\begin{tabular}{lcccccccc}
\hline $\begin{array}{c}\text { Nivel de } \\
\text { éxito }\end{array}$ & AD & CH & DA & JP & PE & YK & $\begin{array}{c}\text { Futuros profesores } \\
\text { pantidad de } \\
\text { que lo } \\
\text { manifiestan }\end{array}$ & $\begin{array}{c}\text { Porcentaje } \\
\text { de } \\
\text { participantes } \\
\text { que lo } \\
\text { manifiestan }\end{array}$ \\
\hline Total & X & X & X & & & & 3 & $50 \%$ \\
Parcial & & & & X & X & X & 3 & $50 \%$ \\
Nulo & & & & & & & 0 & $0 \%$ \\
\hline
\end{tabular}

Tabla 22. Nivel de éxito de cada futuro profesor en la tarea 3

\begin{tabular}{|c|c|c|c|c|c|c|c|c|}
\hline \multirow{2}{*}{$\begin{array}{l}\text { Nivel de } \\
\text { éxito }\end{array}$} & \multicolumn{6}{|c|}{ Futuros profesores } & \multirow{2}{*}{$\begin{array}{l}\text { Cantidad de } \\
\text { participantes que } \\
\text { lo manifiestan }\end{array}$} & \multirow{2}{*}{$\begin{array}{l}\text { Porcentaje } \\
\text { de } \\
\text { participantes } \\
\text { que lo } \\
\text { manifiestan }\end{array}$} \\
\hline & $\mathrm{AD}$ & $\mathrm{CH}$ & DA & JP & PE & YK & & \\
\hline Total & & & & & & $X$ & 1 & $16.67 \%$ \\
\hline Parcial & & $\mathrm{X}$ & $\mathrm{X}$ & $X$ & $\mathrm{X}$ & & 4 & $66.67 \%$ \\
\hline Nulo & $X$ & & & & & & 1 & $16.67 \%$ \\
\hline
\end{tabular}

